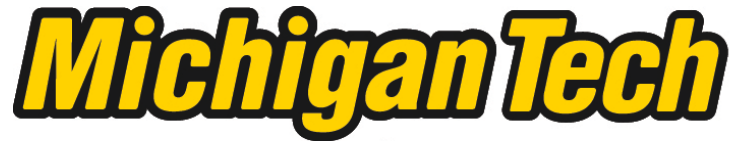 \\ Michigan Technological University Create the Future Digital Commons @ Michigan Tech
}

2014

\section{UNDERSTANDING CHASSIS INPUTS FROM THE REAR SUSPENSION OF A SNOWMOBILE}

Jamie L. Kleinendorst

Michigan Technological University

Follow this and additional works at: https://digitalcommons.mtu.edu/etds

Part of the Mechanical Engineering Commons

Copyright 2014 Jamie L. Kleinendorst

\section{Recommended Citation}

Kleinendorst, Jamie L., "UNDERSTANDING CHASSIS INPUTS FROM THE REAR SUSPENSION OF A SNOWMOBILE", Master's Thesis, Michigan Technological University, 2014.

https://doi.org/10.37099/mtu.dc.etds/878

Follow this and additional works at: https://digitalcommons.mtu.edu/etds

Part of the Mechanical Engineering Commons 


\title{
UNDERSTANDING CHASSIS INPUTS FROM THE REAR SUSPENSION OF A
} SNOWMOBILE

\author{
By \\ Jamie L. Kleinendorst
}

\begin{abstract}
A THESIS
Submitted in partial fulfillment of the requirements for the degree of MASTER OF SCIENCE

In Mechanical Engineering
\end{abstract}

MICHIGAN TECHNOLOGICAL UNIVERSITY

2014

(C) 2014 Jamie L. Kleinendorst 
This thesis has been approved in partial fulfillment of the requirements for the Degree of MASTER OF SCIENCE in Mechanical Engineering

Department of Mechanical Engineering - Engineering Mechanics

\author{
Thesis Co-Advisor: Charles Van Karsen
}

Thesis Co-Advisor: Jason R. Blough

Committee Member: $\quad$ Allan Struthers

Department Chair: William W. Predebon 
For my husband.

I'm blessed to have found a man who would willingly stay committed to a college student for nearly a decade. 


\section{Table of Contents}

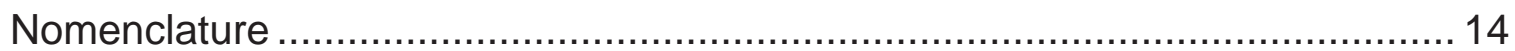

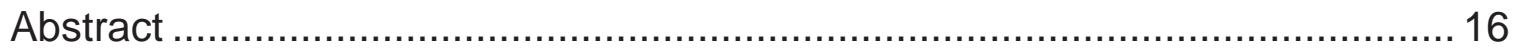

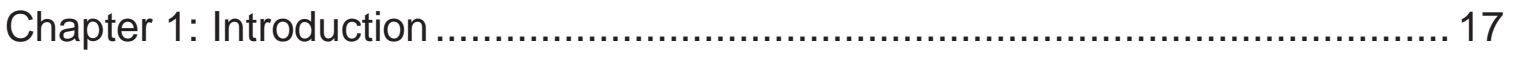

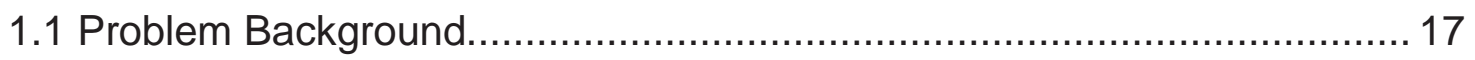

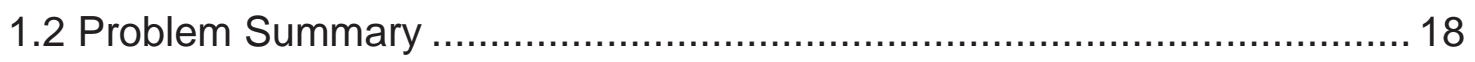

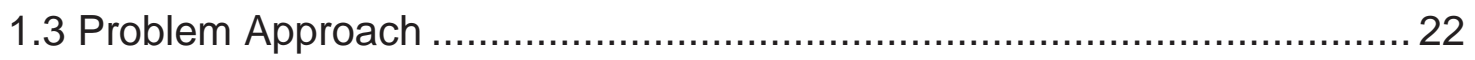

1.3.1 Structural Paths from the Rear Suspension to the Chassis................ 23

1.3.2 Structural Paths within the Rear Suspension ................................. 25

1.3.3 Phase 1: Measuring Frequency Response Functions ...................... 28

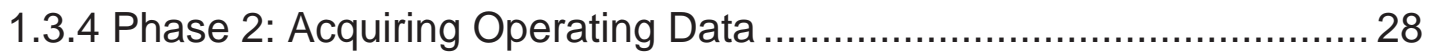

1.3.5 Phase 3: Analytical Transfer Path Analysis ........................................ 29

Chapter 2: Phase 1 Measuring Frequency Response Functions....................... 30

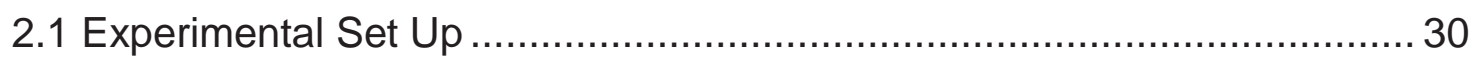

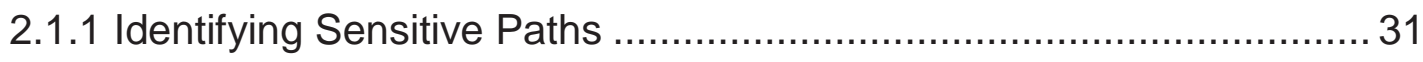

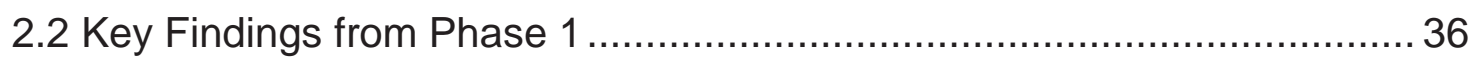

Chapter 3: Phase 2 Acquiring Operating Data................................................... 37

3.1 Experimental Set Up for Round One................................................. 37

3.1.1 Data Acquired in Round One....................................................... 40

3.2 Experimental Set Up for Round Two................................................... 43

3.2.1 Data Acquired in Round Two ............................................................ 45

3.2.2 Collecting Drive Shaft FRFs ..................................................... 48

3.3 Experimental Set Up for Round Three ................................................ 51

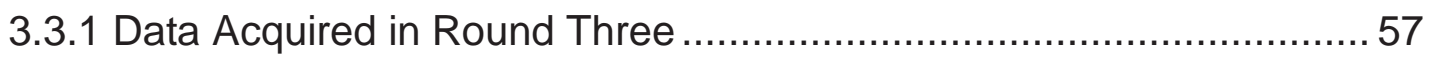


3.3.2 Modal Analysis on the Snowmobile Track ...................................... 59

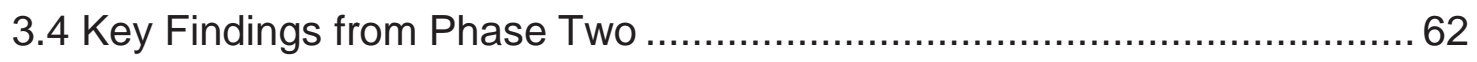

Chapter 4: Phase 3 Analytical Transfer Path Analyses .................................... 63

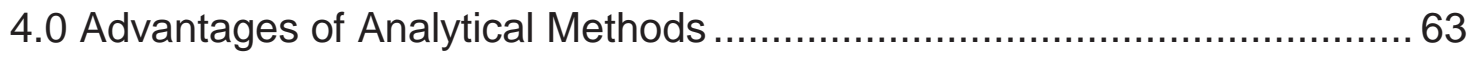

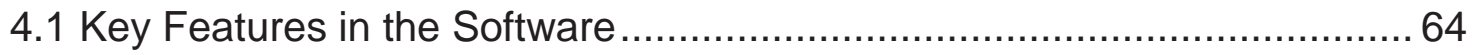

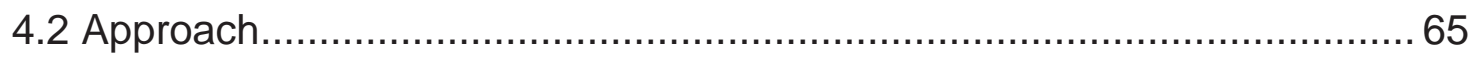

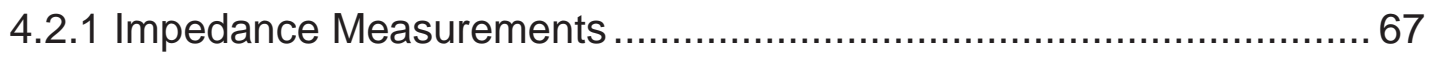

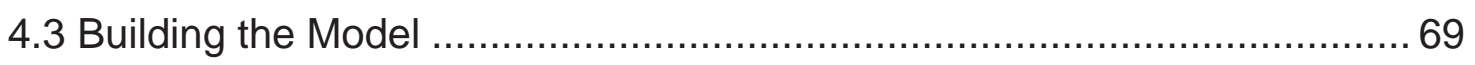

4.3.1 Limiting the Degrees of Freedom using Joints ................................ 72

4.3.2 Modeling Forces within the Rear Suspension ................................... 74

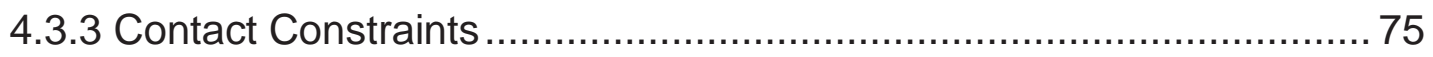

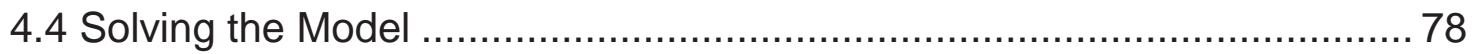

4.4.1 Interpreting the Solutions and Key Findings from Phase Three ............. 88

Chapter 5: Conclusions and Future Work ........................................................ 91

5.1 Conclusions for the Experimental Approach ......................................... 91

5.2 Future Work for the Experimental Approach ............................................ 92

5.3 Conclusions for the Analytical Approach............................................... 93

5.4 Future Work for the Analytical Approach............................................... 94

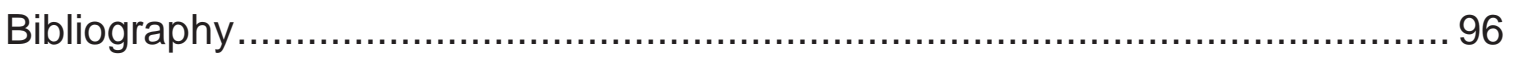

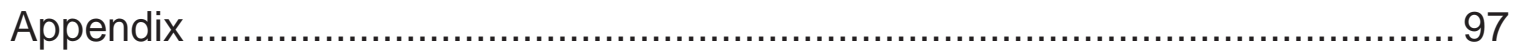




\section{List of Figures}

Figure 1: One of the Test Snowmobiles Provided by the Sponsor .................... 19

Figure 2: Common component locations and terminology of a snowmobile....... 21

Figure 3: Locations of the mounting bolts that connect the rear suspension to the chassis on the left side of the snowmobile ..................................................... 24

Figure 4: Suspension off of the provided snowmobile ..................................... 25

Figure 5: Picture of the snowmobile track identifying three of the fiberglass stiffener rods molding under the rubber in the track by the yellow dotted lines .. 27 Figure 6: Response locations to characterize path sensitivities of the guide

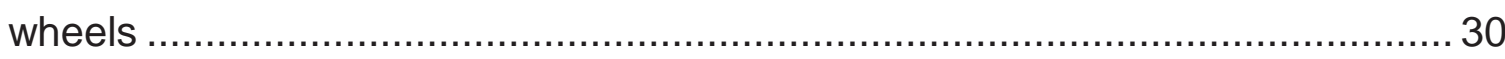

Figure 7: Impact locations to characterize path sensitivities of the guide wheels31 Figure 8: FRF comparison between the impact at the top of wheel seven and the microphone for the taped and un-taped coils ................................................. 32 Figure 9: FRFs between all seven guide wheel locations and the FRB for the

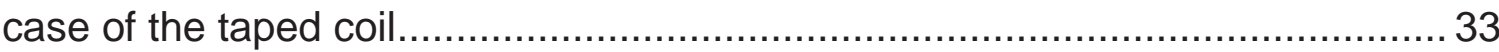

Figure 10: Sensitive path from wheel six to the front right bolt location .............. 34

Figure 11: FRFs between all seven guide wheel locations and the BRB for the

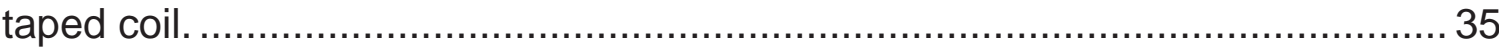

Figure 12: Sensitive path from wheel one, two and three to the back right bolt

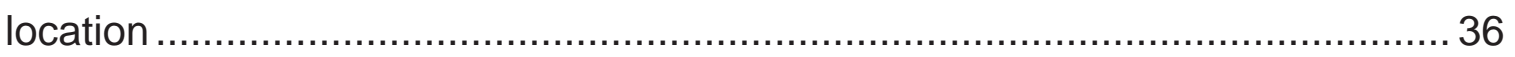

Figure 13: Custom harness designed to hold a 1/4" microphone 1" from the operator's right ear inside a snowmobile helmet.

Figure 14: Operational test setup including an LMS Scadas DAQ, laptop and 1/4" microphone. 39

Figure 15: Operational test setup including response measurement locations with respect to the body of the sled. 40 Figure 16: Driver microphone frequency spectrum colormap for the control rear suspension configuration 
Figure 17: Driver microphone frequency spectrum for the staggered rear

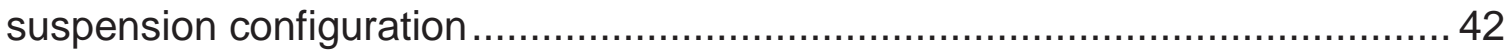

Figure 18: Grass field testing location for acquiring operating data .................. 44

Figure 19: Method used to collect speedometer voltage during operating data acquisition.

Figure 20: LMS Test.Lab Offline RPM Extraction point picking to process raw time data with respect to engine order.... 46

Figure 21: RPM trace identifying the lower and upper limits for a speed sweep from $0 \mathrm{MPH}$ to $50 \mathrm{MPH}$

Figure 22: Comparison of post processing with respect to the engine orders (top) and the track orders (bottom) 48

Figure 23: Accelerometer and impact locations used in FRF measurements of the drive shaft

Figure 24: FRF and coherence between hit location six and accelerometer six in the $X$ and $Z$ directions (legend text too small) 50

Figure 25: Animation of shaft geometry at mode for $227 \mathrm{~Hz}$ 51

Figure 26: Testing method to check for proper track tension in the rear suspension 52

Figure 27: Suspension A, the baseline rear suspension configuration 54 Figure 28: Suspension B, same suspension as A with two less guide wheels ... 54 Figure 29: Suspension C (lower) pictured with suspension B (upper) ................ 55 Figure 30: Upper idler guide wheel comparison of baseline to test size ............. 55 Figure 31: New prototype driver and track pictured with the baseline driver and track. 56

Figure 32: Microphone response of run one with suspension A and the baseline driver and track. 57 Figure 33: Microphone response for run four with suspension B, prototype driver and the new track. 58 Figure 34: Microphone auto power of run five with suspension $C$ and baseline driver and track. 59 
Figure 35: Rear suspension test set up for track modal analysis. 60

Figure 36: Locations of the scales used to determine preload 61 Figure 37: Track modal roving hammer impact locations on the top surface of the track. 62

Figure 38: LMS Virtual.Lab solution from the DSP Case for FRB..................... 66 Figure 39: The Aachen head fitted with a custom microphone harness for the impedance measurements 67

Figure 40: Test set up of the left side of the snowmobile for measuring the chassis impedances 68

Figure 41: Driving point impedance measurements in the $X, Y$ and $Z$ directions 69 Figure 42: Schematic of the road profile modeled in LMS Virtual.Lab to simulate the geometry of the fiberglass stiffener rods as sources of impact into the guide wheels 70

Figure 43: Completed model of the rear suspension with simulated track ground 70

Figure 44: Aerial view of the modeled suspension with component names........ 71

Figure 45: Side view of modeled suspension with component names................ 71

Figure 46: Isometric view of modeled suspension with component names ........ 72 Figure 47: Test setup used to find the spring constant of the front shock absorber

Figure 48: Stiffness measurement for spring in front shock absorber 75 Figure 49: Sphere elements modeled between the ski and flat ground surface 76 Figure 50: Spheres modeled between the guide wheels and the track ground surface. 77

Figure 51: Locations of applied preloads to simulate chassis and driver 78 Figure 52: Flow chart of the process used to solve for the responses at the receiver locations. 78

Figure 53: Time history for FRB at $20 \mathrm{mph}$ from Analysis Case solution............ 79

Figure 54: Position of the One Body Position Drivers on shaft A ....................... 79

Figure 55: FRFs for BLB, BRB, FLB, FRB SL and SR at $20 \mathrm{mph} . . \ldots \ldots \ldots \ldots \ldots \ldots . . . . . . . . .80$ 
Figure 56: FRFs for BLB, BRB, FLB, FRB, SL and SR at $30 \mathrm{mph} \ldots \ldots \ldots \ldots \ldots \ldots . . . . . . . . .11$

Figure 57: FRFs for BLB, BRB, FLB, FRB, SL and SR at 50 mph.................... 82

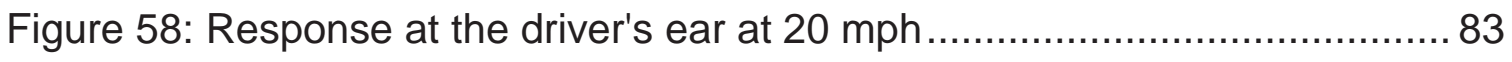

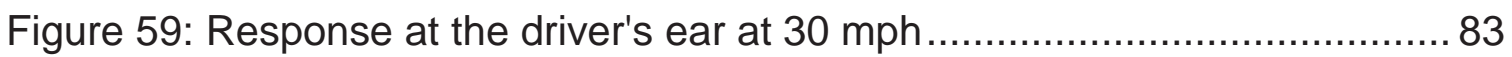

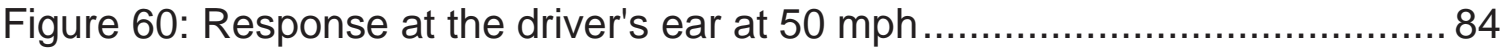

Figure 61: Forced response for SL, SR, FRB, FLB, BRB and BLB at $20 \mathrm{mph}$ in

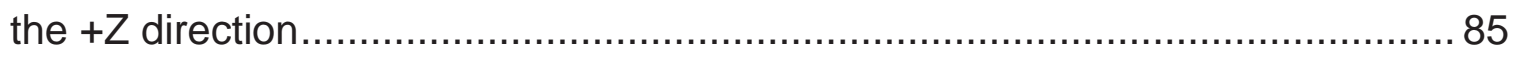

Figure 62: Operating data response for SL, SR, FRB, FLB, and BRB at $20 \mathrm{mph}$ in the $+Z$ direction 86

Figure 63: Forced response for SL, SR, FRB, FLB, BRB and BLB at $30 \mathrm{mph}$ in the $+Z$ direction 87

Figure 64: Operating data response for SL, SR, FRB, FLB, and BRB at $30 \mathrm{mph}$ in

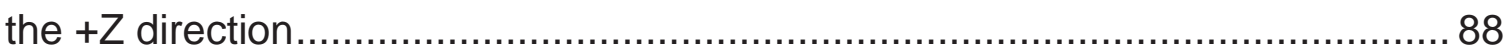

Figure 65: Processing variables used to calculate the FRFs in the DSP Case ..97 Figure 66: DSP Case settings to obtain FRFs from time histories in the Motion

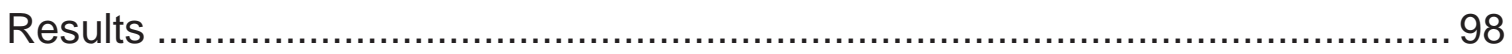

Figure 67: Selections to reproduce the FRF-Based Forced Response Case ..... 99 Figure 68: Selections to reproduce the FRF-Based Forced Response Solution 


\section{List of Tables}

Table 1: Technical Specification for the Snowmobile Provided by the Sponsor . 20 Table 2: Audible frequencies and speeds of interest ....................................... 21

Table 3: Possible sources, paths and receivers identified for the snowmobile ...23

Table 4: Specifications of the variables tested in each run ...............................53

Table 5: Common joints used to define relative motion between two bodies ..... 65

Table 6: Model components and their measured masses ................................ 73

Table 7: Elements modeled as forces in the model and their respective dynamic

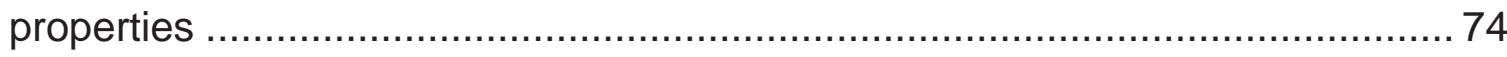

Table 8: Values from strain box and dial indicator used to fins the stiffness of the

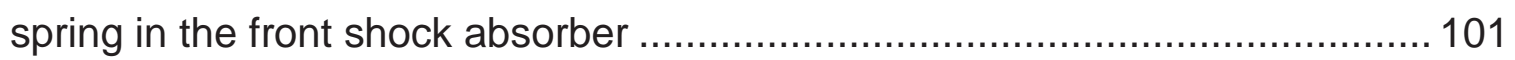




\section{Acknowledgements}

Looking back on my graduate school experience I want to acknowledge the people who have helped me become who I am today. When I began my academic journey though engineering I never imagined I would find a topic I would be interested in pursuing as a graduate degree until I was exposed to Modal Analysis while in Senior Design. Professor Chuck Van Karsen was the advisor of my Capstone Design project with Whirlpool Corporation and was the most influential factor in my pursuit of a master's degree in mechanical engineering. His excitement about the field of dynamic systems in conjunction with his encouragement helped me make the decision to apply to graduate school. In addition to his role as a professor and mentor, Chuck and his wife also developed a relationship with my husband. Brandon worked on some remodeling projects for them and he and Chuck played a lot of golf in the summers. They became our family while we were in $\mathrm{Ml}$.

As a graduate student your office soon becomes like a second home because of the number of hours you spend there. My years in the sub-basement of the mechanical engineering building were some of the most life changing l've experienced. Through similar classes and sharing an office Andy, Mike, Steve and Kaustub became my close friends. Between late night homework sessions, data analysis, candy bar indulgences, coloring sessions, play dough modeling and Carbles games we made some of my favorite memories from graduate school. These people have become my closest friends we have shared many laughs.

Special gratitude goes to Steve. I consider you family and I wouldn't be the person I am today without our friendship. You have always been there to believe in me especially when I doubted myself. 
I would also like to think Kaustubh Peddi for building the suspension parts in Catia and helping with the modeling process. I feel like l've rebuilt this model a hundred times but without the skills we learned through many hours of LMS helpline support phone calls I couldn't have gotten to the where I am now. It was great having someone so patient and humorous to help out.

I'm blessed with numerous influences in my life but none compare to the influence of my advisors. I've learned so much from their experience and their areas of expertise. Professor Chuck Van Karsen and Dr. Jason Blough, you made graduate school fun and I learned so many professional skills from you over the years. Without you, I wouldn't be where I am today. Thank you for your patience and understanding over the years. I wouldn't be here without you.

In addition to my primary advisors I always felt there were people who were eager to share the knowledge they had whenever I asked for help. Dr. Jim DeClerk you were certainly one of the people that was always there to help and to provide valuable input. Your passion is contagious and I hope to one day have as much impact on my students as you have had on yours. It's truly been a pleasure working with you.

I would like to thank the sponsors who helped to fund this project for their financial support and their hospitality during our visit to their testing facilities. Without the experience and help Jim and Andy offered, this project would not have been possible. I thoroughly enjoyed field testing and compiling data for this project with you.

When things became difficult it was reassuring to know I had so many friends and family members behind me in Minnesota. I am grateful to have such a loving and supporting network of friends and family to help me throughout all the years I've spent pursuing my degree. I love you all so much! 
In conclusion, I want to thank my husband for his continued support and love throughout this process. Brandon, you are truly a gift in my life that I thank God for every day. You have been so patient throughout this process and have shown me more love then I could have ever imagined someone could. You stood by me through the good and the bad and sat through every single graduation ceremony and achievement. I can't think of one person I owe my success to more than you. You are the glue that held me together. I love you very much. 


\section{Nomenclature}

Rails: The aluminum structure that runs the length of the rear suspension which supports the weight of the load above.

Hyfax: A lubricious molded plastic piece that is formed to the bottom of the rails.

Guide Wheel: A molded wheel with rubber formed to it that rides on the inner surface of the rubber track.

Track Rods: The track rods are made of a composite material and are molded inside the rubber of the track. They run the width of the track.

Track Pitch: The track pitch is the measurement of the repeating portion of the track.

FLB: Front left bolt that connects the rear suspension to the tunnel of the snowmobile.

FRB: Front right bolt that connects the rear suspension to the tunnel of the snowmobile.

BLB: Back left bolt that connects the rear suspension to the tunnel of the snowmobile.

BRB: Back right bolt that connects the rear suspension to the tunnel of the snowmobile.

SL: The point on the body closest to the left side of the shaft.

SR: The point on the body closest to the right side of the shaft.

SAE: Society of Automotive Engineers

ISO: International Organization for Standardization

CVT: Continuous Variable Transmission

Orders: Harmonics of rotational speed 
Frequency: the rate that something occurs or is repeated over a particular period of time

Transfer Path: Mechanism that transmits energy between the source and the receiver 


\section{Abstract}

Today's snowmobile industry faces great challenges in the field of noise \& vibration. The area of main concern is the pass-by noise restriction defined by the Society of Automotive Engineers (SAE) test standard J192, with a maximum sound pressure level of $78 \mathrm{~dB}(\mathrm{~A})$ being required by many states and national parks. To continue meet or beat this requirement without effecting machine performance, a deeper understanding of the sound transfer paths is required.

This thesis examines the transfer paths created by the tunnel, rear suspension, drive shaft, and rubber composite track, with the primary source being suspension input through the ground. Using a combination of field experiments and analytical modeling, perspective was gained on which suspension and drive elements create the primary transfer paths. With further understanding of these paths, industry can tailor and fine-tune the approaches taken in to control overall noise output. 


\section{Chapter 1: Introduction}

Snowmobile consumers are expecting manufacturers to continue to produce a product that meets their expectations in multiple areas including comfort, noise and quality while maintaining or improving performance. In this chapter the background of noise problems within the snowmobiling industry and how it pertains to the specific project within this thesis will be discussed. The remainder of the chapter will outline a summary of the sponsors concerns for the provided model of snowmobile as well as the process used to solve the problem.

\subsection{Problem Background}

Both consumers and government agencies are pressing the snowmobile industry to gain a better understanding of sound and vibration within their product. The consumer is concerned with riding comfort and expected performance. In addition to meeting the demands of the consumers, manufacturers are increasingly being tasked with meeting the demands of governing bodies in various parts of the globe in areas such as exhaust emissions and noise generation ${ }^{2}$. These entities are concerned with noise pollution in state parks and residential areas. Some solutions implemented to control sources of noise and vibration to meet these standards could come at a cost to the consumer who expects the quick acceleration they've come to enjoy amongst other factors. In order to meet these needs a better understanding of how vibration travels through the machine to the driver interfaces is growing.

In order to know that snowmobiles being released to market are meeting similar noise standards each manufacturer has to perform its own noise testing. To help regulate test methods of multiple manufacturers, organizations including the Society of Automotive Engineers (SAE) and the International Organization for Standardization (ISO) have developed and published testing standards which are 
enforced in the United States and around the world ${ }^{3}$. The pass-by test method used to measure the exterior noise of snowmobiles is SAE J192 which was first published in $1970^{\circ}$. Because each snowmobile manufacturer has different environmental conditions in which they perform their sound testing, this standard has helped to provide as much consistency as possible between testing locations.

After passing the required noise standards the manufacturers attempt to meet the needs of a variety of consumers. The consumer chooses a snowmobile platform based upon the desired application and riding style. An example would be a rider choosing a longer track length with longer lugs for better traction in powder snow conditions versus a rider choosing shorter track length and shorter lugs for increased surface area on packed groomed trails ${ }^{2}$. Those who ride off trail in loose powder might not have concerns with excessive noise when driving 45 to $50 \mathrm{mph}$. However, this same machine could possibly be driven on groomed trails for weekend long vacations and this noise could become agitating. This variation demonstrates the need to understand the snowmobile's intended demographic before deciding which noises are concerns and which are not.

\subsection{Problem Summary}

The provided snowmobile appeals to consumers looking for longer rides on groomed snowmobile trails. As such, this snowmobile will face a more critical customer from a noise and vibration standpoint. Figure 1 shows one of the snowmobiles provided by the sponsor on a groomed snowmobile trail. The technical specifications of this specific model of snowmobile can be found in Table 1. 


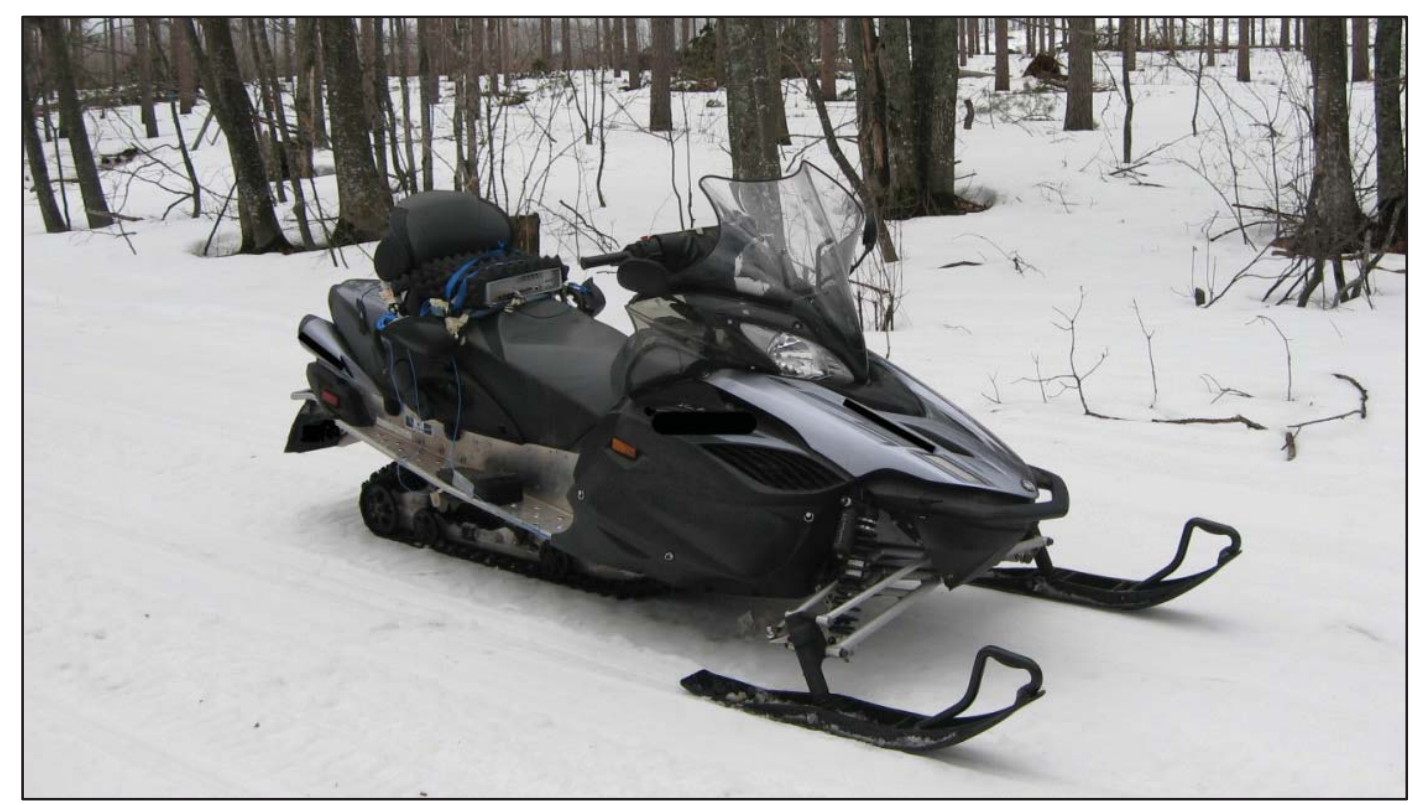

Figure 1: One of the Test Snowmobiles Provided by the Sponsor 
Table 1: Technical Specification for the Snowmobile Provided by the Sponsor

\begin{tabular}{|c|c|}
\hline Category & Specification \\
\hline Model Type & Touring \\
\hline Engine Types & Horizontal In-Line/4-stroke \\
\hline Cylinders & Electric \\
\hline Valve Configuration & 10.28 feet \\
\hline Starter & 48.2 inches \\
\hline Length & 52.4 inches \\
\hline Width & 42.7 inches \\
\hline Height & 645 lbs \\
\hline Ski Stance & 10.4 gallons \\
\hline Dry Weight & 144 inches \\
\hline Fuel Capacity & 15 inches \\
\hline Track Length & 1.25 inches \\
\hline Track Width & \\
\hline Lug Height & Doud Camst \\
\hline
\end{tabular}

Using a combination of consumer feedback and experimental data, the sponsor provided three speeds of concern which can be found in Table 2. Also contained in Table 2 are experimentally found frequencies using microphones in the driver's helmet during operation. It is theorized that these frequencies were caused by drive train and suspension components based on data taken from accelerometers placed on suspension mounting bolts.

Furthermore the sponsor laid out a general frequency range from $0 \mathrm{~Hz}$ to $500 \mathrm{~Hz}$. This range was used for all data acquisition for this thesis. 
Table 2: Audible frequencies and speeds of interest

\begin{tabular}{|c|c|}
\hline Audible Frequencies of Interest & Snowmobile Ground Speeds \\
\hline $140 \mathrm{~Hz}$ & $20 \mathrm{mph}$ \\
\hline $225 \mathrm{~Hz}$ & $35 \mathrm{mph}$ \\
\hline $315 \mathrm{~Hz}$ & $50 \mathrm{mph}$ \\
\hline
\end{tabular}

Information about noise and vibration within the snowmobile cannot be understood without understanding the snowmobiles geometry. All snowmobiles have similar components that contribute to the noise levels heard by the driver including the composite track, continuous variable transmission (CVT) clutch and chassis ${ }^{1}$. Figure 2 shows a side photograph that calls out common components using general snowmobile terminology.

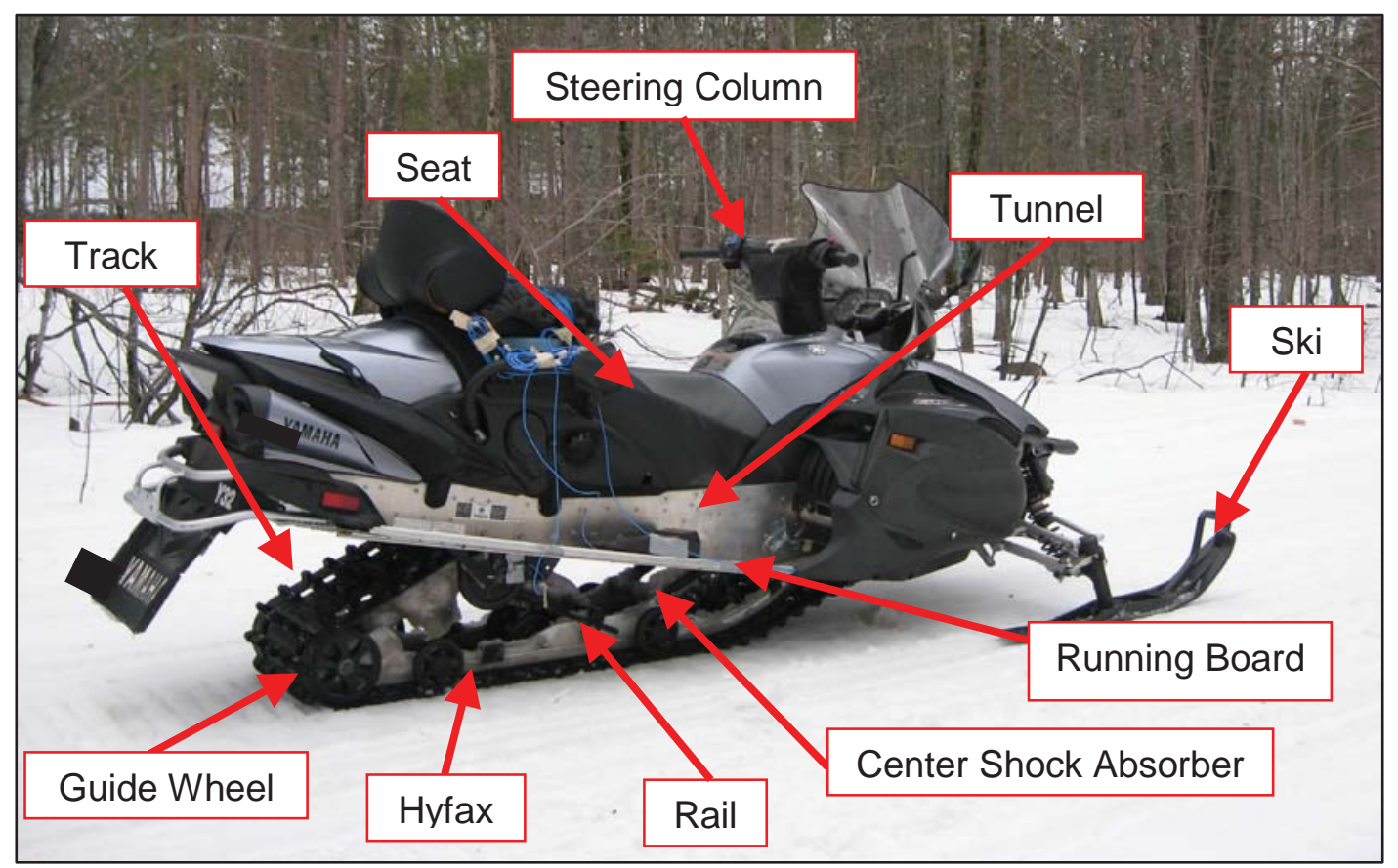

Figure 2: Common component locations and terminology of a snowmobile 
Each of these mechanical systems contains structural paths that energy can travel along in the form of vibration from the source to the receiver ${ }^{4}$. When a particular receiver location experiences unwanted responses in the form of noise or vibration it can lead to discomfort while operating the snowmobile.

By understanding how the energy sound and vibration reaches the receiver points during operation at the given speeds, the sponsor will be able to work towards effectively designing a system that reduces the effects of or attenuates energy from the sources.

\subsection{Problem Approach}

A common approach to solving noise and vibration problems in industry is the transfer path analysis (TPA) method. TPA can be expressed by Equation 1.0. This technique breaks down contributions from internal or external load paths in order to figure out which paths are more sensitive than others. The higher the contribution through a specific path the more sensitive it is classified.

$$
\{X(\omega)\}=[H(\omega)]\{F(\omega)\}
$$

Equation 1.0

Where:

$X(\omega)$ is the Reciver expressed as a vector of output

$H(\omega)$ is the Path: typically expressed as a matrix

$F(\omega)$ is the Source: typically expressed as a vector of inputs

The receiver represents how motion or sound pressure is observed and is also referred to as the output of a given system. The source is primarily a qualitative description of the force entering a system ${ }^{4}$. The path is any mechanism by which 
the energy travels form the source to the receiver. This can include vibration or acoustic responses depending on the system of interest ${ }^{4}$. Examples of identified TPA components as they relate to the provided snowmobile are identified in Table 3.

Table 3: Possible sources, paths and receivers identified for the snowmobile

\begin{tabular}{|l|l|l|}
\hline \multicolumn{1}{|c|}{ Possible Sources } & \multicolumn{1}{|c|}{ Possible Paths } & \multicolumn{1}{c|}{ Possible Receivers } \\
\hline - Road Profile & - Structure of the rear & - Driver's Seat (Vibration) \\
- Engine Operation & \multicolumn{1}{|c|}{ Suspension and Chassis } & $\begin{array}{l}\text { Driver's Ear (Sound } \\
\text { Pressure) }\end{array}$ \\
- Track Engagement & - Air & $\begin{array}{l}\text { Driver's Handle Grips } \\
\text { (Vibration) }\end{array}$ \\
Through Driveshaft & - Steering Column & \\
\hline
\end{tabular}

Traditionally TPAs are performed by finding two of the unknowns experimentally and then using numerical method to solve for the third unknown. Analytical TPAs are becoming more popular due to their ability to simulate factors difficult to measure such as force inputs within a bushing.

\subsubsection{Structural Paths from the Rear Suspension to the Chassis}

There are six locations that makeup the structure borne paths connecting the rear suspension to the chassis. Four of the six paths are formed by the four mounting bolts that attach the mechanisms in the rear suspension to the solid chassis. The final two are formed by each end of the drive shaft. Figure 4 shows the locations of the mounting bolts and their point identification (ID) names. 


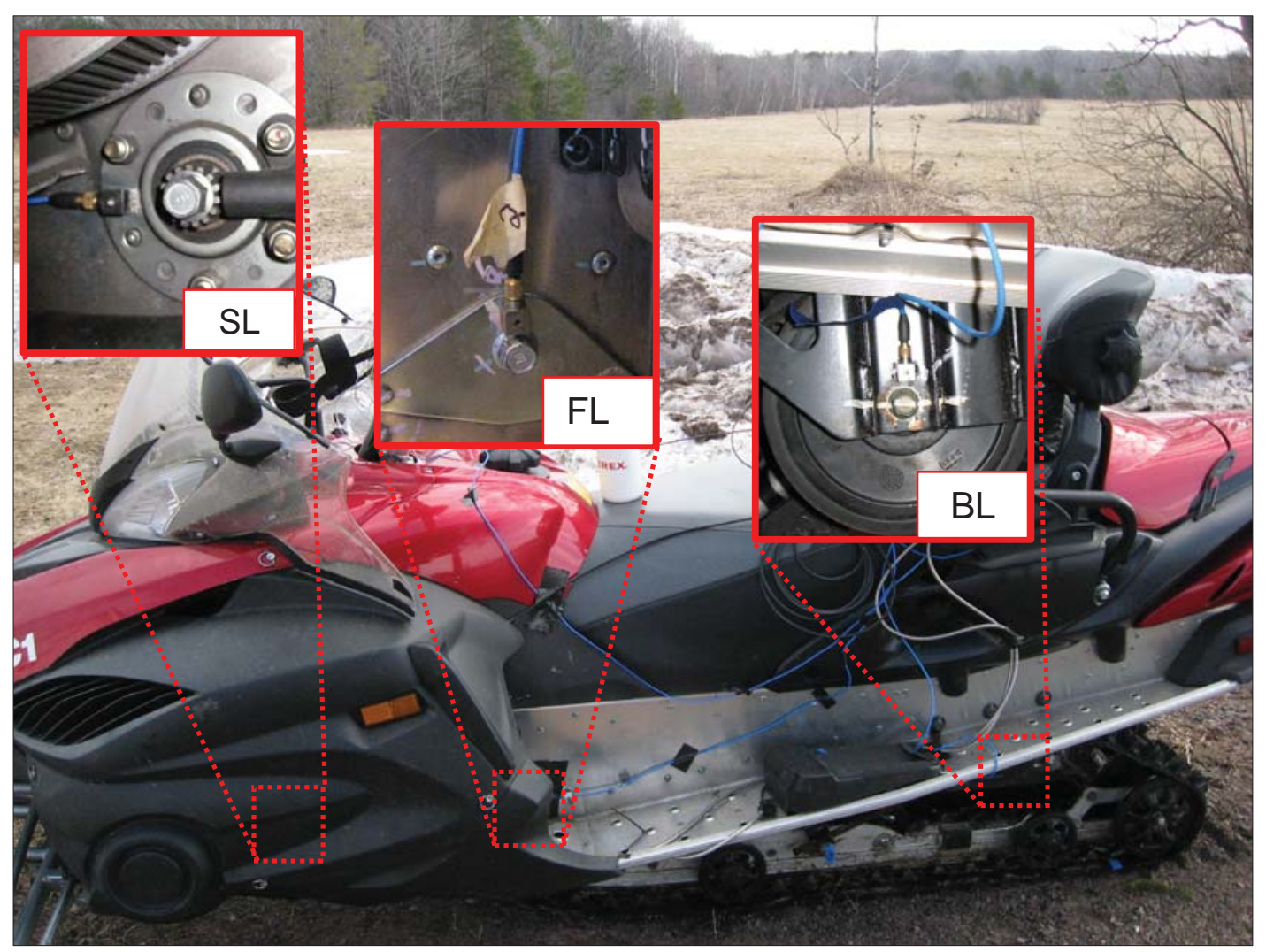

Figure 3: Locations of the mounting bolts that connect the rear suspension to the chassis on the left side of the snowmobile

The front left bolt (FLB) and front right bolt (FRB) are exposed on the tunnel surface and located approximately four inches from the running board the driver's foot rides on during operation. The back left bolts (BLB) and back right bolts (BRB) are exposed below the running board. All four locations were instrumented with tri-axial accelerometers while acquiring operational data.

Two additional interfaces that energy can transfer through during operation are the left and right sides of the driveshaft. The connection point between the right side of the driveshaft and the chassis was labeled shaft right (SR). The location on the left side was labeled to as shaft left (SL). These locations were also instrumented with tri-axial accelerometers for data acquisition as needed. 


\subsubsection{Structural Paths within the Rear Suspension}

Guide wheels are the portion of the suspension that supports the load of the sled along with the hyfax that protects the bottom of the rails. These wheels make up a portion of the path that energy travels through from the ground to the receiver points at the steer column, seat and running boards. The wheels see the force from the ground surface as well as the input from each embedded fiberglass stiffener rod that passes while the track turns during operation. Having a better understanding of which wheels in the system contain more sensitive paths than others would be crucial in material selection and designing wheel placement.

The provided snowmobile suspension contained 15 guide wheels, one damper and one damper and spring combination as seen in Figure 4.

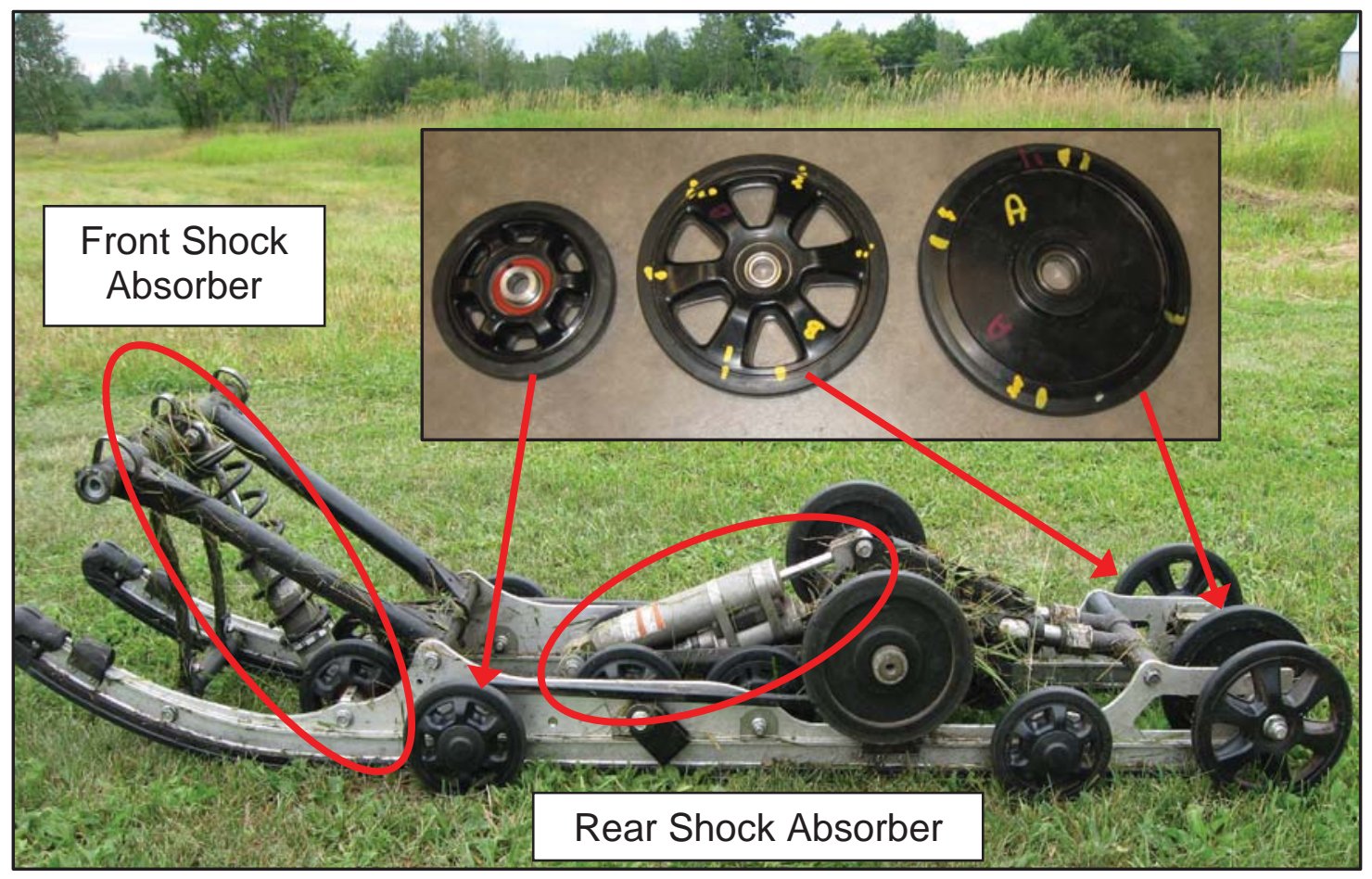

Figure 4: Suspension off of the provided snowmobile 
Upon an initial roving of the hammer the front shock absorber spring was noted to ring for an extended period of time. Testing whether or not controlling this ringing would affect the frequencies of interest was carried out in the first round of experimental testing.

In addition to the guide wheels, shock absorbers and structural paths to the chassis are the paths from the fiberglass stiffener rods to the guide wheels. A major component of the rear suspension is the composite track. The track contacts each guide wheel and the rails continuously during operation making it a possible path for energy to reach the suspension mounting bolts. Due to the great amount of surface area in contact with the track the guide wheel placement stands to play a critical role in providing structural path for energy to reach the seat, handlebars, and tunnel or for sound to become airborne during operation.

Rubber snowmobile tracks contain fiberglass stiffener rods that are molded into the rubber which run perpendicular the face of the guide wheels. There is one rod once every track pitch. The track pitch varies from one manufacturer to the next. For this project the control snowmobile's track pitch was 2.52 inches. Figure 5 shows the direction three of the rods run with respect to the track's length. 


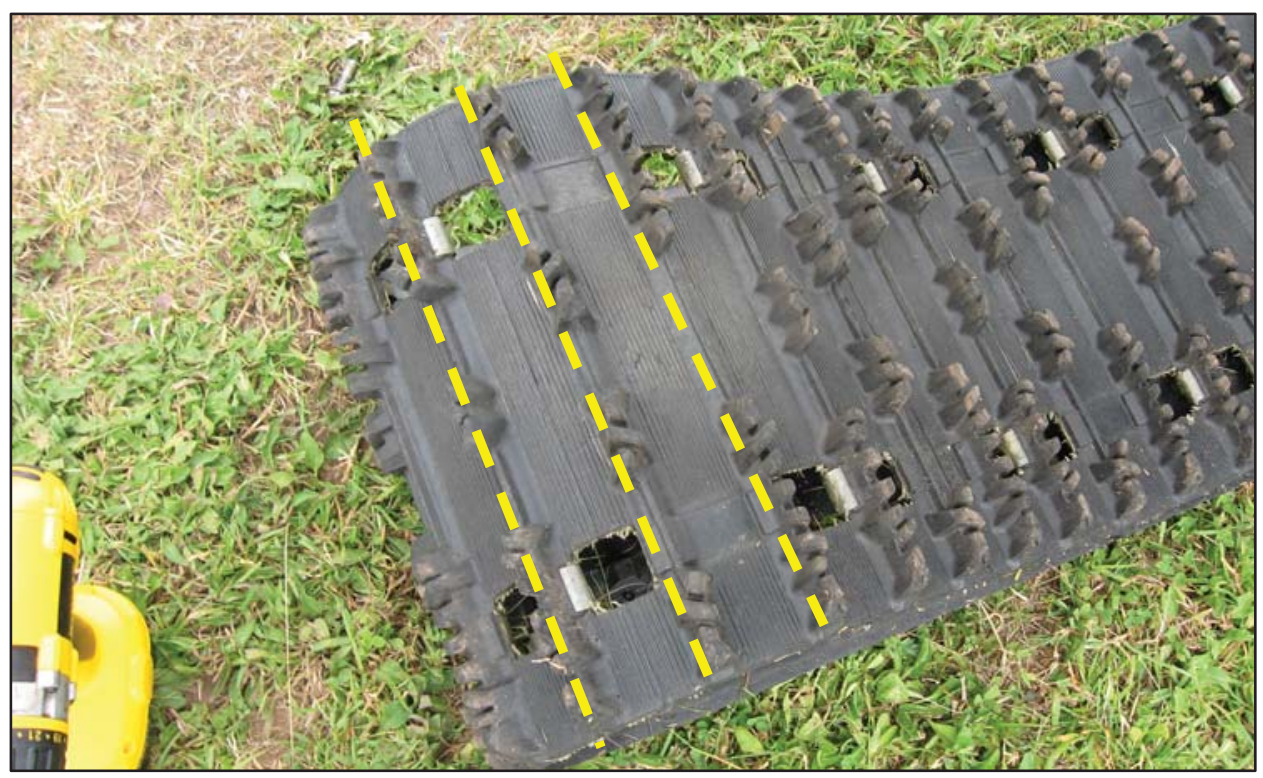

Figure 5: Picture of the snowmobile track identifying three of the fiberglass stiffener rods molding under the rubber in the track by the yellow dotted lines

This solid rod passes under each guide wheel while the snowmobile is in operation. This provides a structural path for energy to transmit into the rear suspension and travel to the receiver paths. The event will occur at various frequencies based upon the ground speed the snowmobile is traveling. Equation 2.0, 2.1 and 2.2 show the calculations of the drive shaft engagement frequencies for $20 \mathrm{MPH}, 35 \mathrm{MPH}$ and $50 \mathrm{MPH}$ :

$$
\begin{array}{ll}
\frac{20 \mathrm{mi}}{1 \mathrm{hr}} x \frac{1 \mathrm{hr}}{3600 \mathrm{~s}} \times \frac{5280 \mathrm{ft}}{1 \mathrm{mi}} \times \frac{12 \mathrm{in}}{1 \mathrm{ft}} x \frac{\text { impacts }}{2.52 \mathrm{in}}=140 \frac{\text { impacts }}{\mathrm{sec}}=140 \mathrm{~Hz} & \text { Equation } 2.0 \\
\frac{33 \mathrm{mi}}{1 \mathrm{hr}} \times \frac{1 \mathrm{hr}}{3600 \mathrm{~s}} \times \frac{5280 \mathrm{ft}}{1 \mathrm{mi}} \times \frac{12 \mathrm{in}}{1 \mathrm{ft}} x \frac{\text { impacts }}{2.52 \mathrm{in}}=225 \frac{\text { impacts }}{\mathrm{sec}}=225 \mathrm{~Hz} & \text { Equation } 2.1 \\
\frac{45 \mathrm{mi}}{1 \mathrm{hr}} x \frac{1 \mathrm{hr}}{3600 \mathrm{~s}} x \frac{5280 \mathrm{ft}}{1 \mathrm{mi}} \times \frac{12 \mathrm{in}}{1 \mathrm{ft}} x \frac{\text { impacts }}{2.52 \mathrm{in}}=315 \frac{\text { impacts }}{\mathrm{sec}}=315 \mathrm{~Hz} & \text { Equation } 2.2
\end{array}
$$

Using $50 \mathrm{MPH}$ as an example the calculation demonstrates that at $50 \mathrm{MPH}$ each guide wheel sees 315 rods every second. The current guide wheel set up contained fourteen guide wheels which were all in paired sets lining up straight 27 
across from one another. The wheel on the right would, as a result, pass over the same fiberglass rod as the wheel on the left simultaneously. To verify the relationships between these equations and the track frequencies operating data was required to learn if the guide wheel placement contributed to the overall response at the receiver locations.

This project was approached using both experimental and analytical methods. The following sections outline the process followed through each phase of the project.

\subsubsection{Phase 1: Measuring Frequency Response Functions}

To begin to gain a general understanding of the snowmobile and how energy traveled through various rear suspension components, frequency response functions were measured while the snowmobile sat at rest on a concrete floor. During this first phase of the experimental approach two areas were found to be amplifying vibration. The first was the center coil which surrounds the front shock. The second was the thin aluminum side wall, called the tunnel. More details about this experiment will be discussed in Chapter 2 .

\subsubsection{Phase 2: Acquiring Operating Data}

The next phase of the experimental approach was to acquire operating data. Each trial included accelerometers and microphones at consistent locations throughout each test set.

The first round of testing verified the need for conducting follow up rounds that included capturing drive shaft rotational speed allowing for order based processing of the data. Following a variety of testing the drive shaft, track pitch

and upper guide wheel diameter were found to have a noticeable effect on the 
response heard by the driver at two of the speeds of concern. Chapter 3 contains the details and results of the operating data.

\subsubsection{Phase 3: Analytical Transfer Path Analysis}

The final phase of the project was to use an analytical approach to attempt to make path identification quick and cost efficient. Instead of building a complex multi-body model an abbreviated model was created. The model included only the mechanical components in the rear suspension and a simulated track serving as the ground the suspension rode on. Using this abbreviated model, a method to run an analytical transfer path analysis (TPA) was attempted.

LMS Virtual.Lab software was used to solve for the solution of $X(\omega)$ using experimentally acquired impedances $H(\omega)$ and analytically derived forces $F(\omega)$. This process will be described in more detail in Chapter 4 . 


\section{Chapter 2: Phase 1 Measuring Frequency Response Functions}

To begin to test the path sensitivities of each wheel and its path through the rear suspension, frequency response functions (FRFs) were measured using an impact hammer, a microphone and thirteen accelerometers. Initial hammer roving found the front suspension coil's response to take a few seconds to completely die out. The location of this coil with respect to the thin wall of the running boards and tunnels led to investigation of this suspension component.

\subsection{Experimental Set Up}

The snowmobile was tested on a concrete surface in colder temperature conditions between 15 and 20 degrees Fahrenheit. The response locations can be seen in Figure 6. The nine impact locations can be seen in Figure 7. Please note that only the right side of the sled was tested because it was assumed that the system was symmetrical.

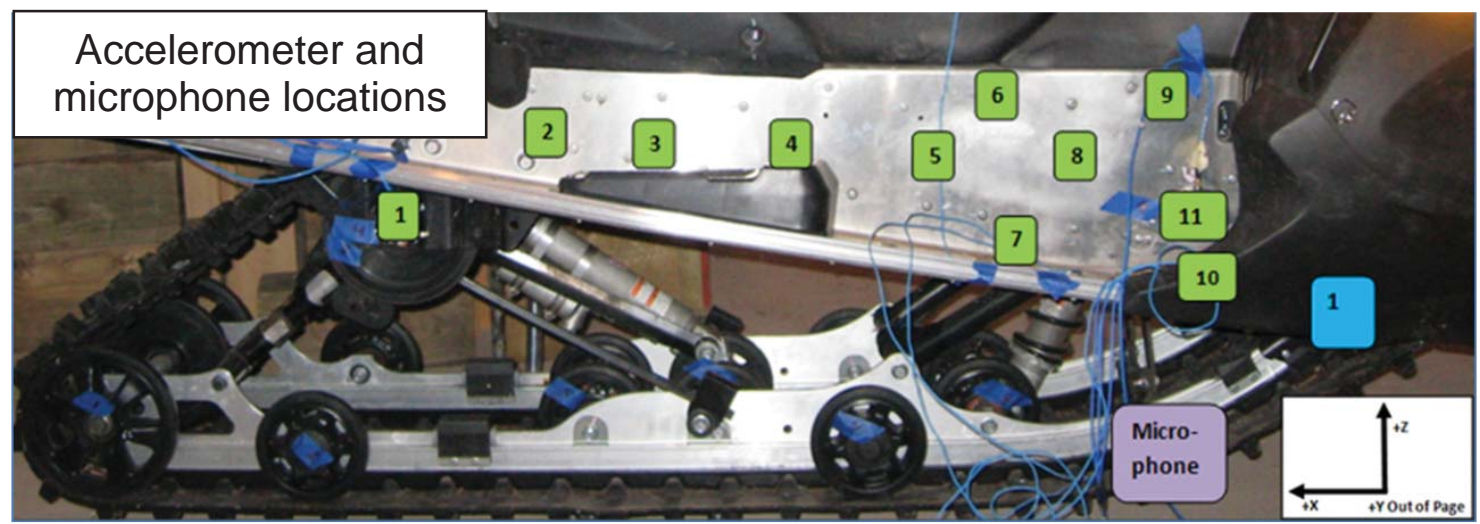

Figure 6: Response locations to characterize path sensitivities of the guide wheels 


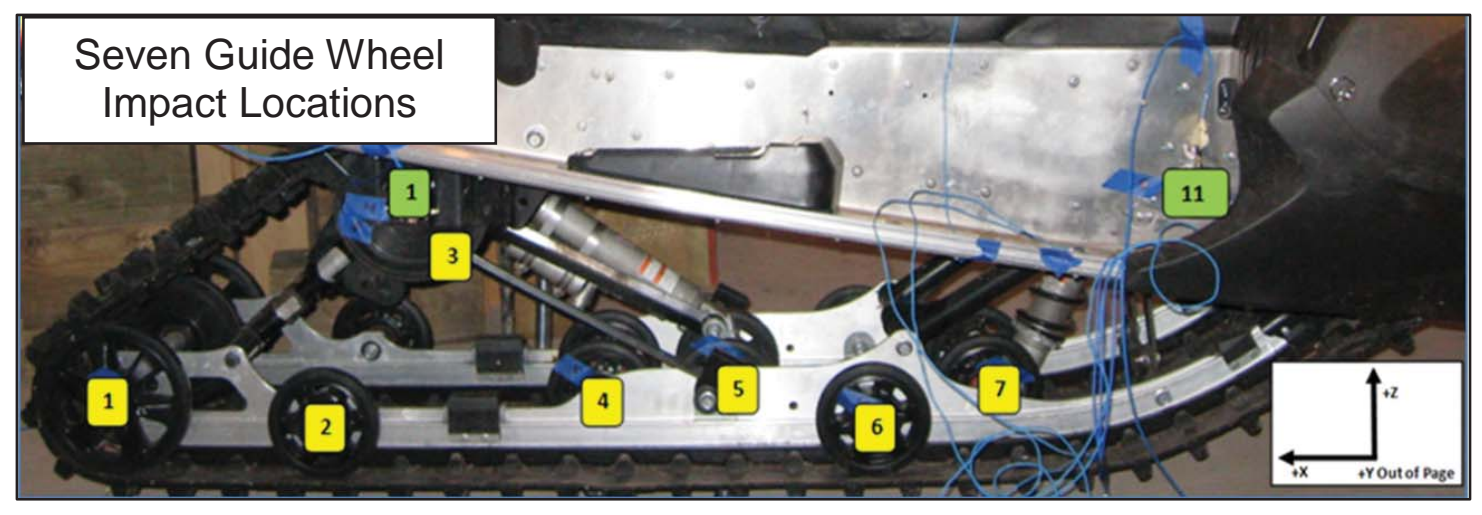

Figure 7: Impact locations to characterize path sensitivities of the guide wheels

Due to a noticeable ringing of the center suspension coil it was hypothesized that it would have an effect on paths within the system. Other models of snowmobiles within the sponsor's product line contained a tight rubber boot that was fit over this center coil to add mass and damping to reduce the ringing amplitude and duration. In order to test the effects a similar boot being added, each guide wheel was impacted for two different cases. In the first case, the suspension coil was left exposed in the state the snowmobile is sold to consumers. In the second case the coil was taped tightly using duct tape to replicate the effects of adding a rubber boot.

A $1 / 4$ inch microphone was located two feet from guide wheel six and approximately six inches from the ground to capture the acoustic response leaving the components in the suspension during each impact. Measuring the airborne noise was important in order to capture what energy could be traveling through the air to reach the drivers ears during operation.

\subsubsection{Identifying Sensitive Paths}

Wheel seven had the shortest, most direct path, to the center coil. The shaft of this wheel connects the rails and bottom portion of the front coil creating a direct structural path. This guide wheel's position is located inside of the rails and is the 
first set of wheels to experience ground impacts from an uneven trail. Figure 8 shows a comparison between the microphone and the top of wheel seven when the coil was taped and not taped.

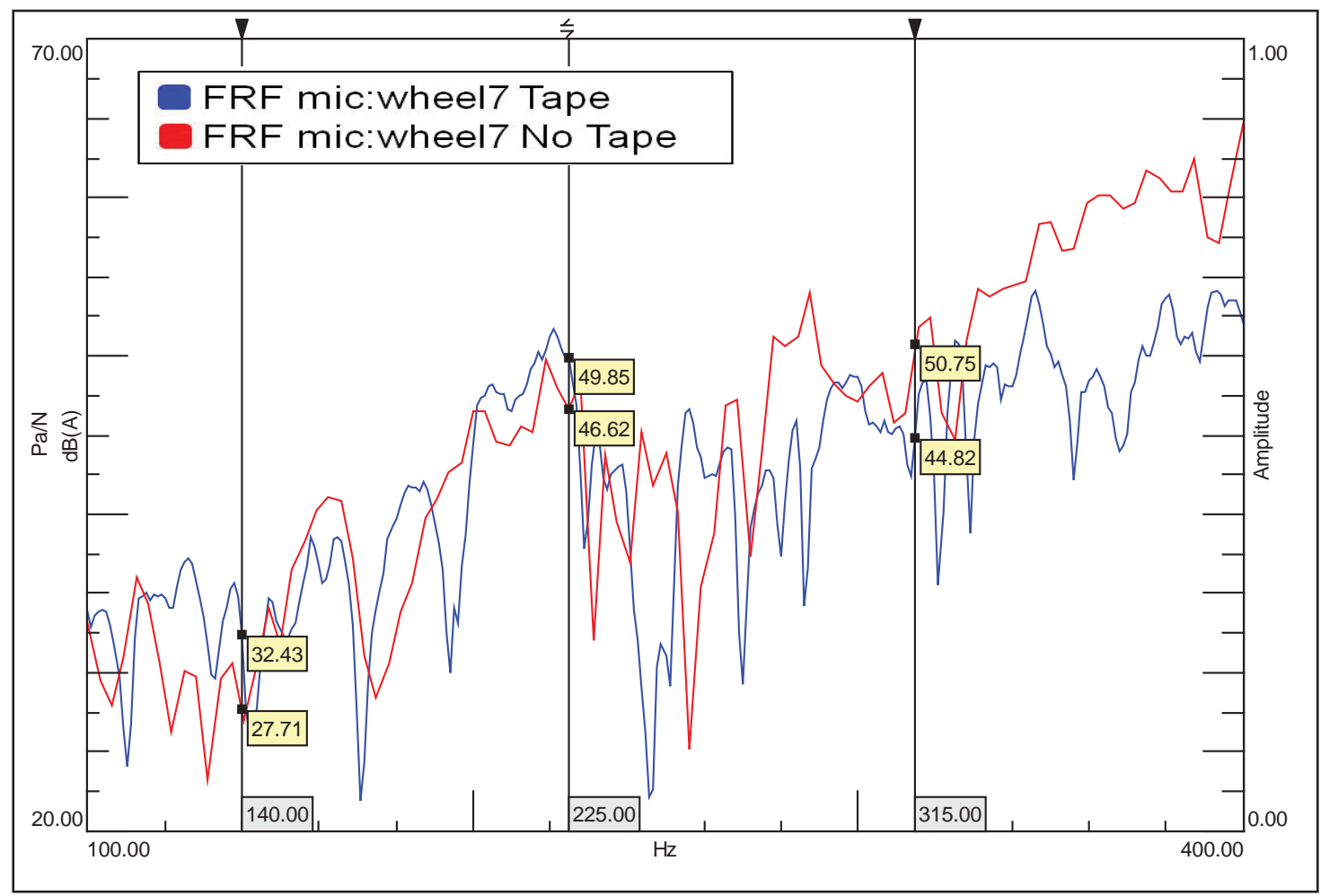

Figure 8: FRF comparison between the impact at the top of wheel seven and the microphone for the taped and un-taped coils

A difference of $4.7 \mathrm{dBA}, 3.2 \mathrm{dBA}$ and $5.9 \mathrm{dBA}$ was found for the frequencies of $140 \mathrm{~Hz}, 225 \mathrm{~Hz}$ and $315 \mathrm{~Hz}$ respectively while comparing the effects of taping the coil. At $315 \mathrm{~Hz}$ difference in acoustic response shows this frequency is the most sensitive to the effects of the ringing coil. This observation led the sponsor to fit this model of snowmobile with a rubber boot that acted similar to the effects of tightly taping the coil.

To better quantify the energy traveling through the mounting bolts at the front right bolt (FRB) and back right bolt (BRB), the FRFs were compared between all 
seven guide wheels and these locations. Figure 9 shows the FRFs between the FRB and the seven guide wheel impact locations.

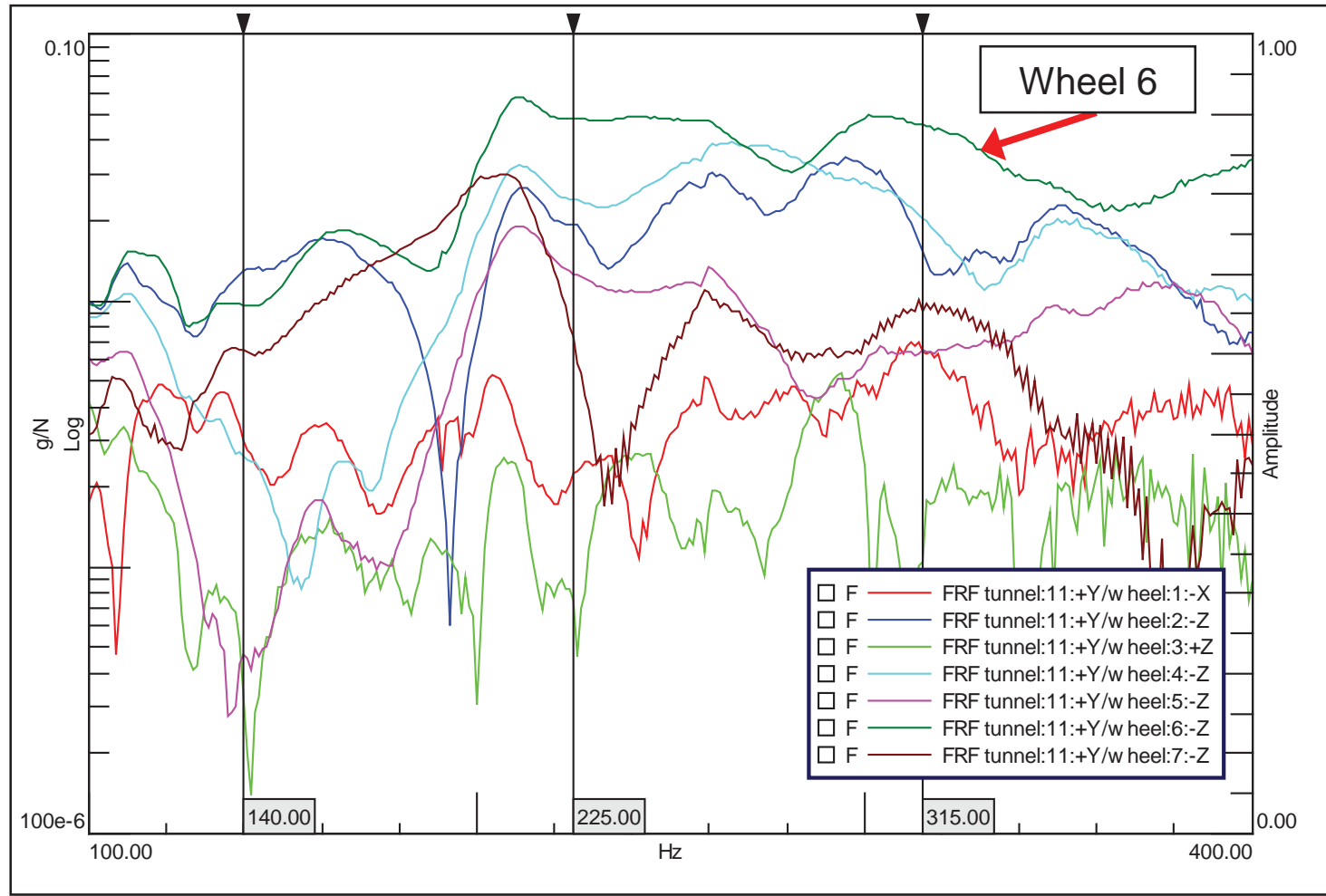

Figure 9: FRFs between all seven guide wheel locations and the FRB for the case of the taped coil

Figure 9 indicates wheel six had the largest response at both the $225 \mathrm{~Hz}$ and 315 $\mathrm{Hz}$ frequency. Wheel six has the shortest structural path from the impact location to the FRB as seen in Figure 10. This demonstrates that this path could be one of the primary paths from the source to the receiver locations. 


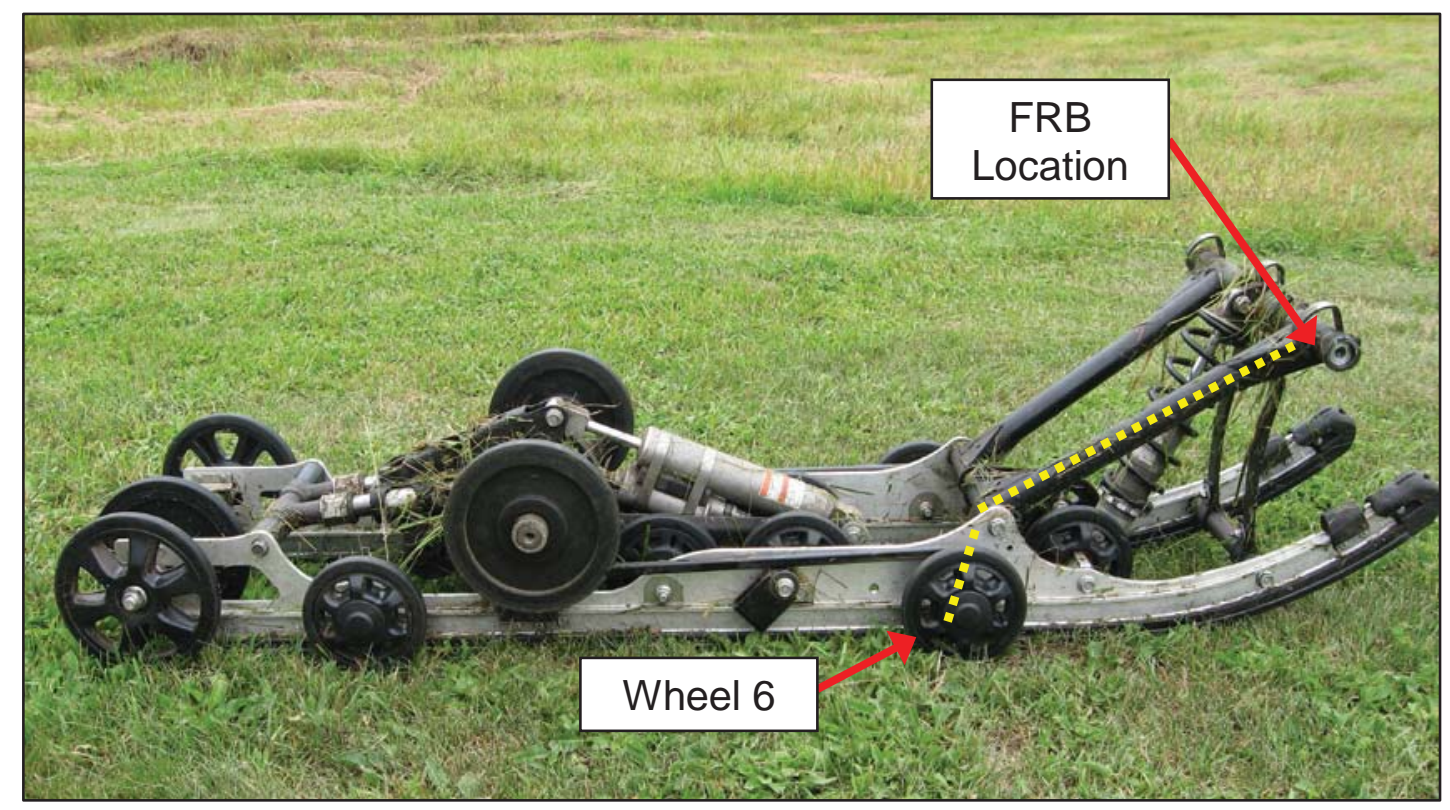

Figure 10: Sensitive path from wheel six to the front right bolt location

Figure 11 shows the FRFs between the BRB and the seven guide wheel impact locations. Unlike the FRFs between the guide wheels and the FRB location, more than one structural path was identified. Wheel 1,2 and 3 were all found to have sensitive structural paths leading to the rear mounting bolt location. 


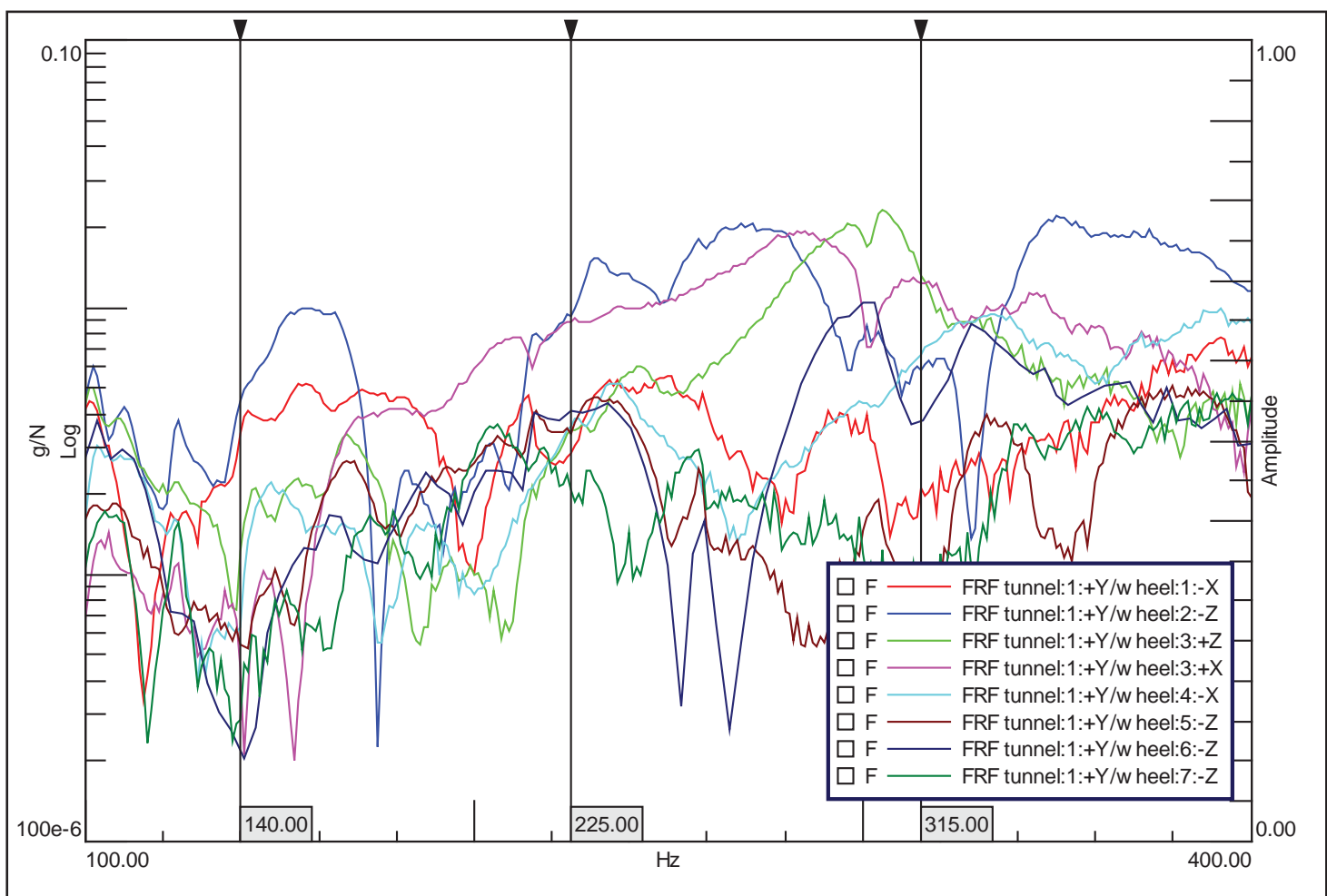

Figure 11: FRFs between all seven guide wheel locations and the BRB for the taped coil.

Wheel two was shown to have the most sensitive path to the BRB for the majority of the frequency range of interest as seen in Figure 12. Around the $315 \mathrm{~Hz}$ frequency of interest wheel three begins to dominate. 


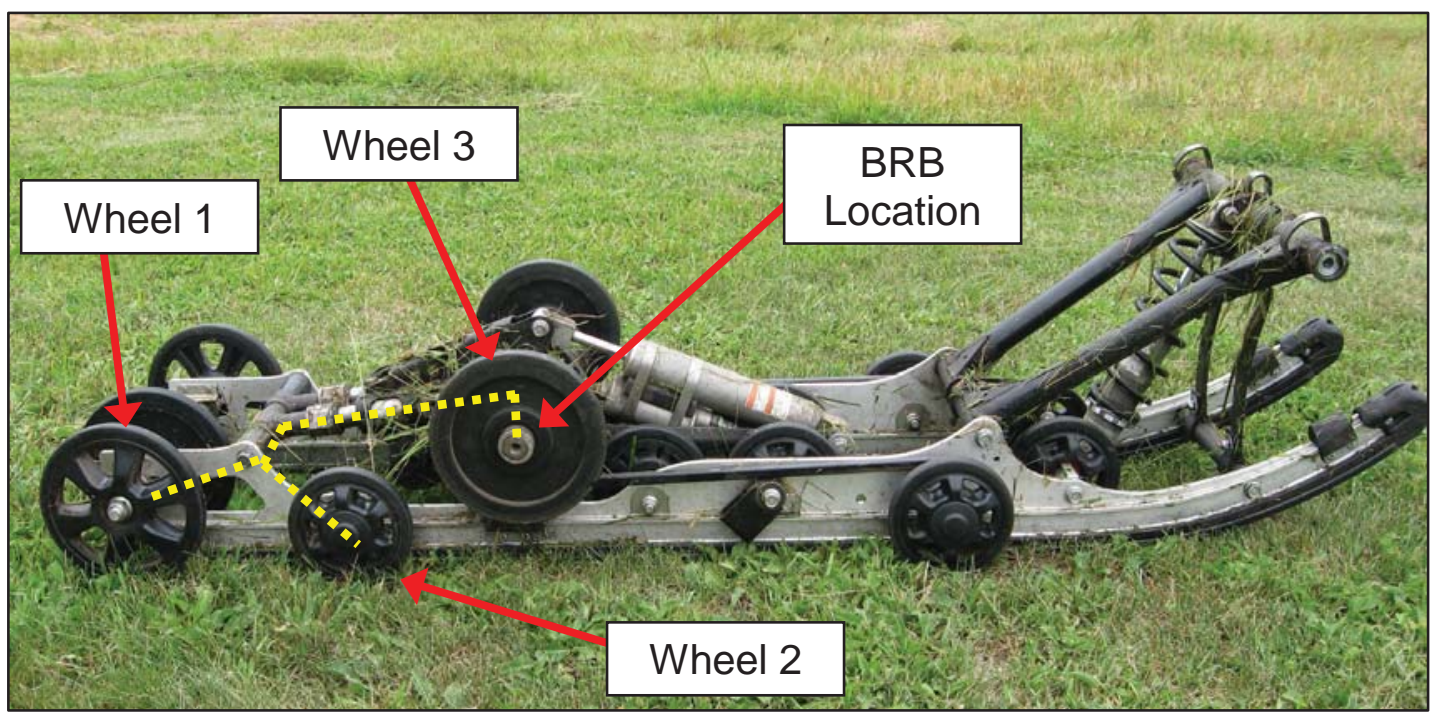

Figure 12: Sensitive path from wheel one, two and three to the back right bolt location

\subsection{Key Findings from Phase 1}

Phase one identified sensitive paths to the front and rear mounting bolts, verified contribution from the ringing of the suspension coil to the response heard around $315 \mathrm{~Hz}$ and verified that the tunnel is capable of amplifying energy that travels through it. This means the tunnel is likely receiving energy from one of the mounting bolt locations and playing it like a speaker to the driver during operation. Any road or track input to the rear suspension is likely to take one of the four sensitive paths highlighted in Figures 10 and 12.

By understanding these sensitivities, future modifications can be made to the rear suspension by adding bushings for damping in the system, changing the material composition of the guide wheels or modifying the location of the guide wheel and shafts. No engineering changes were pursued upon completion of this phase accept for the addition of the rubber boot to the suspension coil. The tightly taped coil produced a desirable result in the amplitude and duration of the ringing heard. 


\section{Chapter 3: Phase 2 Acquiring Operating Data}

Responses found under static conditions may not show up while the machine is in operation requiring further data acquisition while the machine is in use. Drive shaft engagement and contribution of the stiffener rods cannot be tested under static conditions. A variety of operating data was taken throughout the project to test the effects of different variables on the response heard by the driver during operation. This chapter outlines the testing methods used and includes key findings from the three rounds of data.

\subsection{Experimental Set Up for Round One}

Many factors had to be considered when setting up the equipment to acquire data during operation. Variables such as preload, testing surface, safe maximum speed, structural paths and airborne paths all had to be chosen carefully. A data acquisition unit made by LMS called a Scadas was used and had limited channels available making it crucial to choose points that were responding during operation.

The first thing considered was the problem of trying to capture what the driver hears while they're driving. There were no head pieces to hold a microphone available on the market. To keep the acoustic response at the driver's right ear consistent, a special head set was made to hold a $1 / 4$ " microphone an inch from the right ear under a DOT approved BRP Modular2 snowmobile helmet. The helmet had a cavity inside that permitted adequate room for the ears of the operator. This vacancy allowed the microphone to avoid contact with both the driver's face and the side of the helmet. This set up allowed the response measured inside of the helmet to be consistent from run to run. The head piece can be seen in Figure 13. 


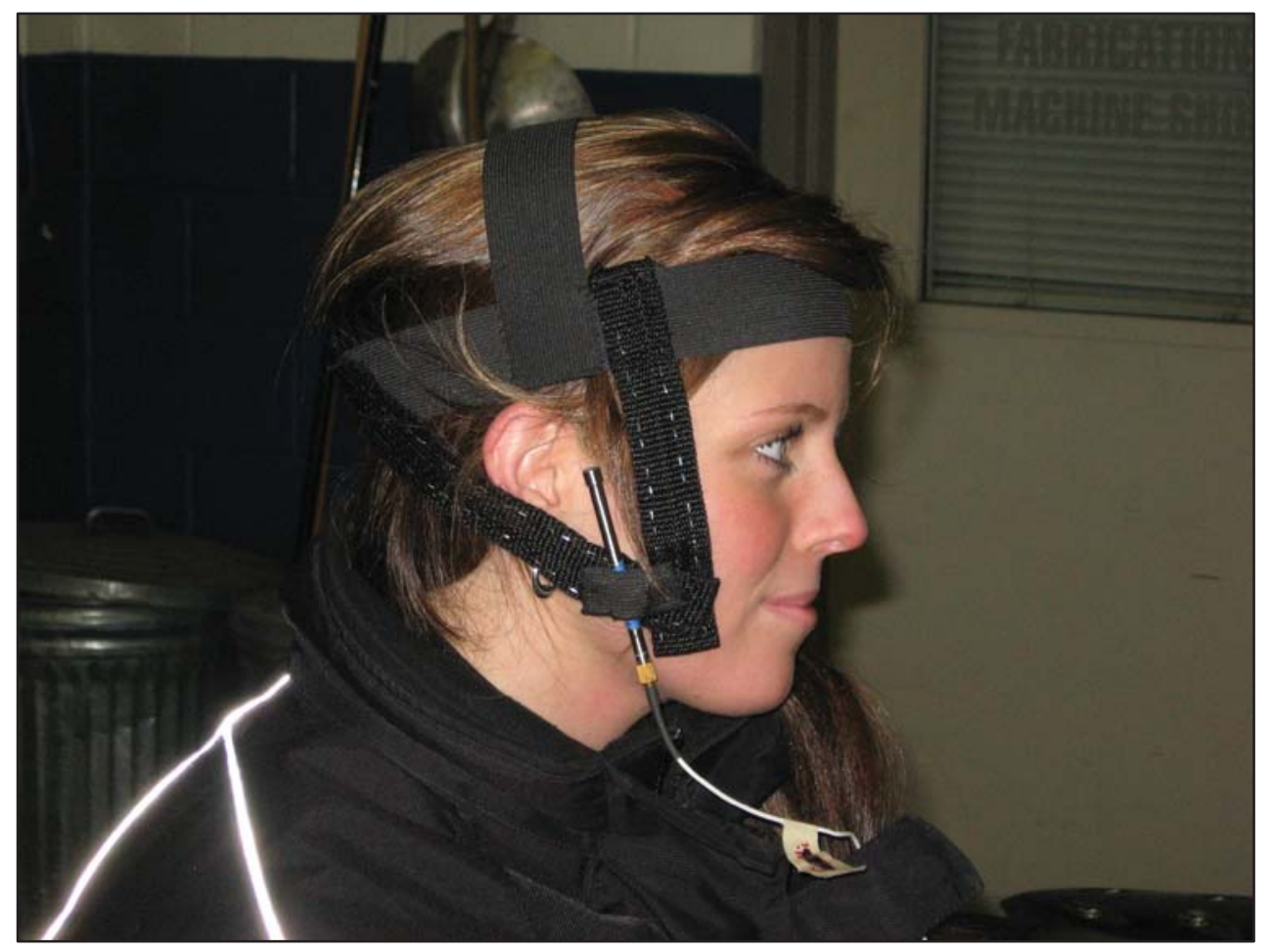

Figure 13: Custom harness designed to hold a 1/4" microphone 1" from the operator's right ear inside a snowmobile helmet

The testing surface was snow covered and groomed by the sponsor. The hard packed surface allowed the safe completion of speed sweeps from $0 \mathrm{MPH}$ to 70 $\mathrm{MPH}$ at half throttle. All testing was completed with two riders with a combined preload of $330 \mathrm{lbs}$. The passenger operated the computer and data acquisition system from a back pack worn backwards. An external battery was strapped in the back to power the devices. Figure 14 show the placement of the Scadas and computer. 


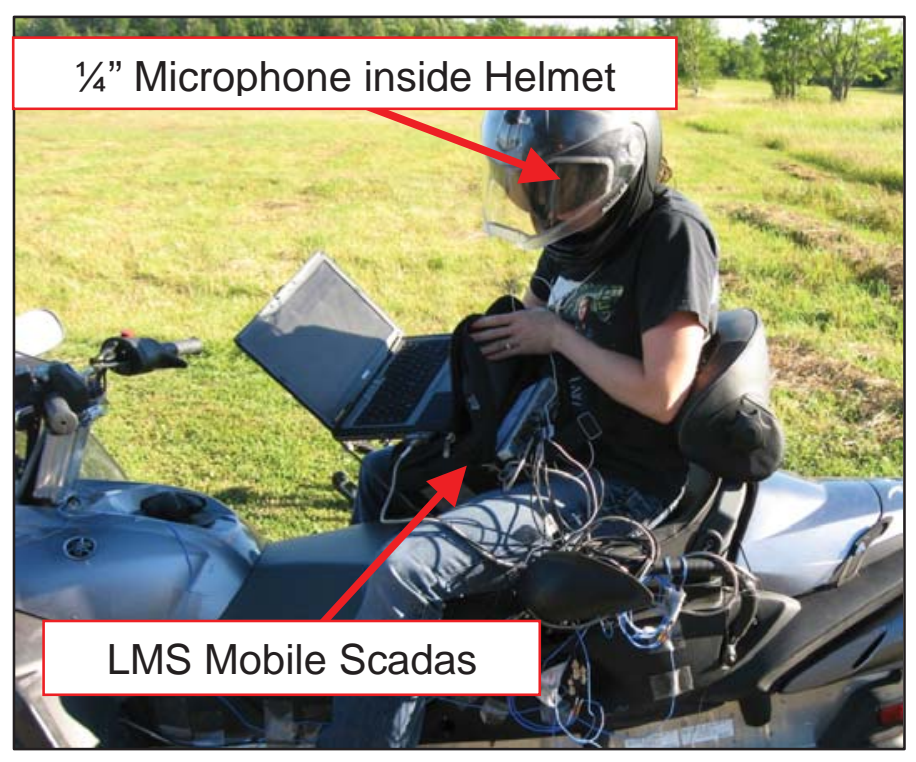

Figure 14: Operational test setup including an LMS Scadas DAQ, laptop and 1/4" microphone

The test set up included a microphone at the ear of the passenger, one tri-axial accelerometer on the steering column, two uni-axial accelerometers measuring the $+Y$ direction at the FLB and BLB and one uni-axial accelerometer measuring the $+Z$ direction attached to the rail next to guide wheel six referred to as the skid. These points were targeted to gain insight into what were believed to be sensitive airborne and structural paths. Figure 15 shows the locations where accelerometers were attached to the snowmobile. 


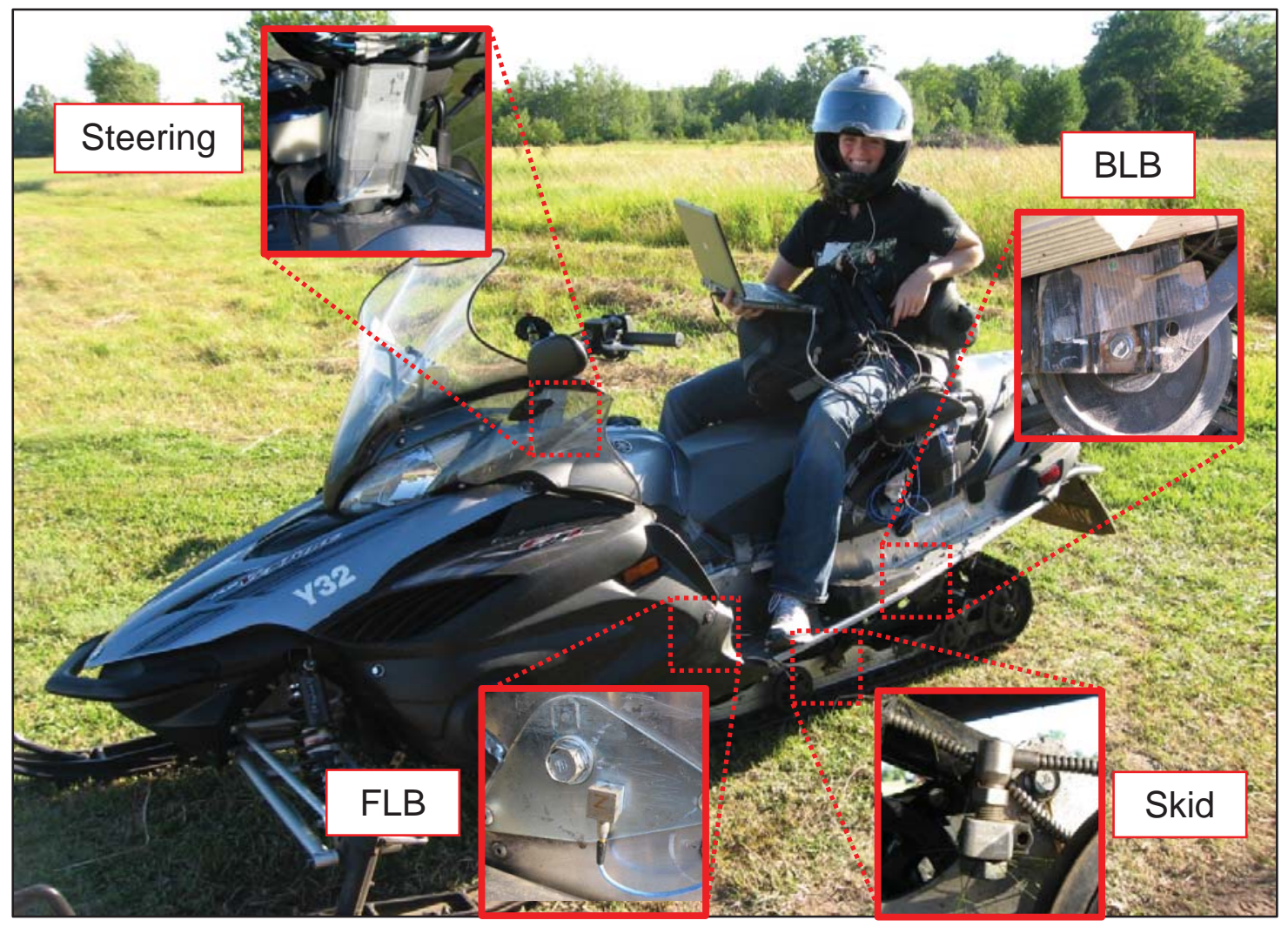

Figure 15: Operational test setup including response measurement locations with respect to the body of the sled

\subsubsection{Data Acquired in Round One}

Figure 16 shows the color map of the frequency spectrum of the driver's microphone for a speed sweep from $0 \mathrm{MPH}$ to $70 \mathrm{MPH}$. Even though the RPMs during each sweep wasn't tracked for this first set of testing the track and engine order still stood out in the spectrum. 


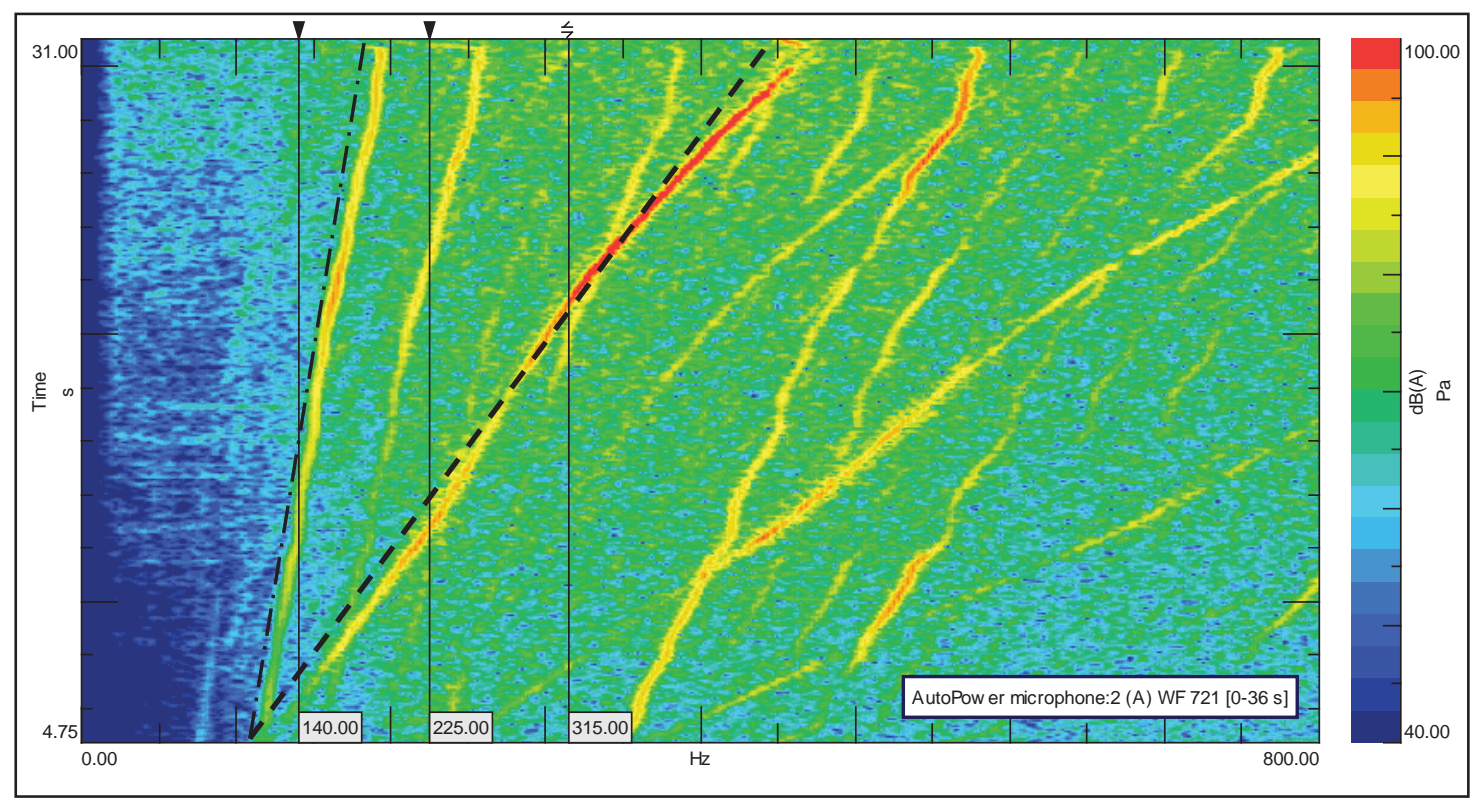

Figure 16: Driver microphone frequency spectrum colormap for the control rear suspension configuration

The harmonics of the continuously variable transmission are seen in the spectrum as the yellow lines that run closer to vertical through the sweep as outlined by the first dotted line. The lines that run close to a 45 degree angle are capturing the harmonics of the track engagement as outlined by the second dotted line.

From Figure 16 it was hypothesized that the response heard by the driver at both $35 \mathrm{mph}$ and $50 \mathrm{mph}$ had contribution from the track rods. The spectrum began approaching $100 \mathrm{dBA}$ in the acoustic response between $285 \mathrm{~Hz}$ and $440 \mathrm{~Hz}$. The fact that these frequencies lit up during operation strengthens the connection between the track rod contribution and its effect on the $225 \mathrm{~Hz}$ frequency of interest.

To determine the effects of wheel spacing and staggering on the amount of energy in the response at those locations, new holes were drilled in the rails and each guide wheel was staggered equal distances from the others. This would 
cause the guide wheels to pass each stiffener rod a half of a second later than the wheel located across from it. Figure 17 shows the colormap of the frequency spectrum for the driver's microphone of the staggered setup.

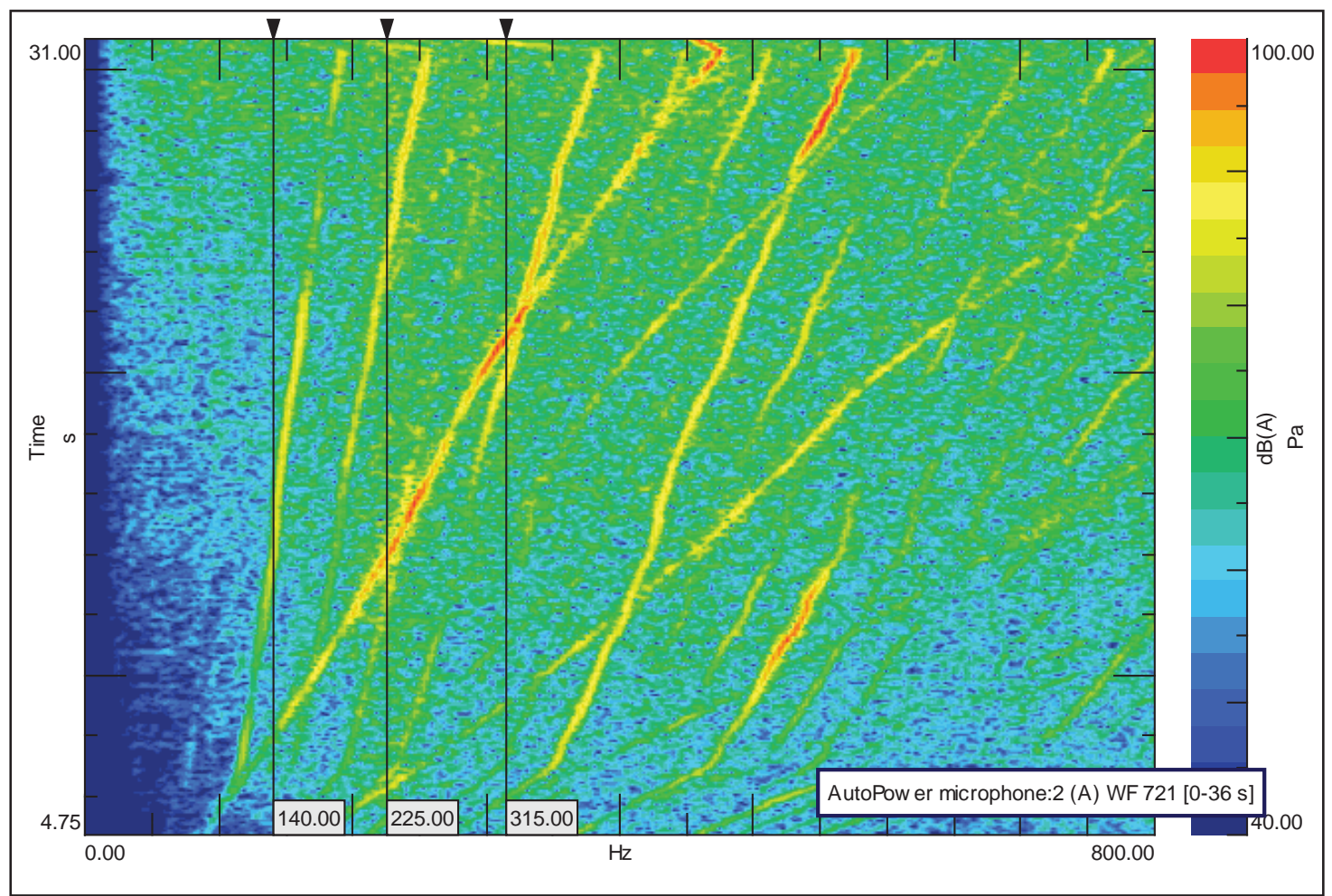

Figure 17: Driver microphone frequency spectrum for the staggered rear suspension configuration

The frequency of interest $315 \mathrm{~Hz}$ still lit up for this run but had changed in intensity and frequency range. Instead of a band from $285 \mathrm{~Hz}$ to $440 \mathrm{~Hz}$, the large response was now located in from $285 \mathrm{~Hz}$ to $350 \mathrm{~Hz}$. The staggering of the guide wheels had reduced the amplitude of the response from $330 \mathrm{~Hz}$ to $450 \mathrm{~Hz}$. Comparison of Figure 16 and 17 show that staggering the guide wheels had reduced the amplitude of the response. . 


\subsection{Experimental Set Up for Round Two}

An engine tachometer was not available for testing during the previous round of operating data; therefore, no direct conclusions could be made about the track or engine orders. Staggering the wheels reduced noise at the receiver but two other sources could also be causing excessive noise including the power train and driveshaft.

The power train involves four stroke firing events as well as various pumps. The sponsor provided information that one pump in particular engages at 1.5 cycles per second. Additionally, the teeth on the drive shaft grab the track creating what's referred to as track engagement. This engagement is based upon the number of teeth on the driver sprocket. In the case of the original drive shaft there were nine standard teeth. The prototype driver was made of a combination of eight extroverted teeth and standard teeth. This difference in the number of teeth is referred to when describing the harmonics of the system. In the case of the original driver the track engagement order would be the $9^{\text {th }}$ and in the case of the prototype driver it would be the $8^{\text {th }}$.

A second set of operating data was collected using the same test setup as the first round with the addition of the collection of the revolutions per minute (RPMs) from the end of the drive shaft. The end of the driveshaft contains tiny teeth that a sensor counts per revolution to calculate the speed read on the speedometer. The testing location changed to a grass covered field as seen in Figure 18. 


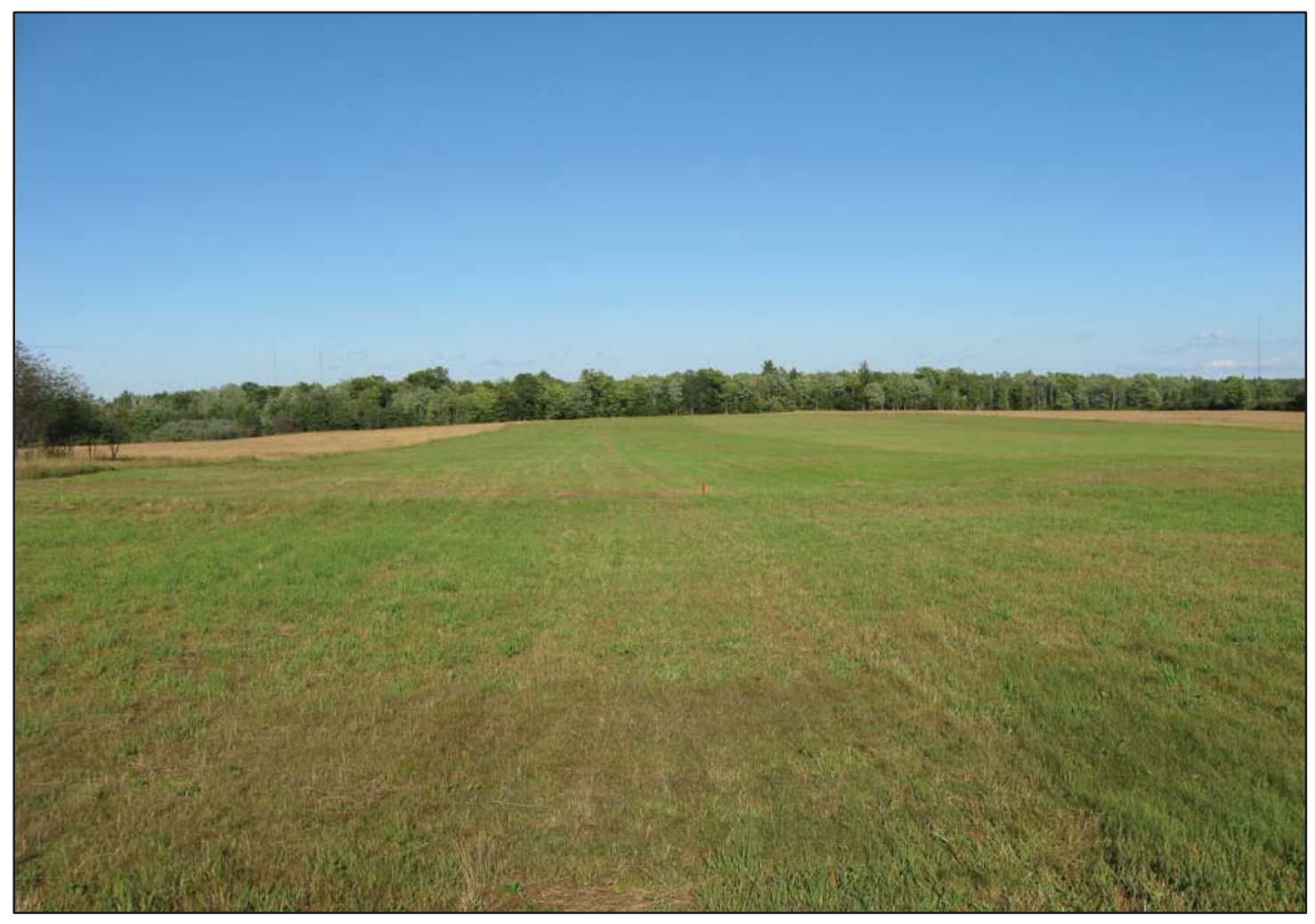

Figure 18: Grass field testing location for acquiring operating data

Collecting the RPMs allowed the data to be processed with respect to specific track and engine harmonics which are called orders. Figure 19 shows the method by which the voltage signal was collected using the LMS Scadas during each run. 


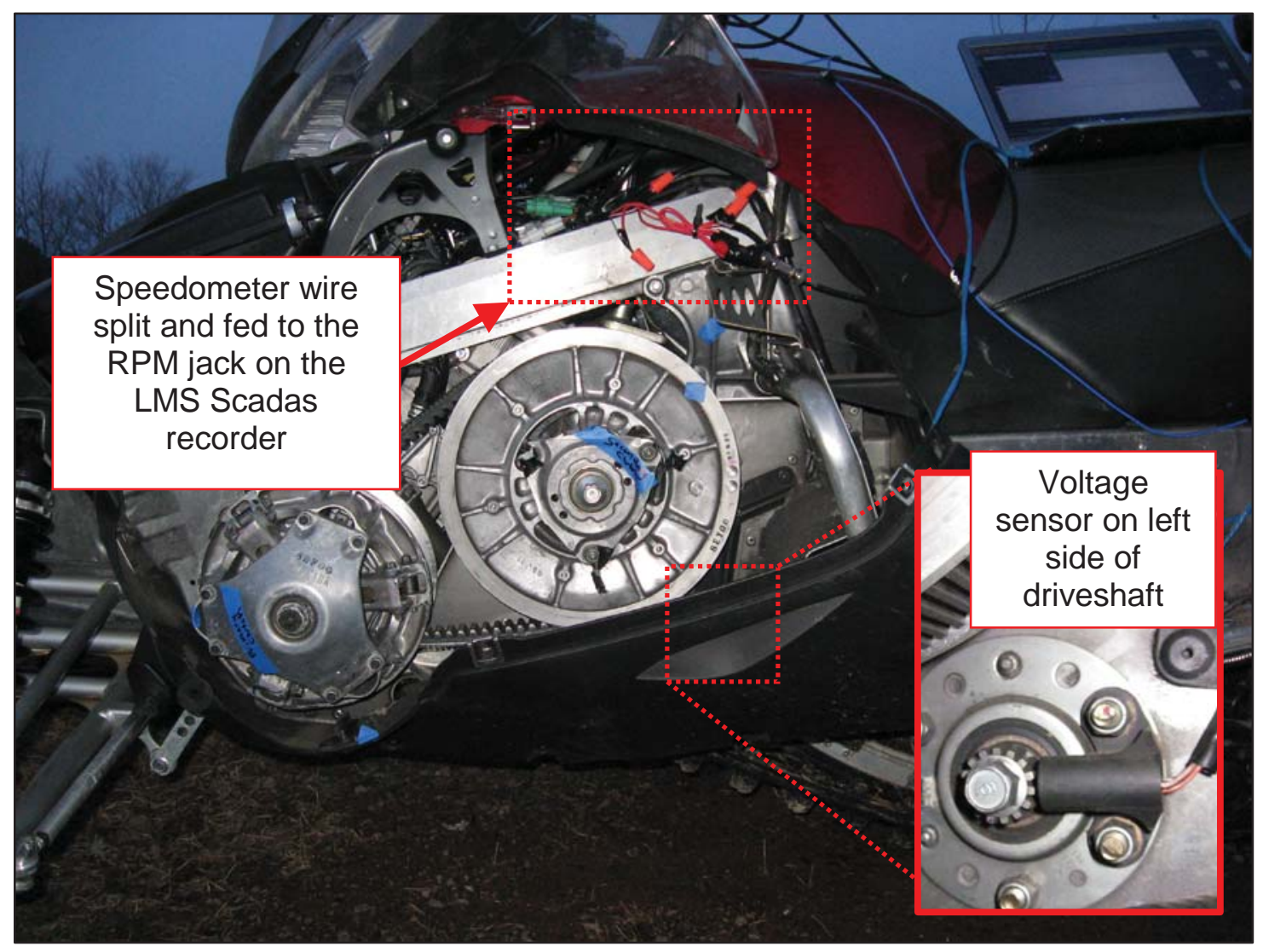

Figure 19: Method used to collect speedometer voltage during operating data acquisition.

Speed sweeps were performed from $0 \mathrm{MPH}$ to $50 \mathrm{MPH}$ at half throttle. The testing surface didn't allow for safe speeds over $50 \mathrm{MPH}$.

\subsubsection{Data Acquired in Round Two}

The data was processed with respect to the track orders and engine orders estimated from round one of testing. Even though the first set of data lacked the direct measurement of the RPMs the software still allows tracking cursers to be selected and set to an order of interest. When these cursers were applied to the graphs the orders were changed until the curser lined up with the data. This experimentation led to direct processing of the data taken in round two using a feature of LMS called Offline RPM Extraction. 
This add-in in LMS Test.Lab was used to process the data with respect to the 1.5 and $9^{\text {th }}$ orders. This software feature calculates RPM time traces from acquired accelerometer or microphone data. Once the important orders are selected a color map can be created for purposes of order analysis. Figure 20 shows the process by which the raw time data from the microphone was processed in Test.Lab.

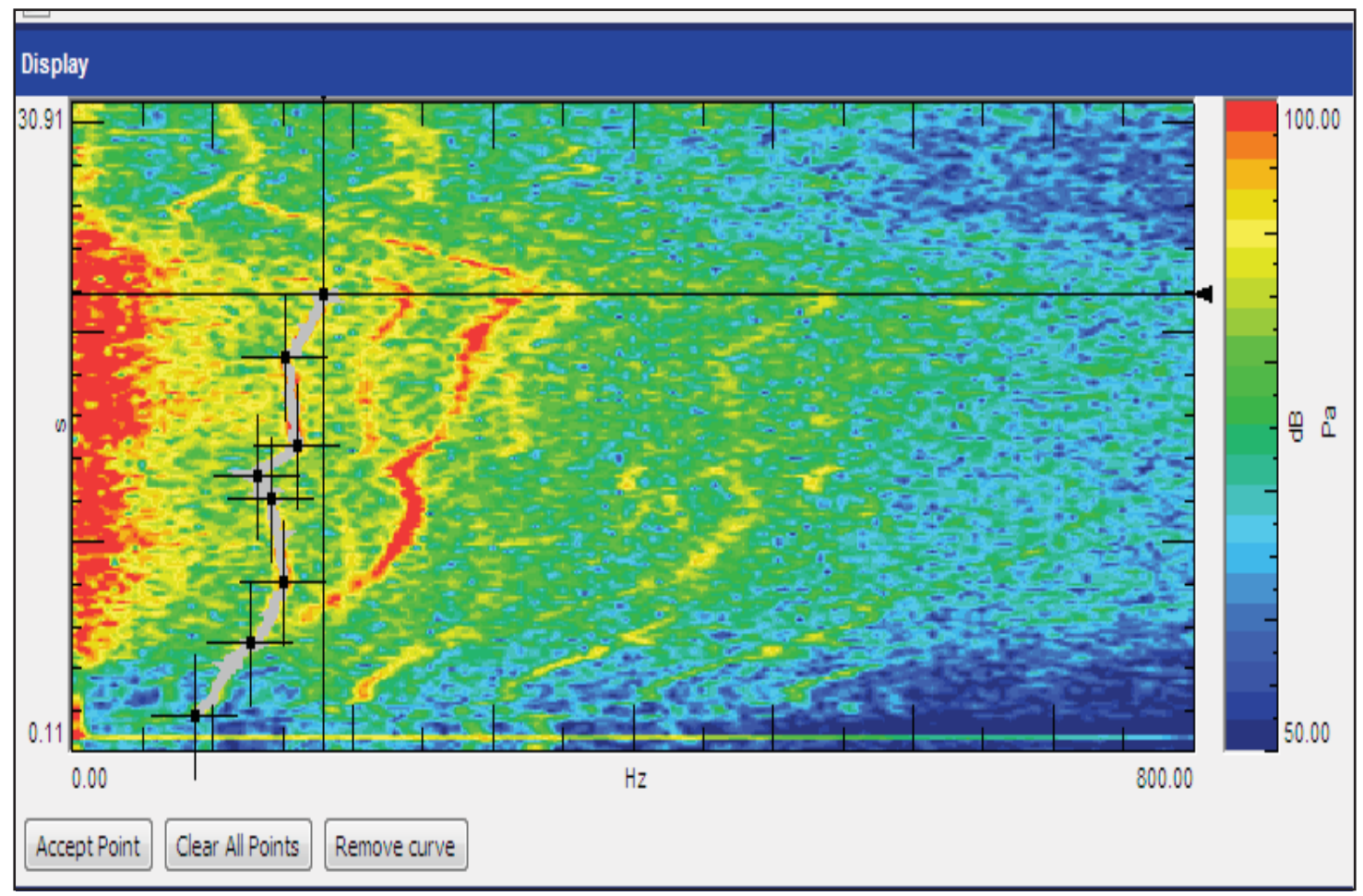

Figure 20: LMS Test.Lab Offline RPM Extraction point picking to process raw time data with respect to engine order

To determine at what RPM $0 \mathrm{MPH}$ corresponded with and what RPM $50 \mathrm{MPH}$ corresponded with the trace measured from the speedometer was plotted as seen in Figure 21. 


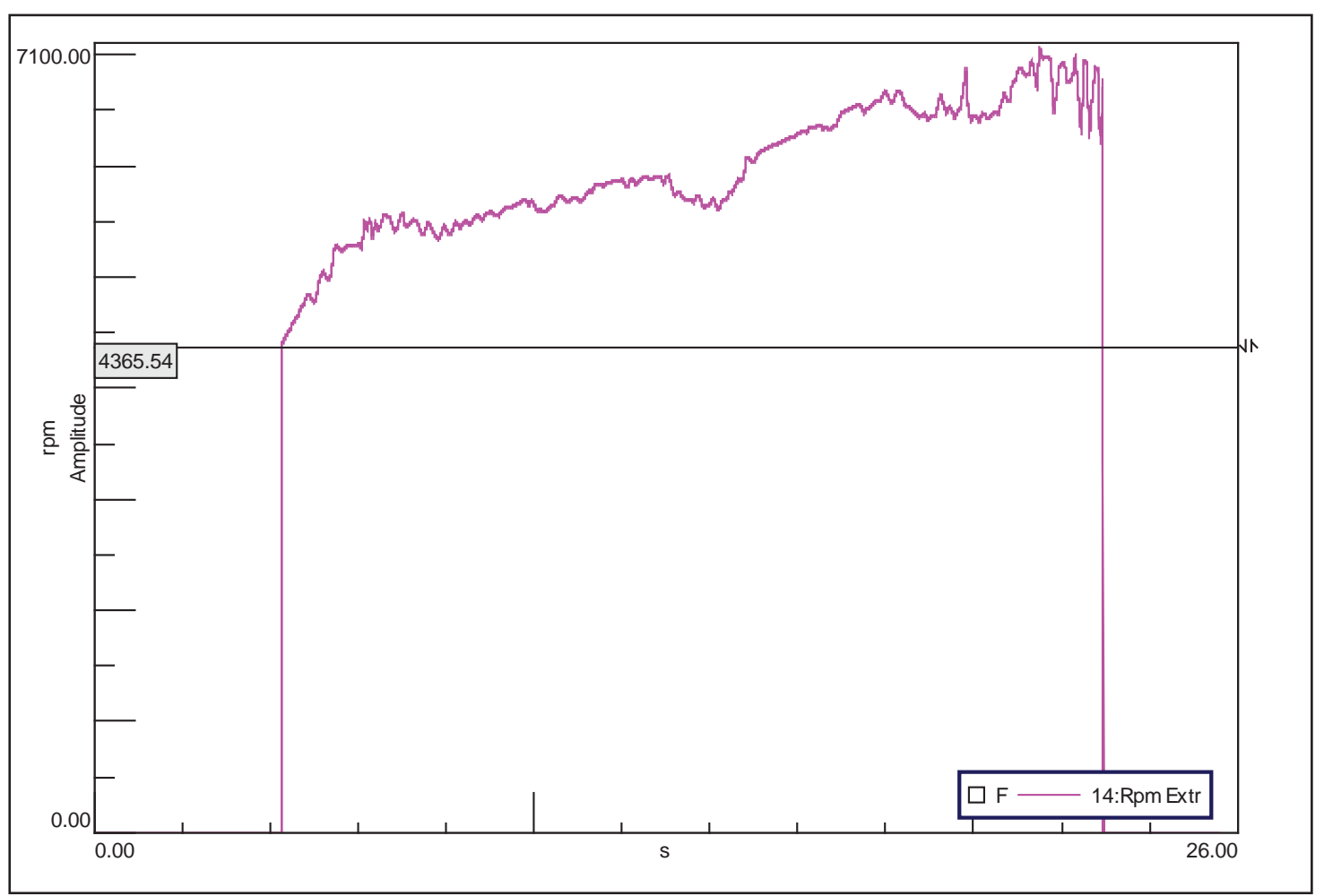

Figure 21: RPM trace identifying the lower and upper limits for a speed sweep from 0 MPH to $50 \mathrm{MPH}$

The trace identifies 4365.54 RPM to 7000 RPM to be the conditions from idle to $50 \mathrm{MPH}$. An example of how one set of data was processed with respect to the track order versus that same data being processed with respect to the power train order can be seen in Figure 22. 


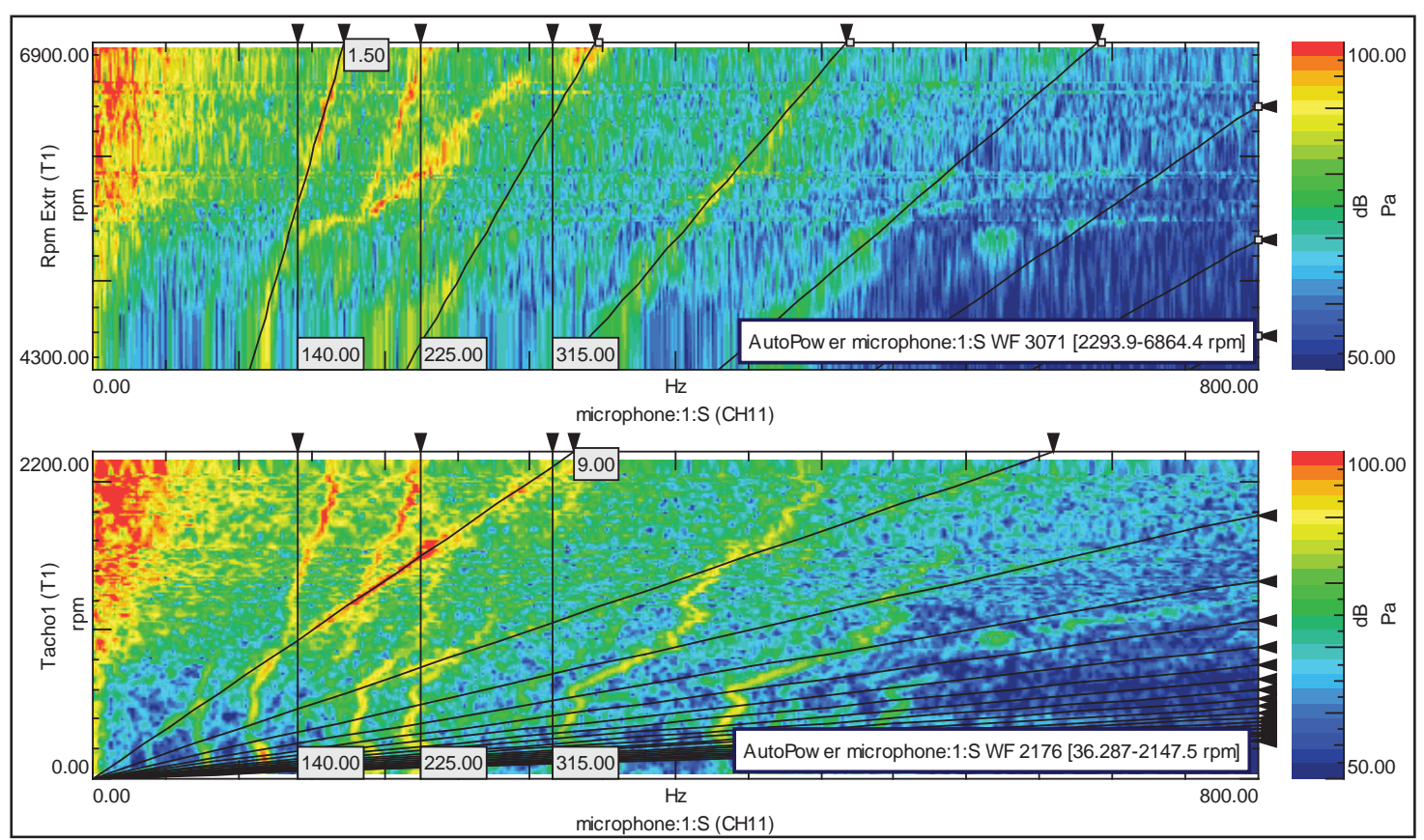

Figure 22: Comparison of post processing with respect to the engine orders (top) and the track orders (bottom)

Figure 22 shows that when the data was processed with respect to the track, a band between $215 \mathrm{~Hz}$ and $235 \mathrm{~Hz}$ approached $100 \mathrm{dBA}$. It also shows that the engine related noise was not contributing to the frequencies of interest. Although this demonstrates that the frequency of $225 \mathrm{~Hz}$ is sensitive to track engagement related noise more needed to be understood about the properties of the driveshaft. Collecting FRFs on the shaft would help identify if this response was created by the track engagement or the drive shaft itself.

\subsubsection{Collecting Drive Shaft FRFs}

The second phase of testing led to questions concerning whether or not the effects at the $225 \mathrm{~Hz}$ frequency were due to properties of the drive shaft or due to the track engagement. In order to learn more about this system, FRFs were measured between the shaft of the driveshaft and the track. The chosen boundary conditions reflected those in operation meaning the shaft was within 
the chassis and preloaded with the track around it. More information about the dynamic properties of the driveshaft within these boundary conditions was needed to understand which variable was contributing. Figure 23 shows the placement of the accelerometers and the locations that were impacted.

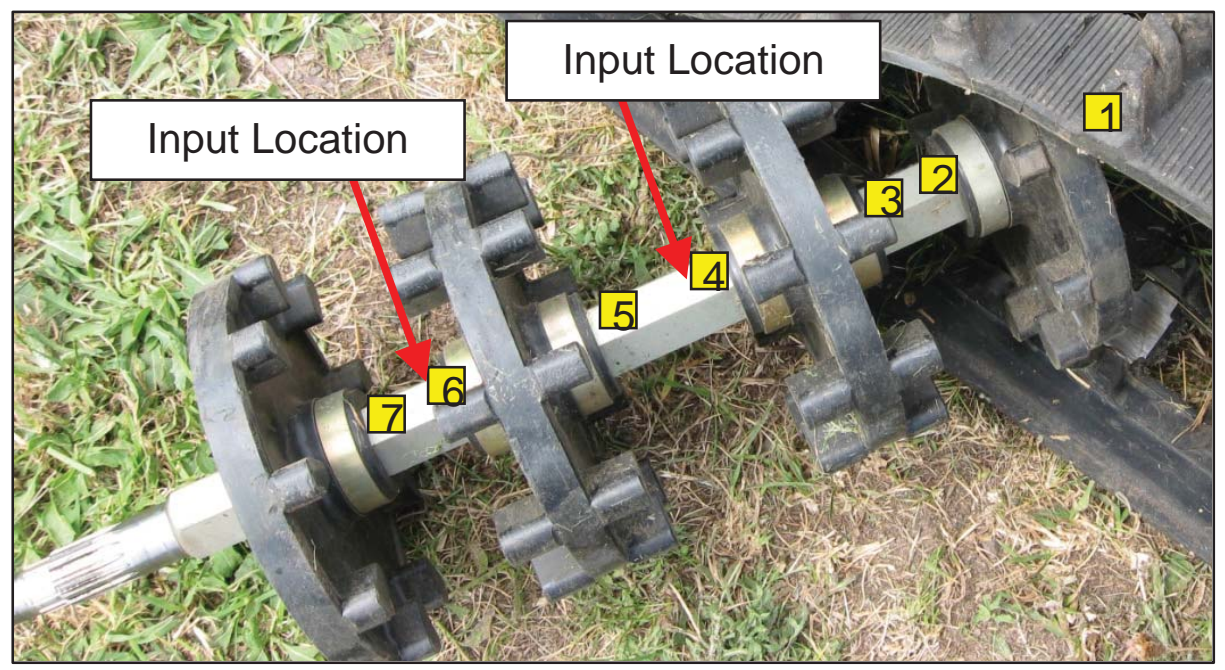

Figure 23: Accelerometer and impact locations used in FRF measurements of the drive shaft

The shaft was impacted at two locations and responses were measured for seven locations along. Space was restricted due to the boundary conditions only allowing one direction to be impacted for each location. Responses were measured in two direction perpendicular to the shaft.

Figure 24 shows the FRFs with responses in both the $X$ and $Z$ direction. 


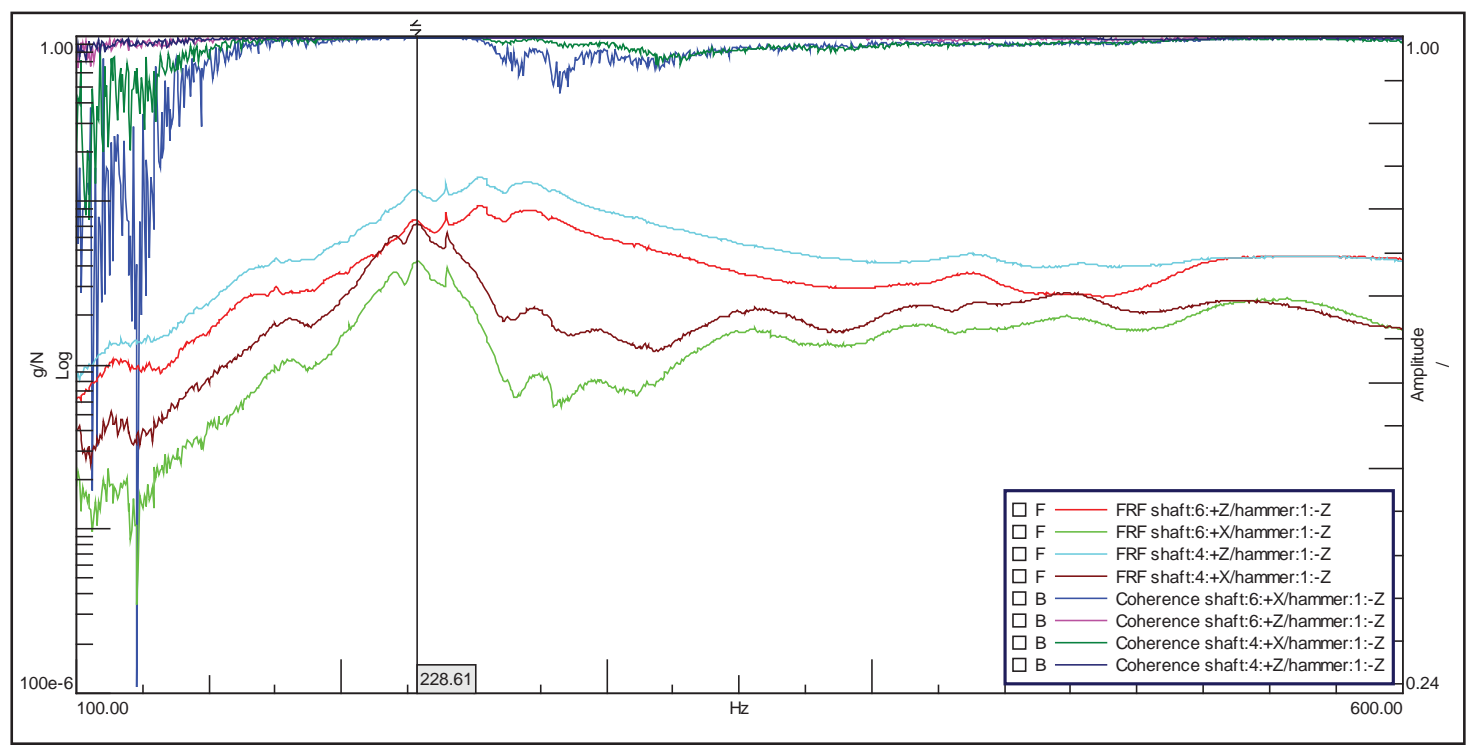

Figure 24: FRF and coherence between hit location six and accelerometer six in the $X$ and $Z$ directions (legend text too small)

This FRF comparison shows peaks aligning around $228 \mathrm{~Hz}$. To further understand what shape the shaft would have at this frequency the functions were curve fit using both a frequency domain curvefitter and a time domain curvefitter. A strong mode shape was indicated at $227 \mathrm{~Hz}$.

After creating geometry for the drive shaft the mode shape was animated. A screen shot of the shafts deflection is shown in Figure 25. 


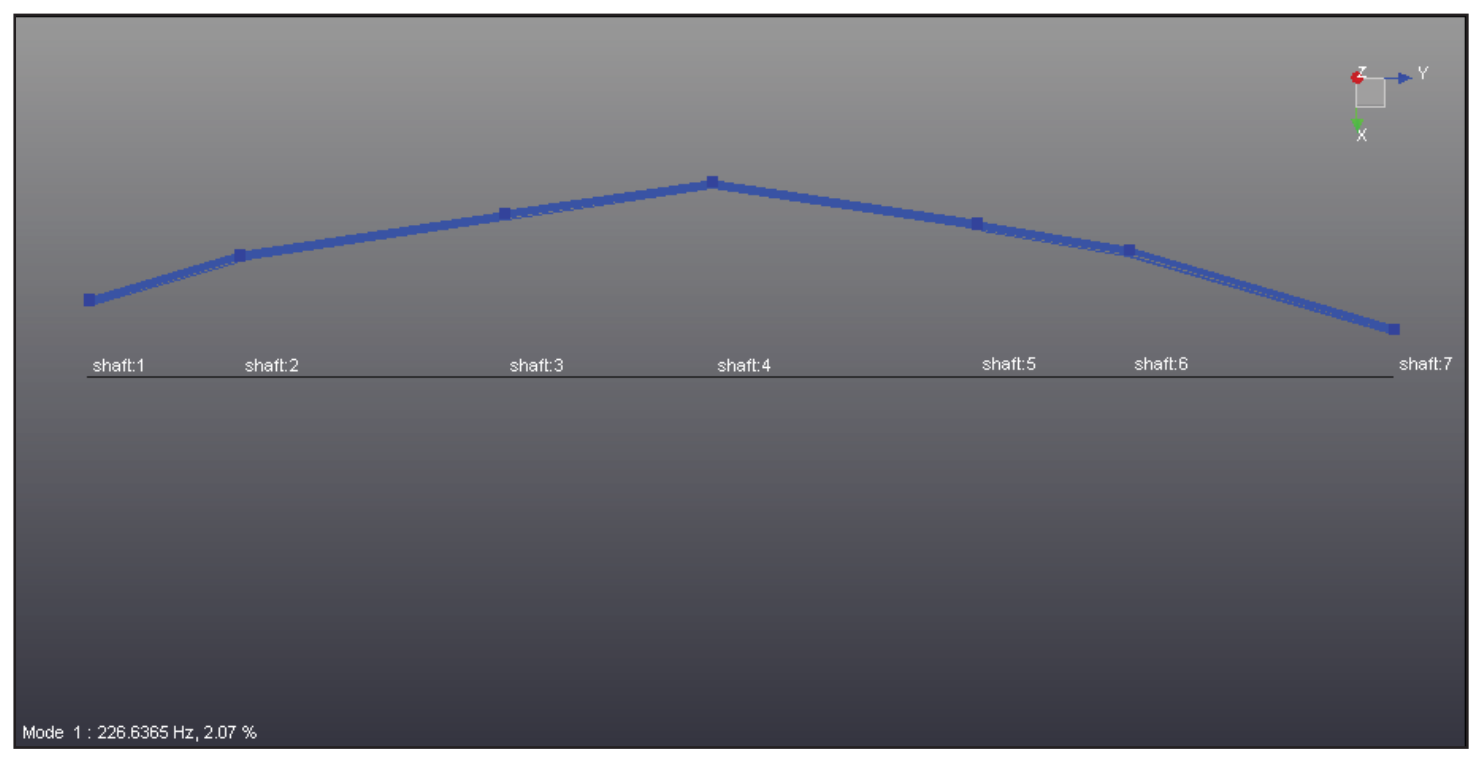

Figure 25: Animation of shaft geometry at mode for $227 \mathrm{~Hz}$

The frequency was very close to $225 \mathrm{~Hz}$. This modal analysis was consistent with the operating data acquired so far in concluding that the drive shaft was a likely contender for transmission of energy during operation to the noise heard by the driver. It was thought that the thin plastic sprockets were also flexing during operation further contributing energy into the system. This led to the need to test a different sprocket design in addition to multiple suspensions for the third round of operating data.

\subsection{Experimental Set Up for Round Three}

Multiple elements had been identified as possible factors that were affecting the frequencies of interest during operation including the drive shaft design, track pitch, and guide wheel spacing. To better identify which were contributing more than others to the responses felt by the receiver more operating data was acquired to test these variables. 
The test set up used for acquiring operating data was kept the same as was used in round two including all the accelerometer locations, RPM collection and driver's microphone location. Six different configurations were tested using speed sweeps from $0 \mathrm{MPH}$ to $40 \mathrm{MPH}$ at half throttle. Table 4 shows the variables for each set up. In between each configuration the track tension was set to the calibration industry standard as shown in Figure 26.

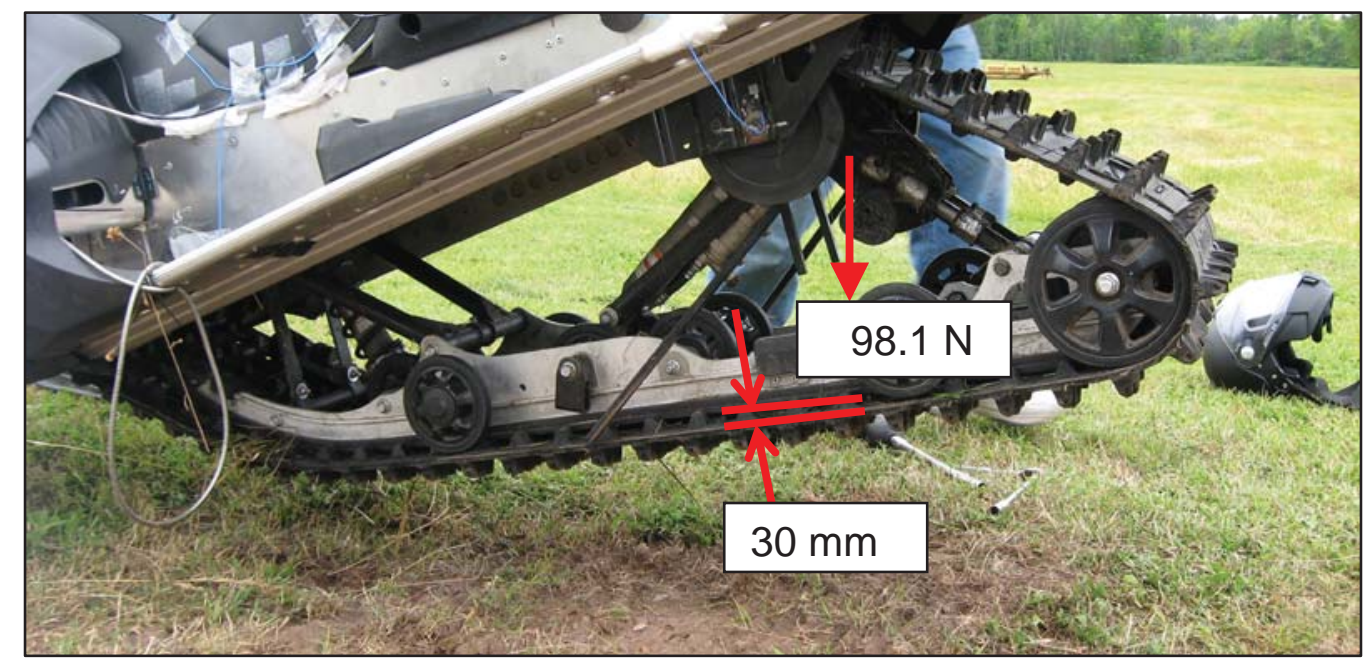

Figure 26: Testing method to check for proper track tension in the rear suspension

When a 98.1 Newton force is applied to the rubber track surface between the bump stops the vertical drop must measure $30 \mathrm{~mm}$. If the drop is not achieved the rear guide wheel is adjusted either direction until the drop equals $30 \mathrm{~mm}$. Another variable changed with each configuration was the hyfax that lines the bottom of the rails.

Three different suspension set-ups were tested amongst the other variables. Figures 25, 26 and 27 show pictures of these three suspension and are labeled as $A, B$ and $C$. 
Table 4: Specifications of the variables tested in each run

\begin{tabular}{|c|c|c|c|c|c|c|c|}
\hline Run & Susp & $\begin{array}{c}\text { Diameter of } \\
\text { Upper Guide } \\
\text { Wheel } \\
\text { (Inches) }\end{array}$ & $\begin{array}{c}\text { Track } \\
\text { Length } \\
\text { (inches) }\end{array}$ & $\begin{array}{c}\text { Track } \\
\text { Pitch } \\
\text { (inches) }\end{array}$ & $\begin{array}{c}\text { Number } \\
\text { of } \\
\text { Pitches }\end{array}$ & $\begin{array}{c}\text { Drive } \\
\text { Shaft }\end{array}$ & $\begin{array}{c}\text { Number } \\
\text { of Teeth } \\
\text { on Drave } \\
\text { Shaft }\end{array}$ \\
\hline A & 8 & 144 & 2.52 & 57 & Baseline & 9 \\
\hline 3 & B & 8 & 144 & 2.52 & 57 & Baseline & 9 \\
\hline 4 & B & 8 & 146 & 2.86 & 51 & New & 8 \\
\hline 5 & C & 8 & 144 & 2.52 & 57 & Baseline & 9 \\
\hline 6 & A & 8 & 144 & 2.52 & 57 & Baseline & 9 \\
\hline
\end{tabular}

Suspension $A$ is the baseline suspension from the original model as seen in Figure 27. Suspension $B$ is the same structure as suspension $A$ accept it has two less sets of inner guide wheels and the third set of guide wheels from the front as seen in Figure 28. Suspension C is a completely different suspension off of a different model and has a variety of different features including a gradual lift in the front and rear, the rear arm is mounted approximately two inches further forward than the baseline, special mounting bolt brackets to extend point BRB and BLB back towards the rear of the sled and a different rail profile. Suspension C can be seen in Figure 29. 


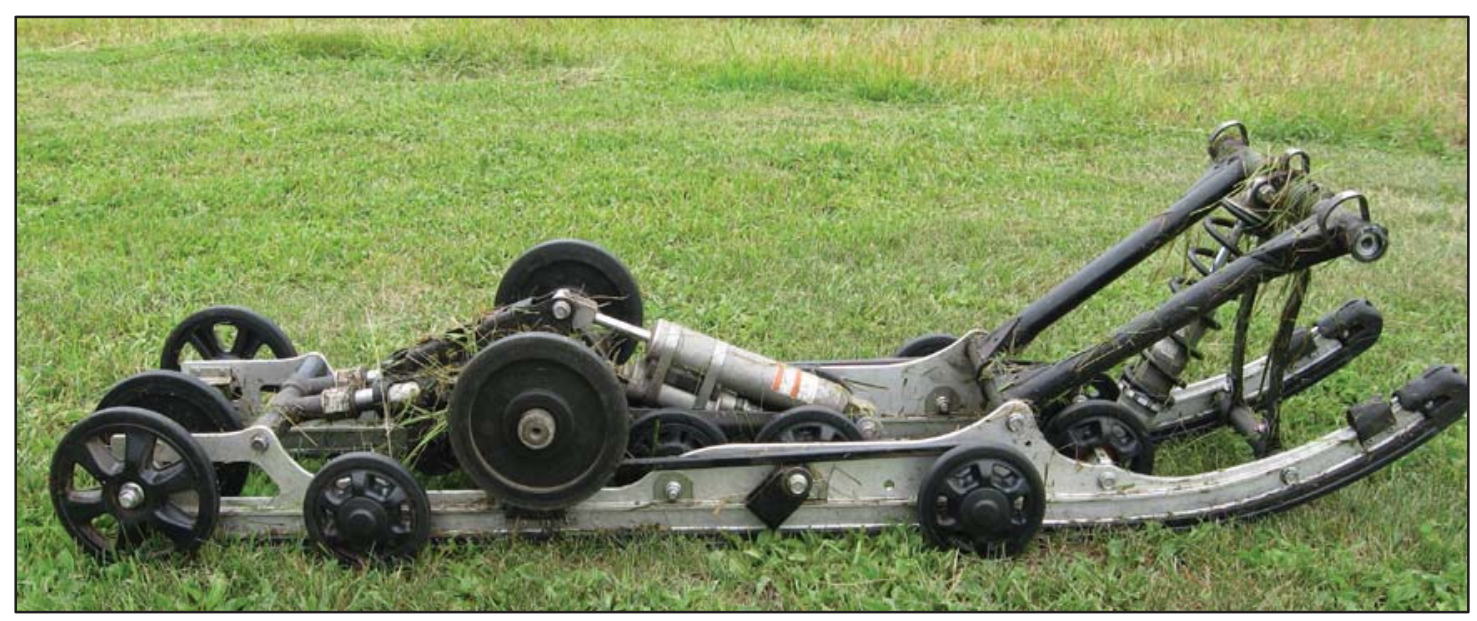

Figure 27: Suspension A, the baseline rear suspension configuration

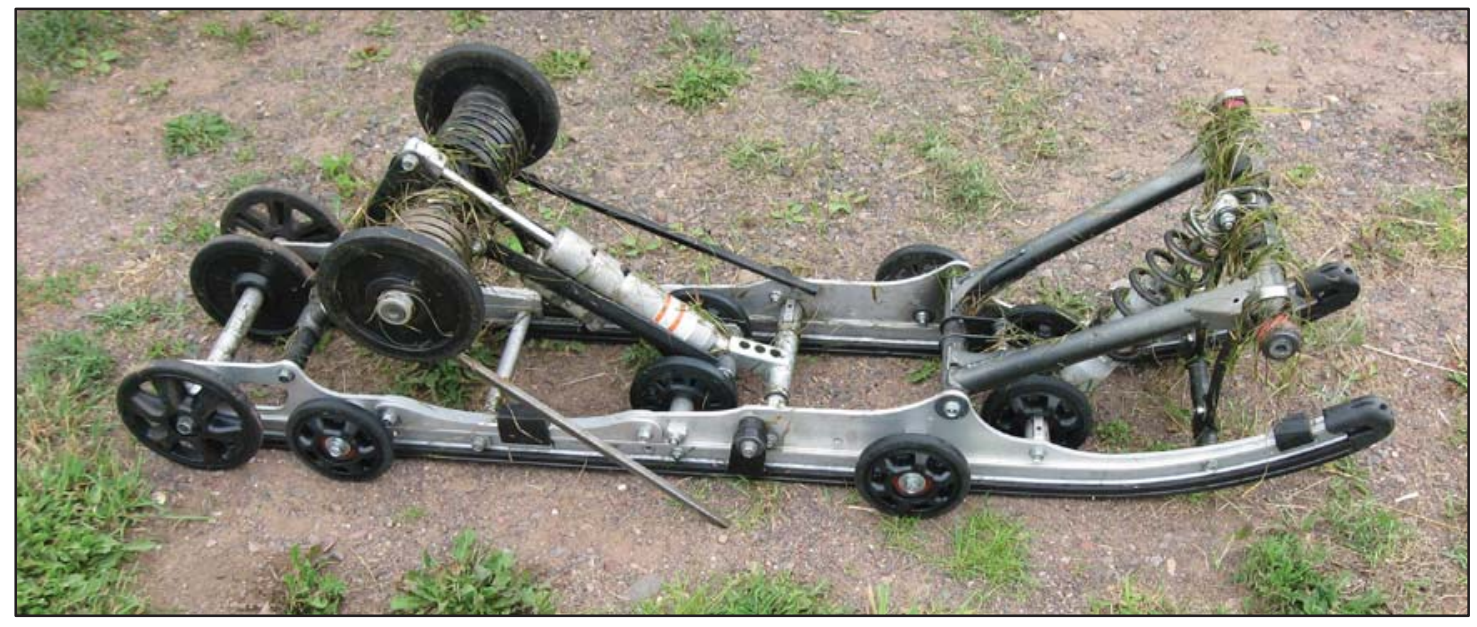

Figure 28: Suspension B, same suspension as A with two less guide wheels 


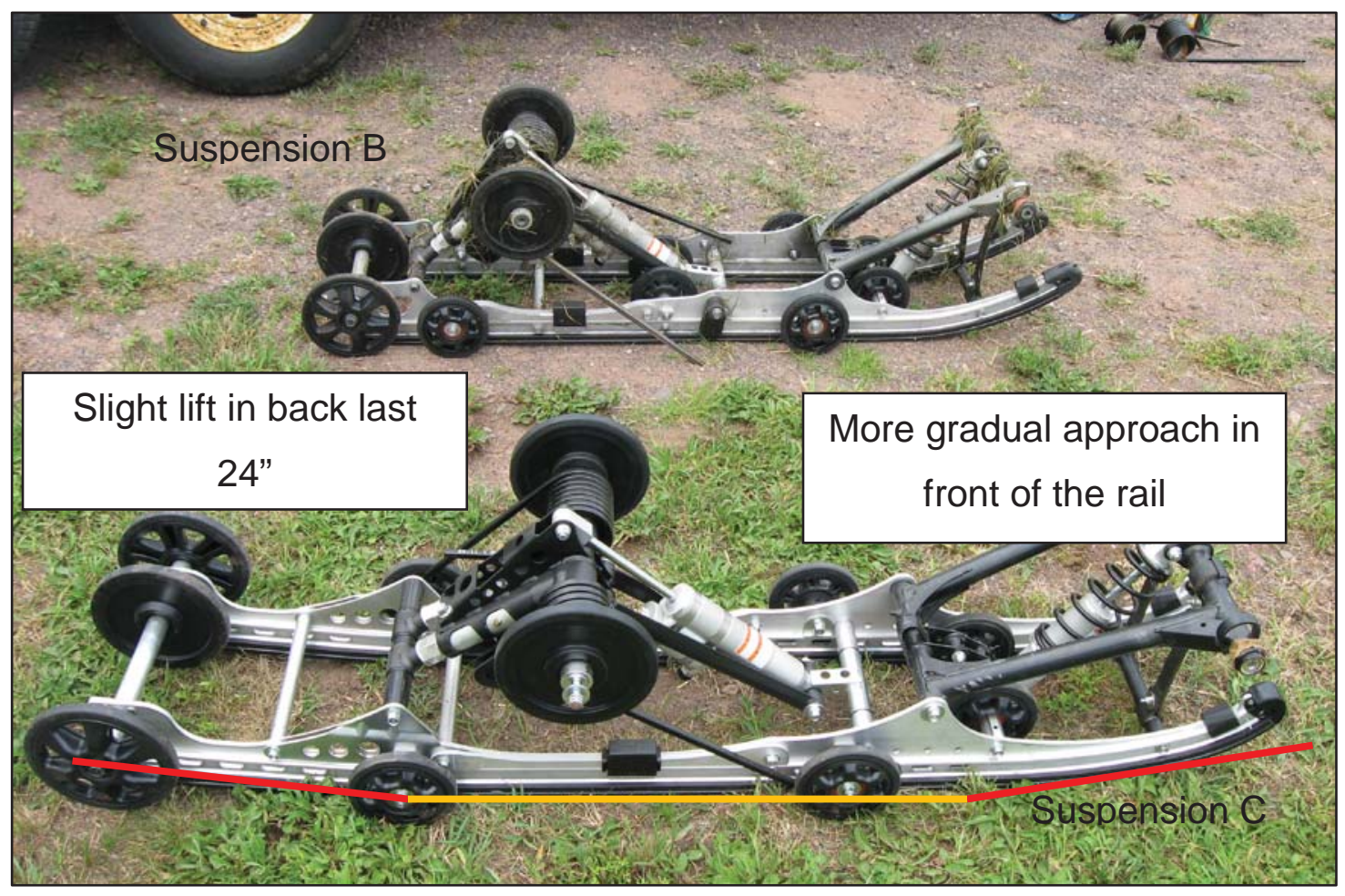

Figure 29: Suspension C (lower) pictured with suspension B (upper)

A smaller upper guide wheel was tested in run three to determine its impact on the frequency band of interest. The guide wheel size can be seen in Figure 30 .

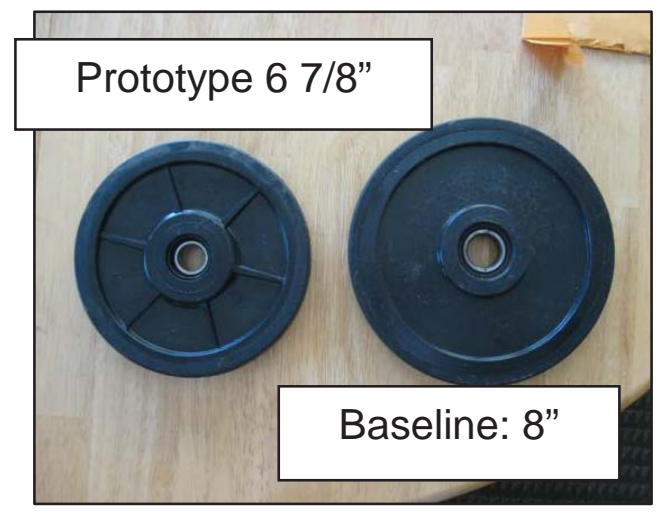

Figure 30: Upper idler guide wheel comparison of baseline to test size 
For the fourth run the effects of the driveshaft design were tested. In round one and two of testing the driveshaft had been identified as a component that would reduce the noise at $225 \mathrm{~Hz}$. To understand this further, a new prototype driveshaft was created by the sponsor. The new shaft had different specifications including eight sprocket teeth instead of nine and two large wide sprockets instead of four separate thin sprockets. Both shafts shared the same hex shaft design. The prototype drive shaft was composed of both standard and extroverted drivers versus only standard drivers on the original. The differences can be seen in Figure 31.



Figure 31: New prototype driver and track pictured with the baseline driver and track 


\subsubsection{Data Acquired in Round Three}

Each run was completed twice and processed using the Offline RPM Extraction tool discussed in section 3.2.1. There were no significant differences noted between suspension A (the baseline) and suspension $\mathrm{C}$. There were also no significant differences noted between the upper guide wheel size and suspension A to suspension B. The only significant noticeable reduction in response in the spectrum was found in the fourth run. The variables tested in run four included the impact of the new driver and track combination using suspension B. Figures 32 and 33 show run one and run four respectively.

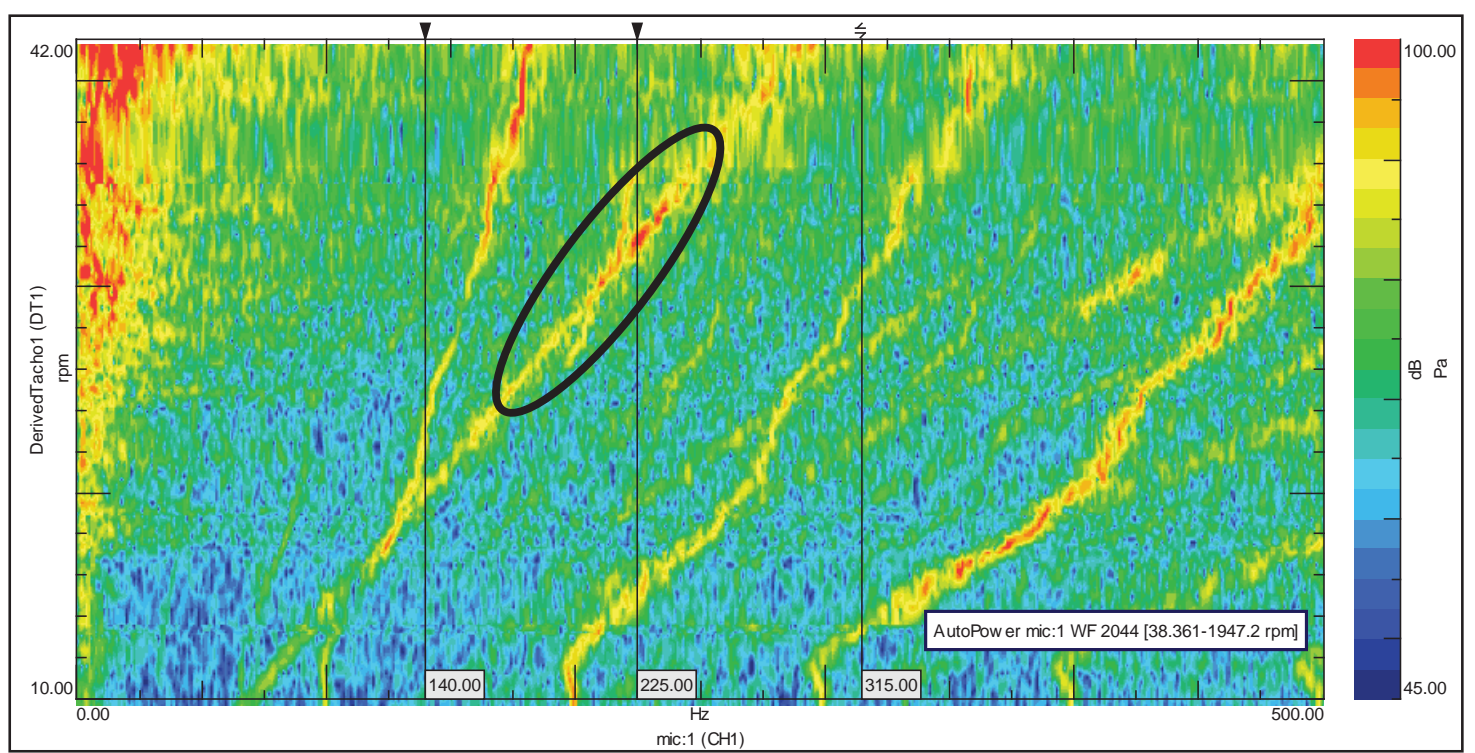

Figure 32: Microphone response of run one with suspension A and the baseline driver and track. 


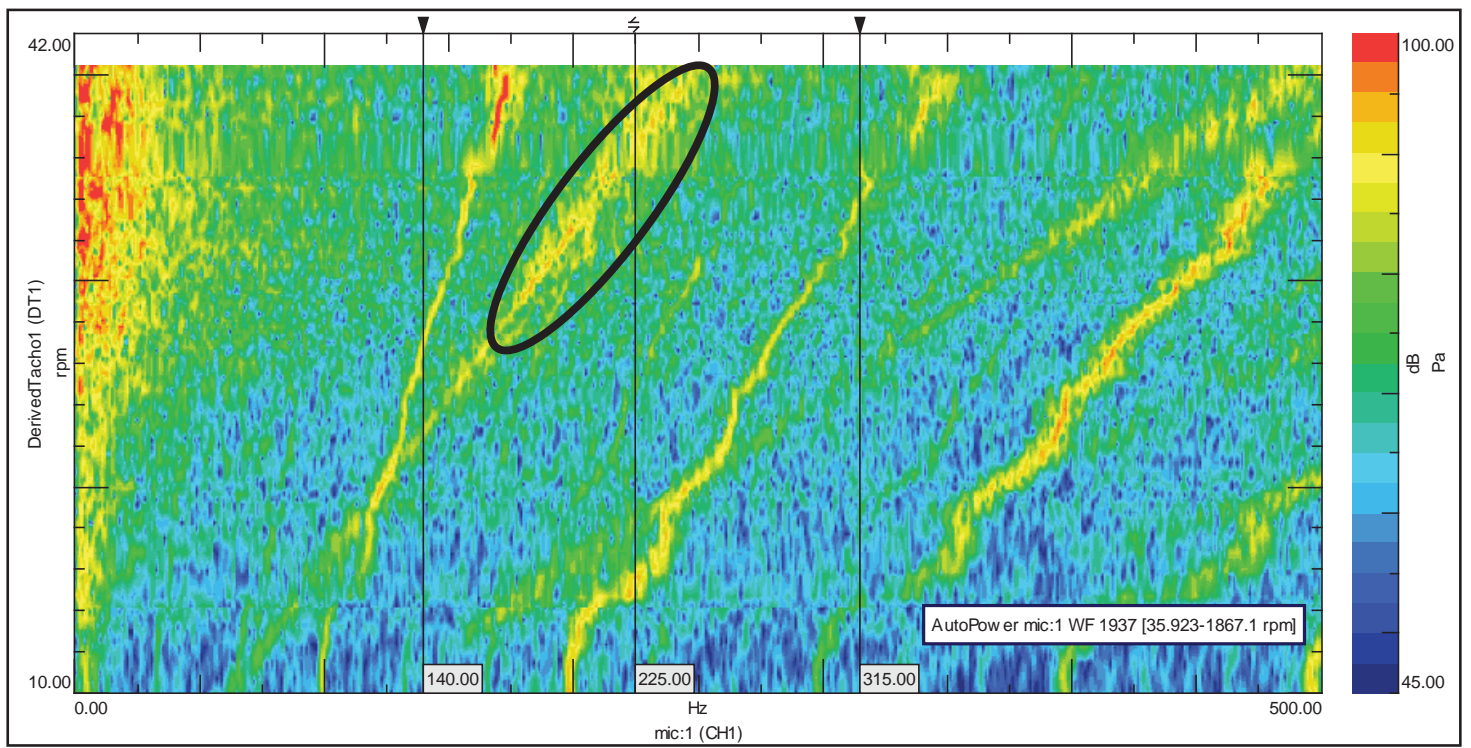

Figure 33: Microphone response for run four with suspension B, prototype driver and the new track.

The comparison between the two circled regions of Figure 32 and 33 shows a significant reduction in the response heard at the frequency of interest of $225 \mathrm{~Hz}$. The new driver and track shifted the noise out of the speeds range of 30 to 35 $\mathrm{MPH}$.

Even though suspension $\mathrm{C}$ didn't eliminate the noise it shifted it within the spectrum to occur at lower operating speeds. Figure 34 shows the microphone response for run five. 


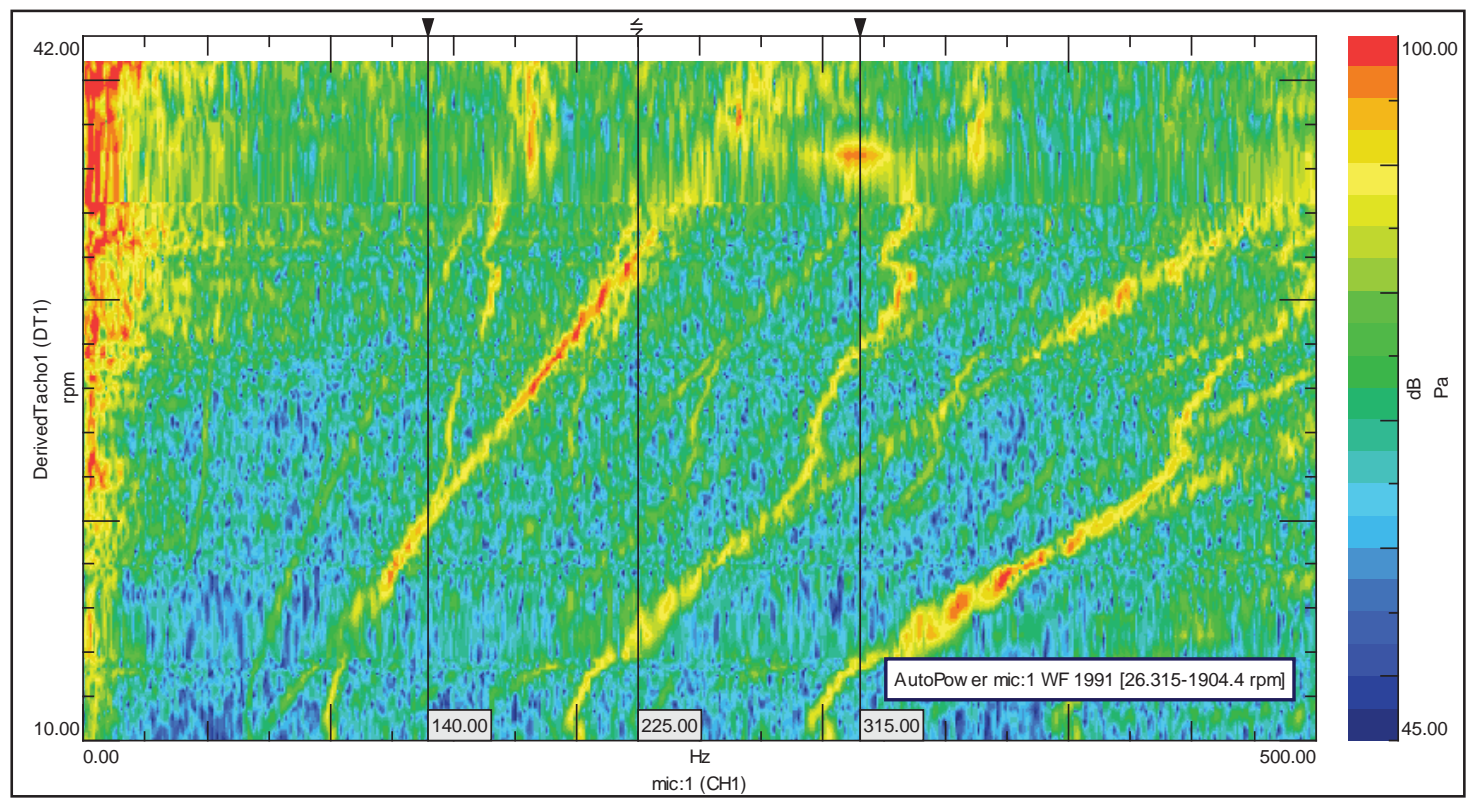

Figure 34: Microphone auto power of run five with suspension $\mathrm{C}$ and baseline driver and track.

One of the key differences found in suspension $\mathrm{C}$ is within the surface contact with the ground. The front and rear rails are designed to lift slowly off of the ground causing less track surface area in contact with the ground at any given time. This reduction in possible input locations could be causing the noticeable difference in the microphone response from the baseline.

\subsubsection{Modal Analysis on the Snowmobile Track}

The third round of operational data gave insight into what rear suspension components contributed to the problem frequency of $225 \mathrm{~Hz}$ but did not yield much insight into the other two frequencies of concern of $140 \mathrm{~Hz}$ and $315 \mathrm{~Hz}$. A modal analysis was performed on the track to determine what effects the dynamic properties of a tight track stretched over the rear suspension could be having on these frequencies. 
In order to duplicate boundary conditions of the rear suspension in the chassis and preloaded with an operator, the test stand seen in Figure 35 was designed.

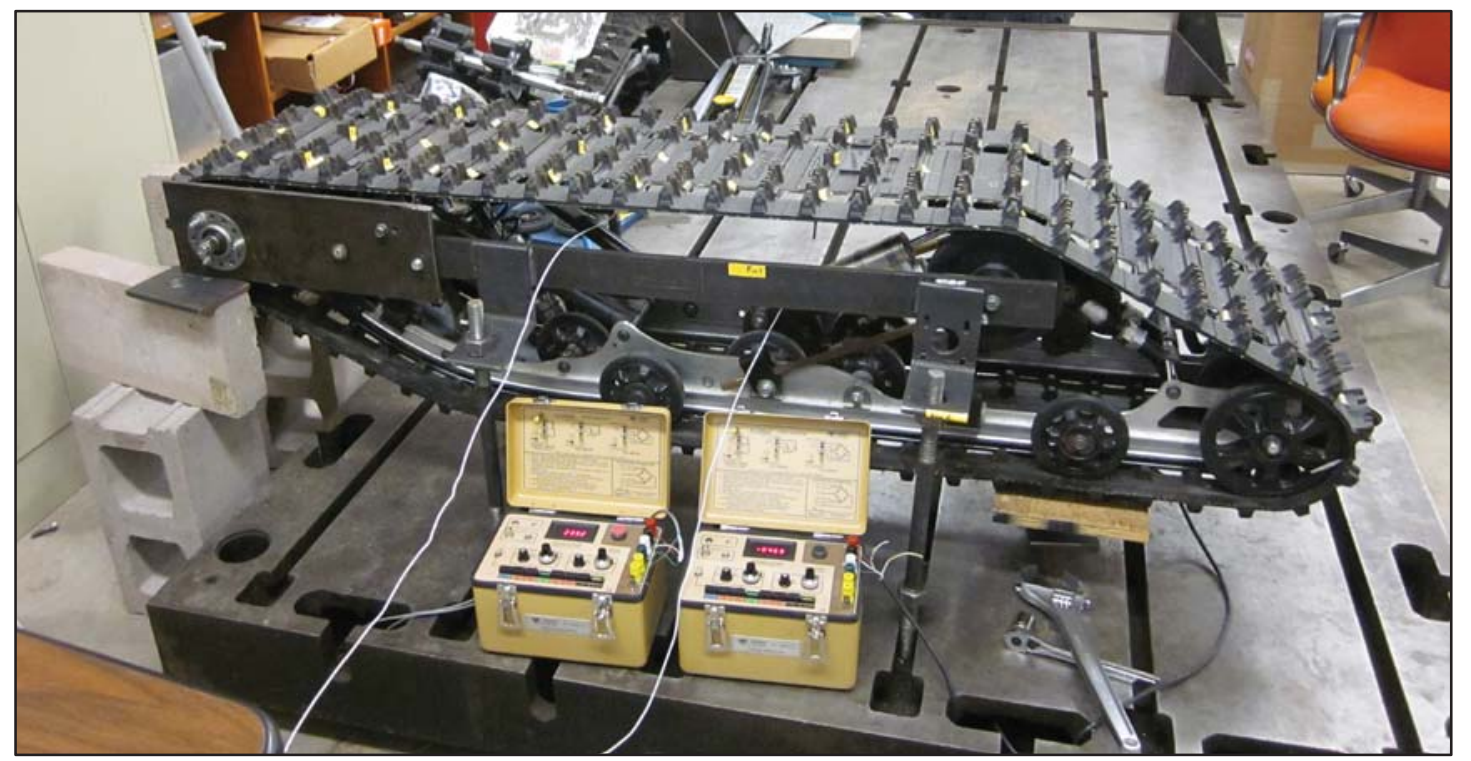

Figure 35: Rear suspension test set up for track modal analysis

The two steel fixtures were attached at location BLB, FLB, SL, BRB, FRB and SR to mimic the position and exact location the chassis is fastened the suspension. Cinder blocks were used to support the form of the shaft structure to mimic the skis and front of the chassis. Two load cells were placed under the front and the rear of the suspension to allow for a specific pre-load to be applied during testing. To determine the preload, the snowmobile was placed on three scales and preloaded with an operator weighing $200 \mathrm{lbs}$, a full gas tank and a specific track tension. The scale locations and readings can be seen in Figure 36. 


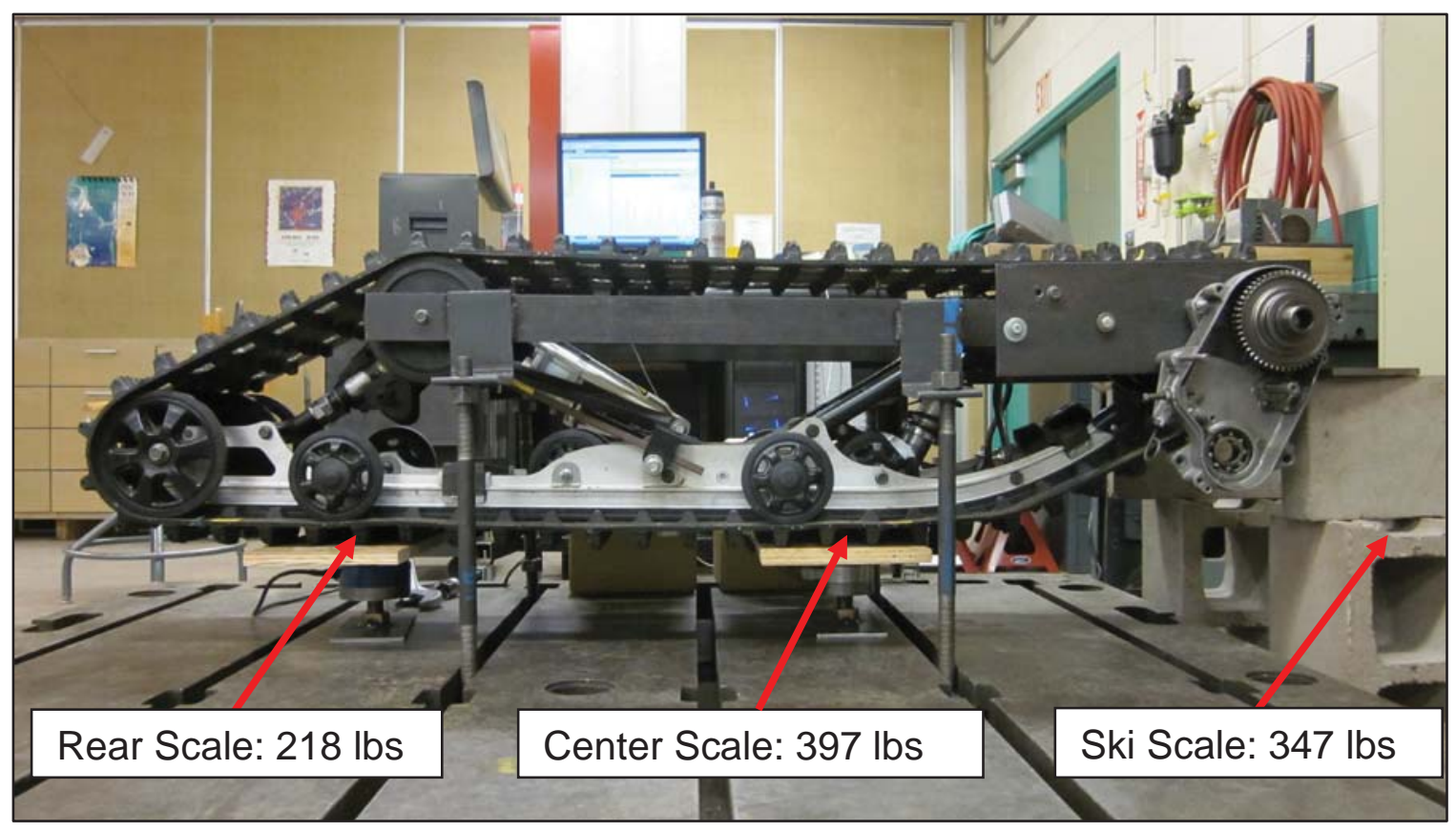

Figure 36: Locations of the scales used to determine preload

To set the preload bolts were tightened at points BLB, FLB, FRB and FLB. Once proper loading was achieved the track was instrumented with accelerometers.

One tri-axial accelerometer was placed on the fixture next to BLB. Three reference uni-axial accelerometers were placed on the track at various points for a roving hammer modal analysis. A hammer with a hard white plastic tip was used to rove to 39 track locations in the direction perpendicular to the track surface. Figure 37 represents the geometry of the hit locations in reference to the top faces of the exposed track in the test set up. 


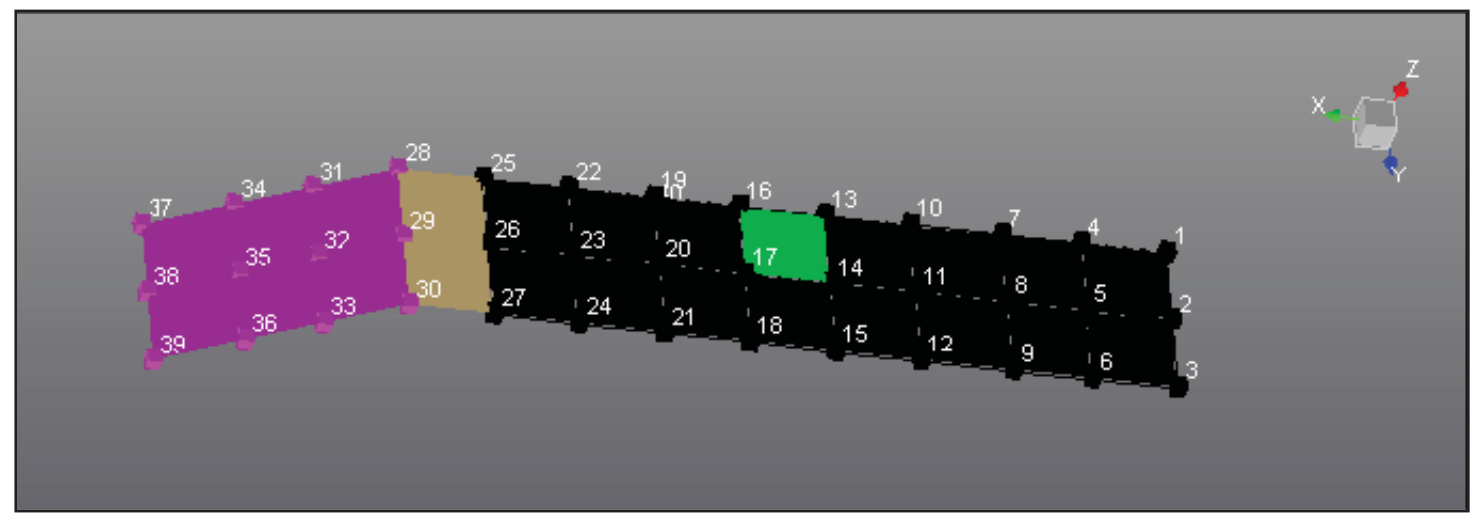

Figure 37: Track modal roving hammer impact locations on the top surface of the track

Spatial resolution was lost around $150 \mathrm{~Hz}$. The track modes were found to be below the frequencies of interest. The low frequencies of these shapes indicated that the track itself could be eliminated as a contributing factor during operation.

\subsection{Key Findings from Phase Two}

Of the frequencies of concern $225 \mathrm{~Hz}$ was shown to be the most sensitive to track engagement related noise. A modal analysis of the drive shaft further identified the shaft to have a mode shape at $228 \mathrm{~Hz}$ which was believed to be causing the plastic discs to flex leading to the design of a prototype which greatly reduced the response at $225 \mathrm{~Hz}$.

In addition to the rubber boot added after phase one, the upper guide wheel diameter was changed from the larger diameter of 8 inches to $67 / 8$ inches. The spectrum didn't reflect any changes in amplitude based upon wheel diameter so it was streamlined with other models within the sponsors' product line. 


\section{Chapter 4: Phase 3 Analytical Transfer Path Analyses}

A multi-body model consists of interconnected rigid or flexible pieces used to analyze the motion of a system. A true multi-body model of a snowmobile would consist of very elaborate components and their measured properties. Variables would span from types of bushings to the stiffness of the rubber. Because of the complexity of building a multi-body model an abbreviated model was attempted. This model included some of the common components that are adjusted to improve path sensitivity with exception of the drive shaft as an input. The model was driven by a position driver instead of a rotating drive shaft. This eliminated the need for an elaborate rubber composite track to properly simulate the motion. Factors such as guide wheel placement, track pitch and shock damping and stiffness could be changed with ease to analyze the effects on the receiver. An abbreviated model could be created more quickly and with testing costs and data acquisition equipment.

Even though the drive shaft would not be represented in the abbreviated model it was still believed it would be useful for testing other variables. This chapter outlines the building of this model while attempting to run an analytical TPA.

\subsection{Advantages of Analytical Methods}

For this project LMS Virtual.Lab software was utilized to simulate the rear suspension of a snowmobile. This is one of many software packages available today capable of modeling interconnected bodies and simulating dynamic behaviors.

A better understanding of the path sensitivities of the operational input forces into the rear suspension of the test snowmobile was desired. The prototype driveshaft had a large impact on the frequency of concern of $225 \mathrm{~Hz}$ during the 
experimental portion of the project. This discovery demonstrated how crucial a working prototype can be to the design of a machine.

Though this model won't be capable of modeling the drive shaft, it can still allow the manufacturer to test other important variables. Having a model of the system that could accurately test high level variables before a prototype is built could save time and money. This type of model would allow the manufacturers to test multiple configurations before making changes or purchases saving them time and money ${ }^{6}$. The time and financial obligation of prototype testing makes models like these effective methods to help ensure the viability of prototypes ordered for experimental testing.

The rear suspension is comprised of various complex subsystems making an abbreviated multi-body model a desirable approach for testing the effects of changing a component in the system. Operating data was acquired using the same test set-up discussed in section 3.1 to help build the model. The solutions at the receiver points could be used to test the effects of changing guide wheel locations, guide wheel material properties, spring rates, and damping. This would allow for faster diagnosis of sound and vibration concerns and faster implementation of solutions ${ }^{6}$.

\subsection{Key Features in the Software}

The basic motion of bodies can be described through kinematics ${ }^{9}$. In most mechanical systems, components can be modeled as either flexible or rigid. The bodies are linked together with connections that limit or allow relative motion known as joints. Each body starts with an initial six degrees of freedom meaning there are six possible directions it can move including translating in the $\mathrm{X}, \mathrm{Y}$ or $\mathrm{Z}$ direction or rotating about the $\mathrm{X}, \mathrm{Y}$ or $\mathrm{Z}$ axes. By defining the joints between bodies within the model the location in space at a given time can be defined mathematically ${ }^{7}$. Each joint restricts various combinations of these six relative 
possibilities. Table 5 describes each of the joints used in the model and the corresponding degree of freedom it allows ${ }^{5}$.

Table 5: Common joints used to define relative motion between two bodies

\begin{tabular}{|c|c|c|c|c|}
\hline Type of Joint & $\begin{array}{l}\text { Rotations } \\
\text { Allowed }\end{array}$ & $\begin{array}{l}\text { Translations } \\
\text { Allowed }\end{array}$ & $\begin{array}{l}\text { Degrees } \\
\text { of } \\
\text { Freedom }\end{array}$ & $\begin{array}{c}\text { Feature Used to Define the } \\
\text { Joint }\end{array}$ \\
\hline Bracket & $0-6$ & $0-6$ & $0-6$ & $\begin{array}{l}\text { Selecting an axis system } \\
\text { associated with each body }\end{array}$ \\
\hline Planar & 1 & 2 & 3 & $\begin{array}{l}\text { Selecting a plane associated } \\
\text { with each body }\end{array}$ \\
\hline $\begin{array}{l}\text { Spherical } \\
\text { (Ball \& } \\
\text { Socket) } \\
\end{array}$ & 3 & 0 & 3 & $\begin{array}{l}\text { Selecting a point associated } \\
\text { with each body }\end{array}$ \\
\hline Cylindrical & 1 & 1 & 2 & $\begin{array}{l}\text { Selecting an axis system } \\
\text { associated with each body }\end{array}$ \\
\hline $\begin{array}{l}\text { Revolute } \\
\text { (Hinge) }\end{array}$ & 1 & 0 & 1 & $\begin{array}{c}\text { Selecting an axis and plane } \\
\text { perpendicular to the axis of } \\
\text { each body }\end{array}$ \\
\hline Translational & 0 & 1 & 1 & $\begin{array}{l}\text { Selecting a line and plane } \\
\text { associated with each body }\end{array}$ \\
\hline Universal & 2 & 0 & 2 & $\begin{array}{l}\text { Selecting a line and point } \\
\text { associated with each body }\end{array}$ \\
\hline
\end{tabular}

\subsection{Approach}

Transfer path analysis was used to find the resulting forced based response at the driver's ear for each operational speed. Recalling Equation 1 from Section 1.1 the model yields a solution for a forced response of $X(\omega)$. For this application the transfer path analysis equation takes the form of Equation 3.0. 


$$
\{X(\omega)\}=[H(\omega)]\{F(\omega)\}
$$

Equation 3.0

Where:

$X(\omega)$ is the response heard at the receiver's right ear

$H(\omega)$ is the path represented by experiemtally aquired impedances

$F(\omega)$ is the virtually aquired source of the rear suspension

To use the software to solve for the solution of $X(\omega)$ a collaborative approach of virtually simulated forces and experimentally derived impedances was employed. The model was used to solve for the FRFs of the rear suspension and impedance measurements taken in the lab were used for the path. An example of the forced response found using the DSP case in the simulated model can be seen in Figure 38.

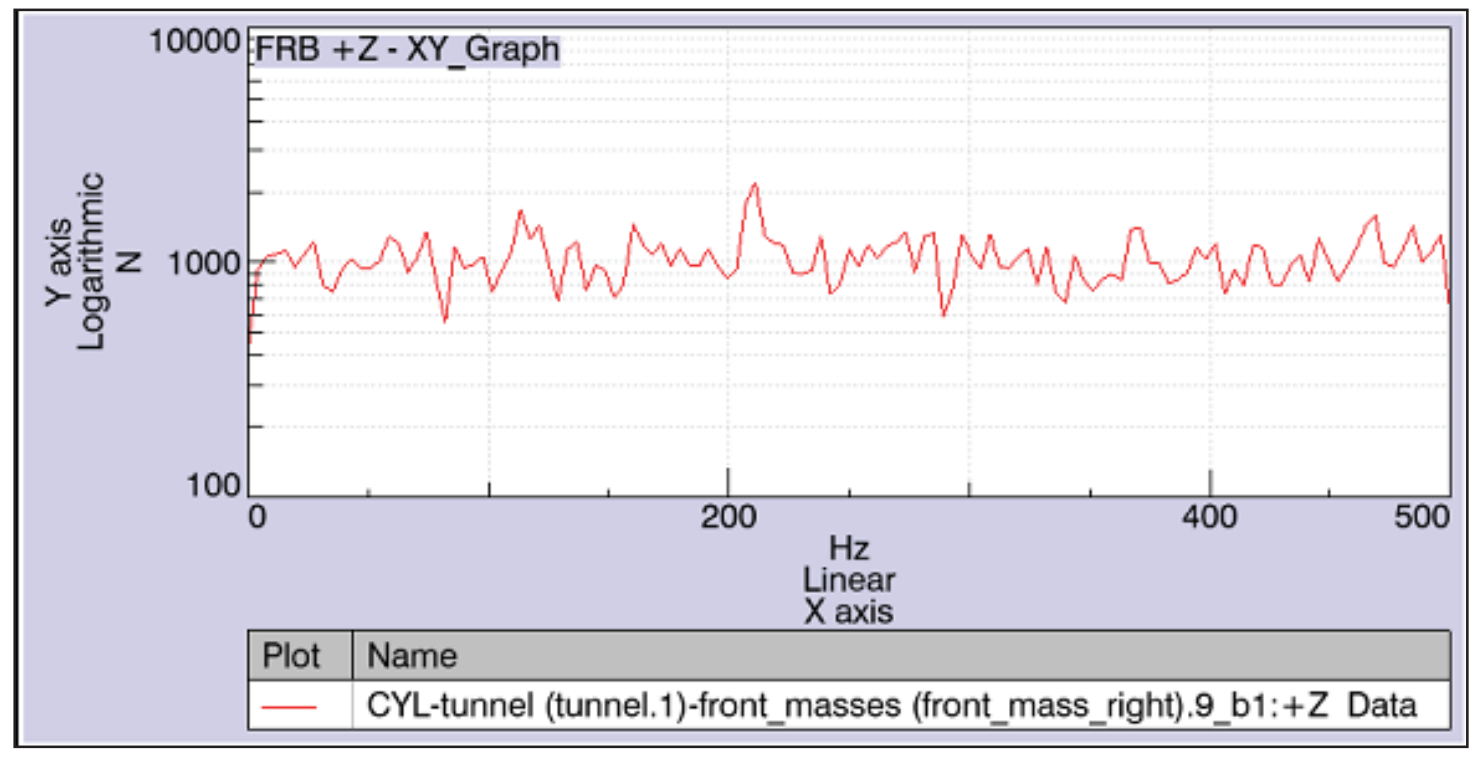

Figure 38: LMS Virtual.Lab solution from the DSP Case for FRB 


\subsubsection{Impedance Measurements}

Impedances were acquired experimentally using the chassis with the rear suspension removed. To acquire $H(\omega)$, an impact hammer was used to excite the six locations.

To accurately measure the sound pressure at the driver's right ear an Aachen head was fitted with a $1 / 4$ inch microphone placed in the helmet harness as seen in Figure 39. A snowmobile helmet was then fit over the head to better represent the riding conditions during operation.

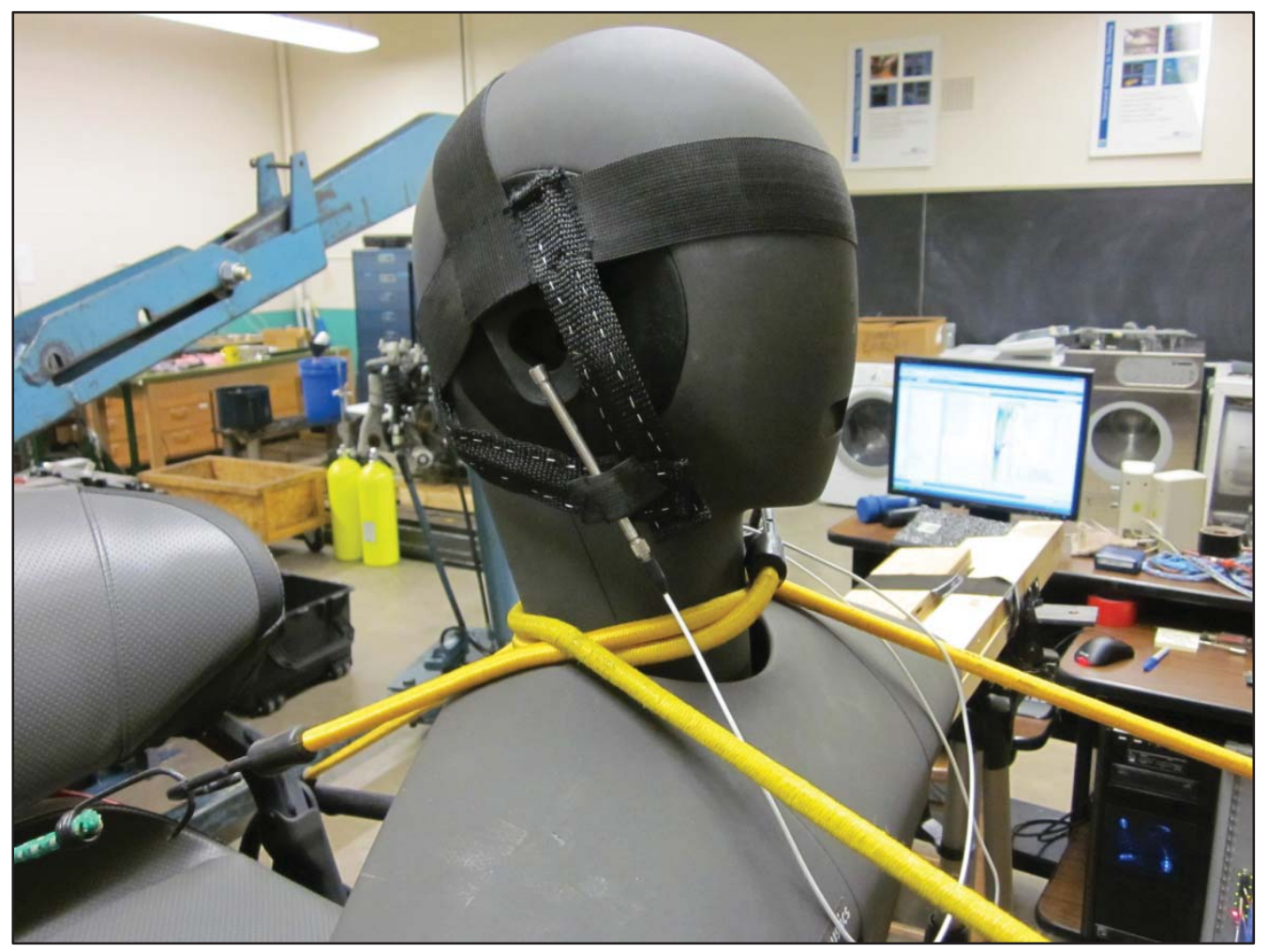

Figure 39: The Aachen head fitted with a custom microphone harness for the impedance measurements

In order to limit impedance measurements to the structure of the snowmobile, excluding the rear suspension, the red snowmobile was disassembled. The rear 
suspension was removed and the bumper was placed on two air bladders. The front of the skis were left on the steel ground surface and left in place.

The chassis was instrumented with six tri-axial accelerometers as shown in Figure 40. Unlike the test set-up for operating data the chassis was instrumented on both sides to include both the left and right points SL, SR, FLB, FRB, BLB and BRB.

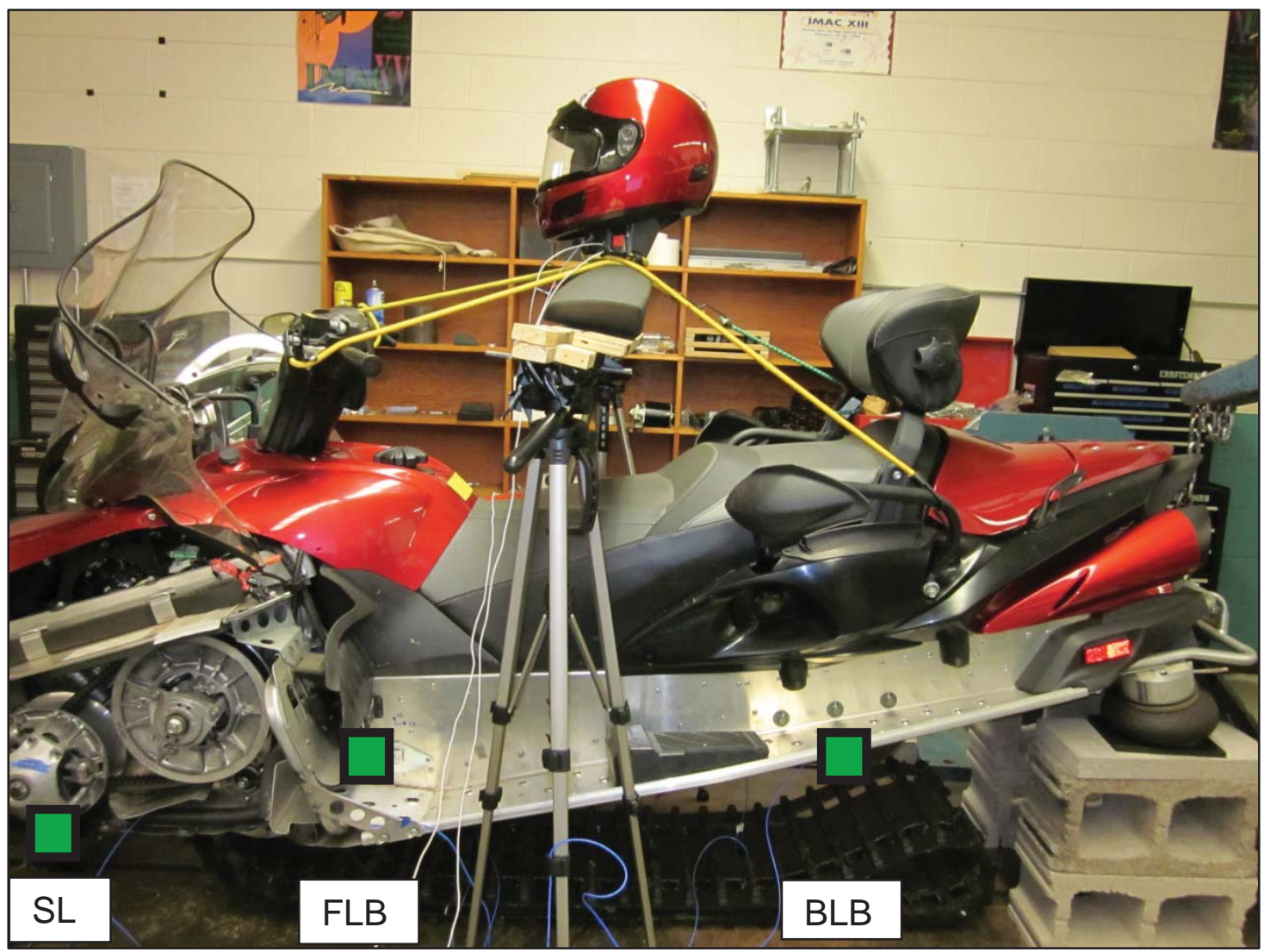

Figure 40: Test set up of the left side of the snowmobile for measuring the chassis impedances

All six locations were measured and impacted in the $X, Y$ and $Z$ directions yielding a complete impedance matrix for use in the forced based solution in the model. As an example the measured sound pressure at the driver's ear when impacting the FLB is found in Figure 41. 


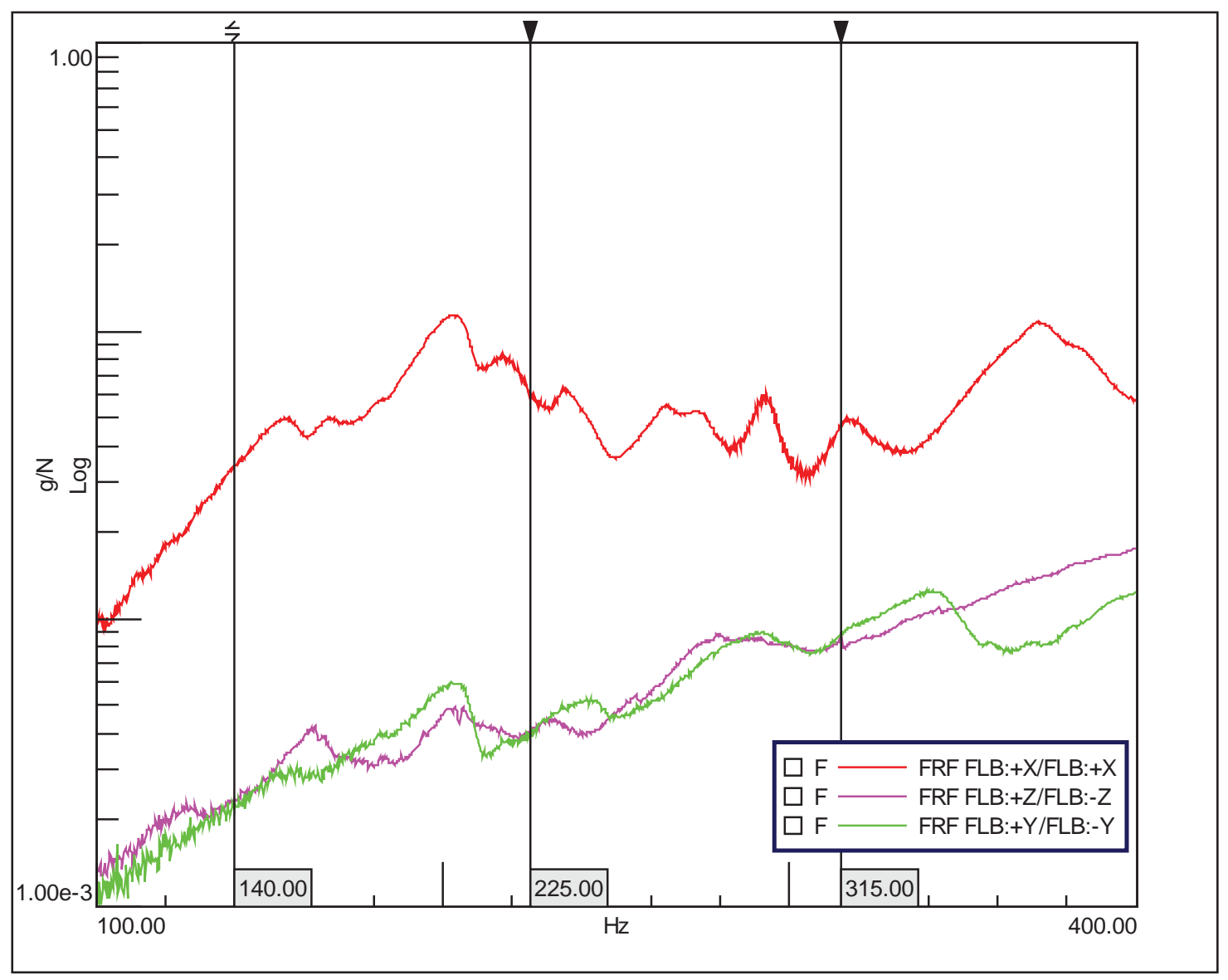

Figure 41: Driving point impedance measurements in the $X, Y$ and $Z$ directions

\subsection{Building the Model}

The snowmobile was disassembled in the lab and each component was weighed and measured. Instead of creating a flexible complex track model the snowmobile track was simulated as the road surface. The road profile replicated the inner surface of the rubber track by modeling bumps that represented the fiberglass stiffener rods seen by the guide wheels as seen in Figure 42. 


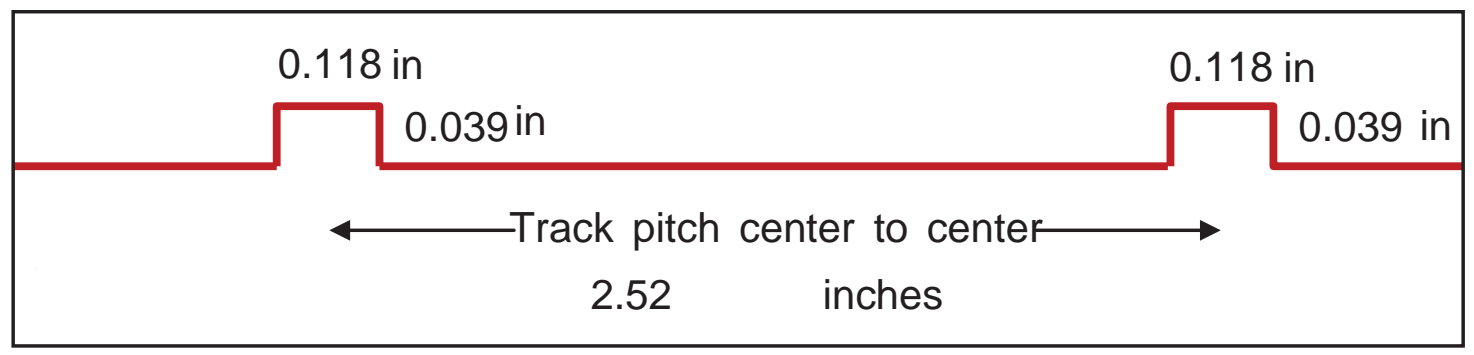

Figure 42: Schematic of the road profile modeled in LMS Virtual.Lab to simulate the geometry of the fiberglass stiffener rods as sources of impact into the guide wheels

This approach to modeling the track was chosen to allow factors such as track pitch to be easily changed without changing variables within a complex flexible track model.

The motion workbench of LMS Virtual.Lab was used to create the model of the rear suspension. Figure 43 shows the completed model.

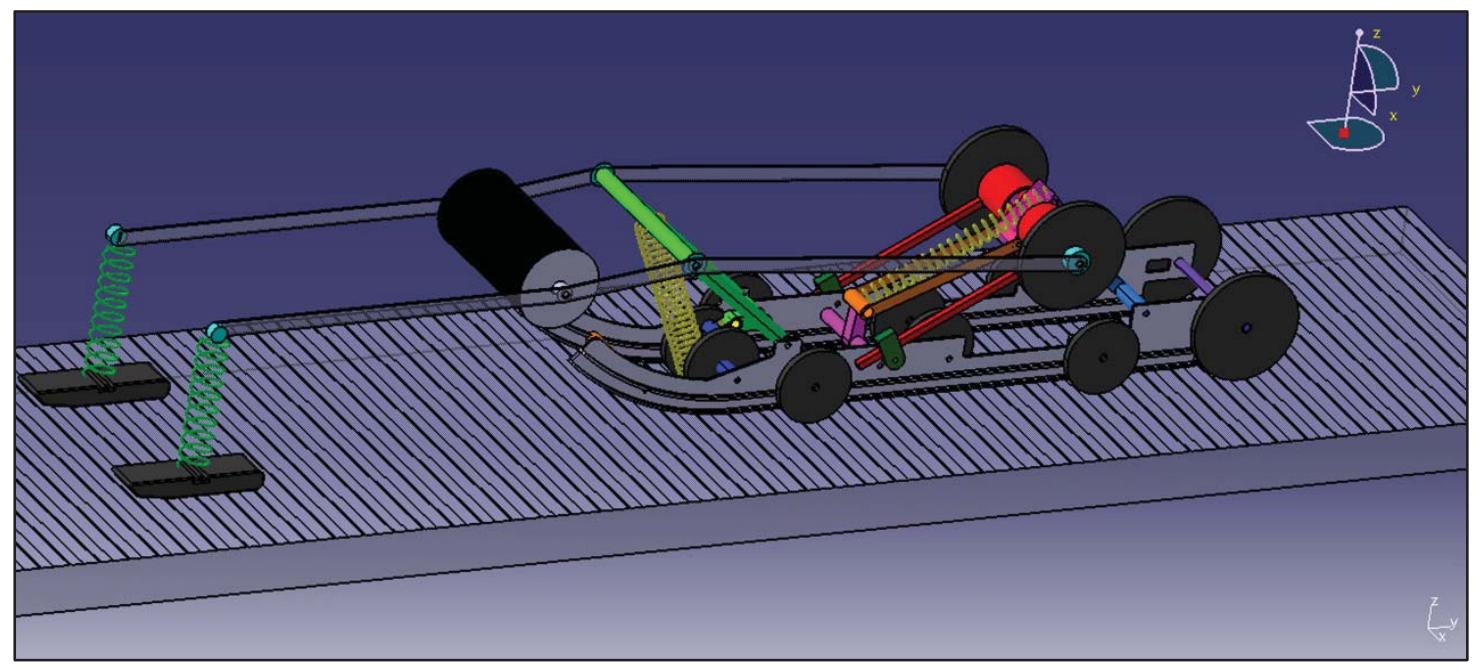

Figure 43: Completed model of the rear suspension with simulated track ground

Each component modeled was named and drawn using the parts from the rear suspension. The names of the drawn components can be seen in Figures 44, 45 and 46. 


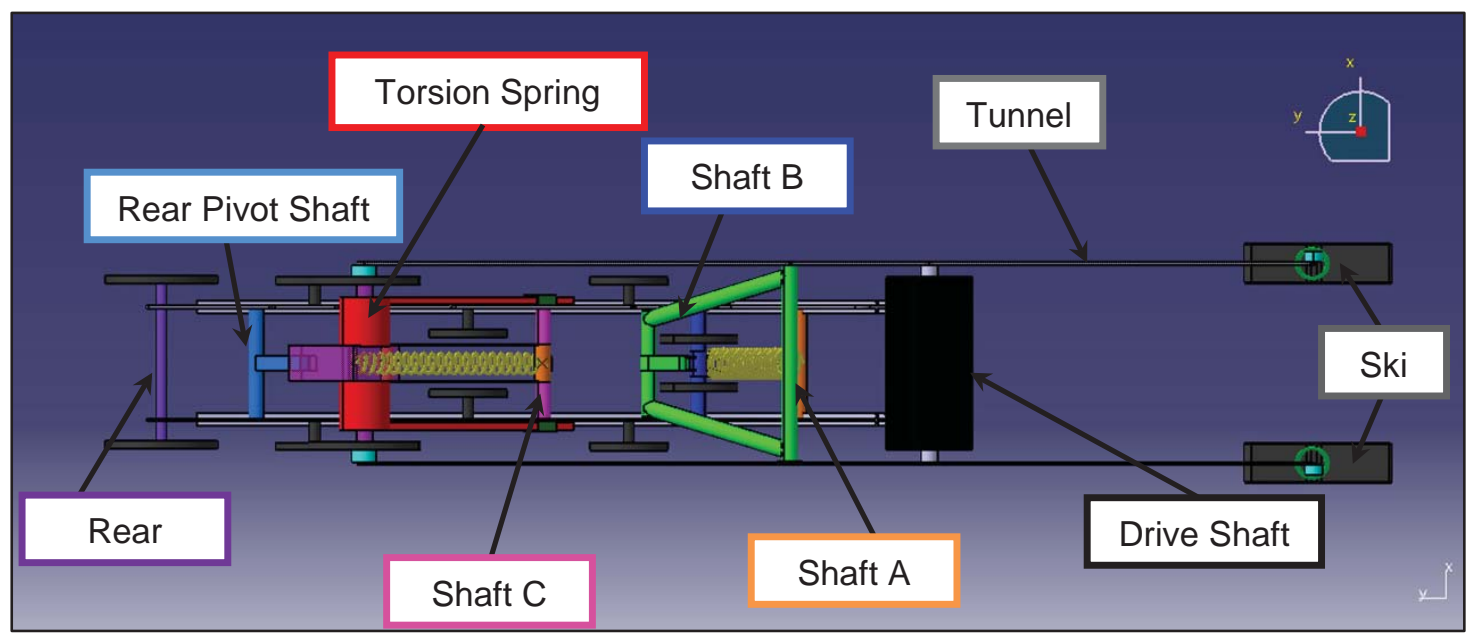

Figure 44: Aerial view of the modeled suspension with component names

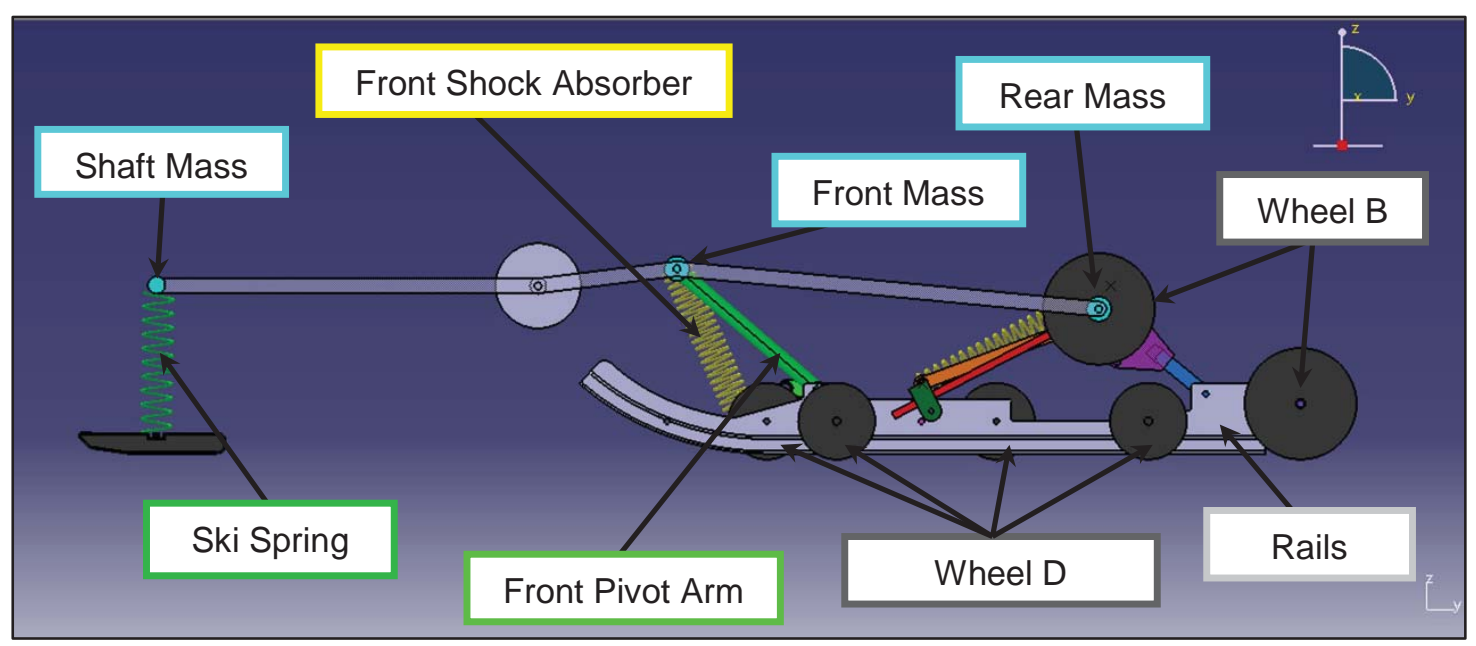

Figure 45: Side view of modeled suspension with component names 


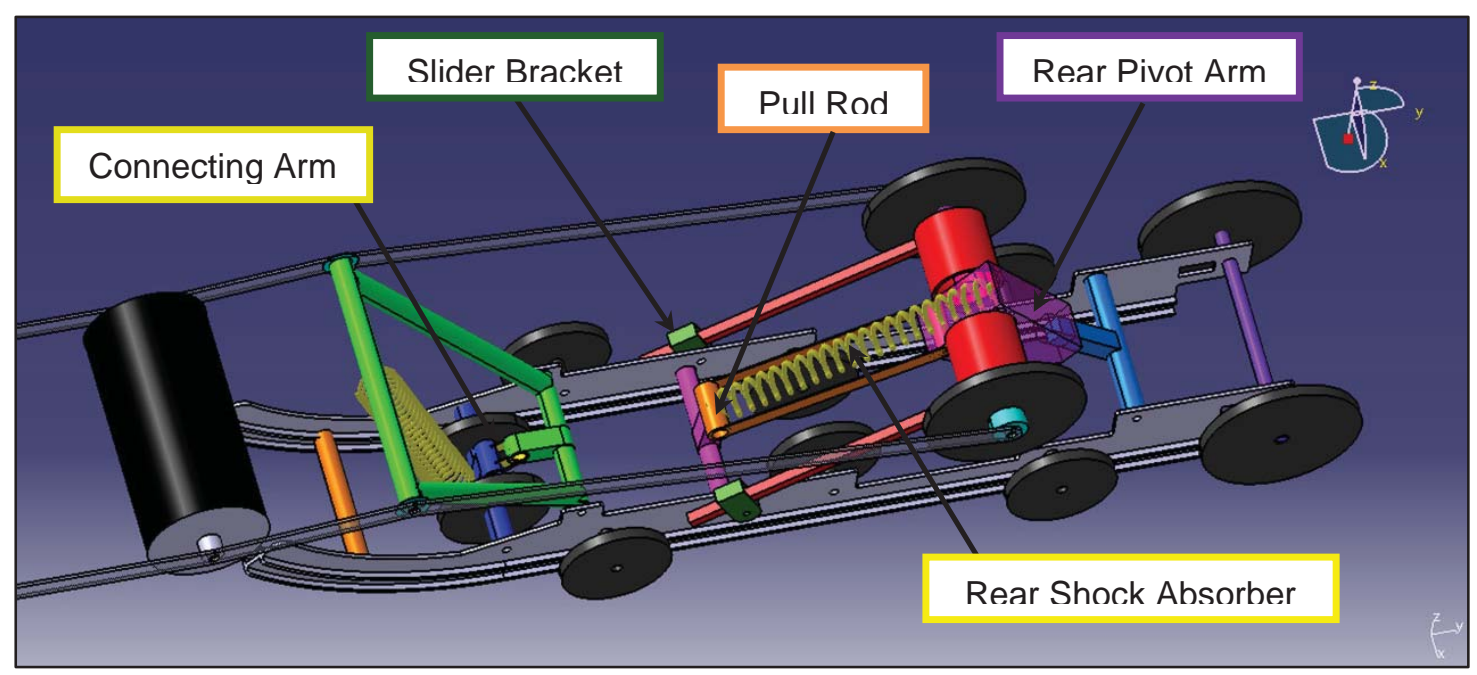

Figure 46: Isometric view of modeled suspension with component names

\subsubsection{Limiting the Degrees of Freedom using Joints}

The components were assembled relative to one another using 43 different assembly joints to restrict various degrees of freedom. The joints were assigned one connection at a time. After each component was added to the model, a solution was computed and animated to ensure the joint behaved as expected. A redundant constraint check was then performed using the automatically generated information file after each solution. Table 6 shows the measured masses of each component and the initial joint used to constrain it. Each joint restricts different degrees of freedom. The final model has 40 bodies with a total of twelve degrees of freedom. 
Table 6: Model components and their measured masses

\begin{tabular}{|l|l|l|}
\hline \multicolumn{1}{|c|}{ Component Name } & \multicolumn{1}{|c|}{$\begin{array}{c}\text { Mass } \\
(\mathrm{kg})\end{array}$} & \multicolumn{1}{|c|}{ Primary Joint } \\
\hline Rear Axle & 0.0572 & Bracket \\
\hline Rear Pivot Arm & 4.028 & Translation/Spherical \\
\hline Torsion Bar (Spring) & 2.034 & Cylindrical \\
\hline Slider Bracket & 0.312 & Translation/Spherical \\
\hline Rear Shock Absorber & 1.545 & N/A \\
\hline Pull Rod & 0.424 & Cylindrical/Spherical \\
\hline Connecting Arm & 0.270 & Spherical \\
\hline Front Pivot Arm & 3.697 & Revolute \\
\hline Front Shock Absorber & 1.624 & N/A \\
\hline Guide Wheel B & 0.358 & Bracket \\
\hline Guide Wheel A & 0.526 & Bracket \\
\hline Guide Wheel D & 0.321 & Bracket \\
\hline Rails & 3.398 & Revolute \\
\hline Shaft A & 0.468 & Bracket \\
\hline Shaft B & 0.554 & Revolute \\
\hline Shaft C & 0.423 & Revolute \\
\hline Rear Pivot Shaft & 1.931 & Revolute \\
\hline Rear Axle & 0.572 & Bracket \\
\hline Ski & 0.871 & Planar \\
\hline Tunnel & 0.00001 & Cylindrical \\
\hline Front Mass & 90.151 & Bracket \\
\hline Rear Mass & 49.600 & Bracket \\
\hline Shaft Mass & 78.698 & Bracket \\
\hline Drive Shaft & 4.716 & Bracket \\
\hline & & \\
\hline
\end{tabular}




\subsubsection{Modeling Forces within the Rear Suspension}

The rear suspension of the provided snowmobile contains one spring and damper combination (named the rear shock absorber), four springs (named the left ski, right ski, left torsion spring and right torsion spring) and one damper. The dynamic properties used in the model are contained in Table 7.

Table 7: Elements modeled as forces in the model and their respective dynamic properties

\begin{tabular}{|c|c|c|c|c|}
\hline Component Name & $\begin{array}{c}\text { Force } \\
\text { Type }\end{array}$ & $\begin{array}{c}\text { Spring } \\
\text { Constant } \\
(\mathrm{N} / \mathrm{m})\end{array}$ & $\begin{array}{c}\text { Damping } \\
\text { Coefficient } \\
(\mathrm{Kg} \mathrm{s})\end{array}$ & $\begin{array}{c}\text { Free } \\
\text { Length } \\
(\mathrm{mm})\end{array}$ \\
\hline Torsion Spring & RSDA & 126.05 & 0.00000001 & $\mathrm{~N} / \mathrm{A}$ \\
\hline $\begin{array}{c}\text { Rear Shock } \\
\text { Absorber }\end{array}$ & TSDA & 0.00000001 & 2,639 & 424 \\
\hline $\begin{array}{c}\text { Front Shock } \\
\text { Absorber }\end{array}$ & TSDA & 27047 & $3,246.50$ & 372.5 \\
\hline Ski Spring & TSDA & $100,159.80$ & 0.00000001 & 281.7 \\
\hline
\end{tabular}

There are three settings on the rear shock absorber that allow the user to adjust the ride quality of the suspension. The middle setting was used for this model to match the setting used during all operational testing. Values were provided by the manufacturer for all constants and coefficients accept the spring constant for the spring contained in the front shock absorber. The stiffness was found experimentally using a strain indicator, a dial indicator and a fixture to compress the spring. The initial height of the spring was set to $77 / 8$ " which matched the initial length of the spring in the rear suspension during operation. To compress the spring, two nuts were tightened at the top of the test fixture. The test set up can be seen in Figure 47. 


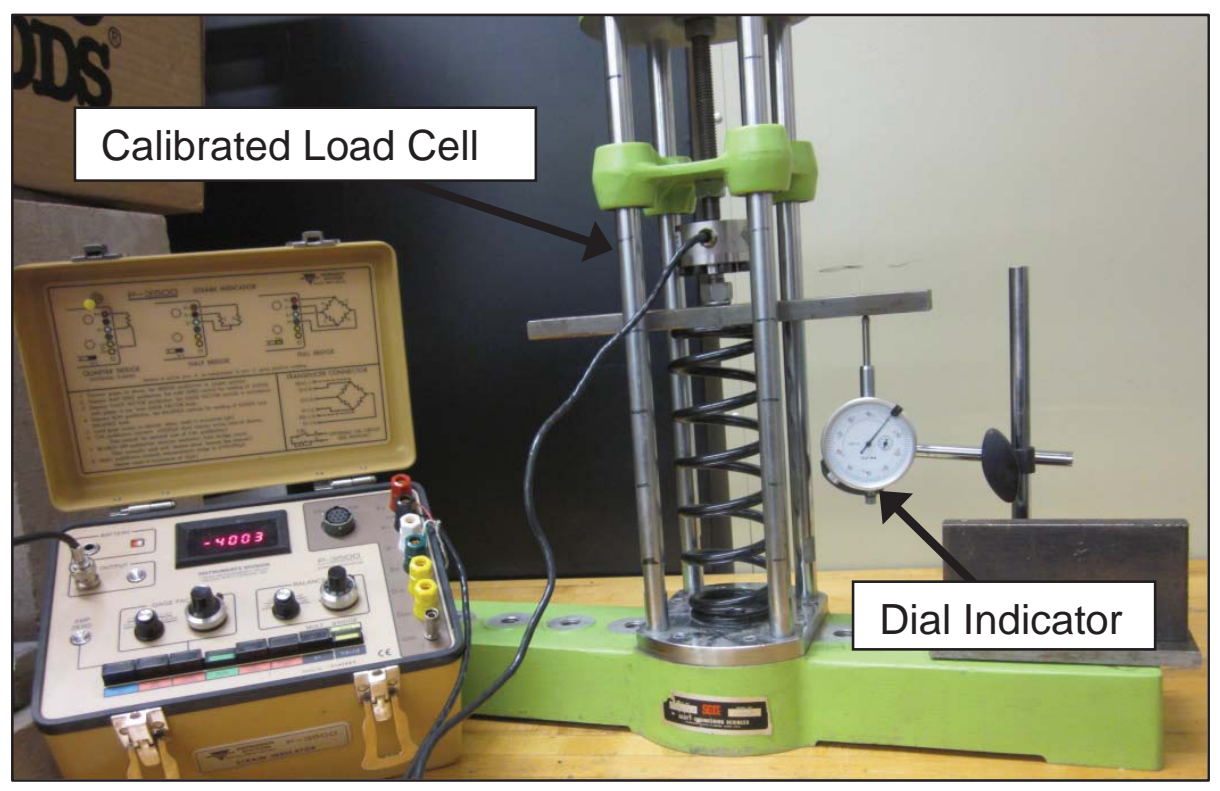

Figure 47: Test setup used to find the spring constant of the front shock absorber

A plot of the fourteen data points used to find the spring stiffness of $27047 \mathrm{Nm}$ can be seen in Figure 48.

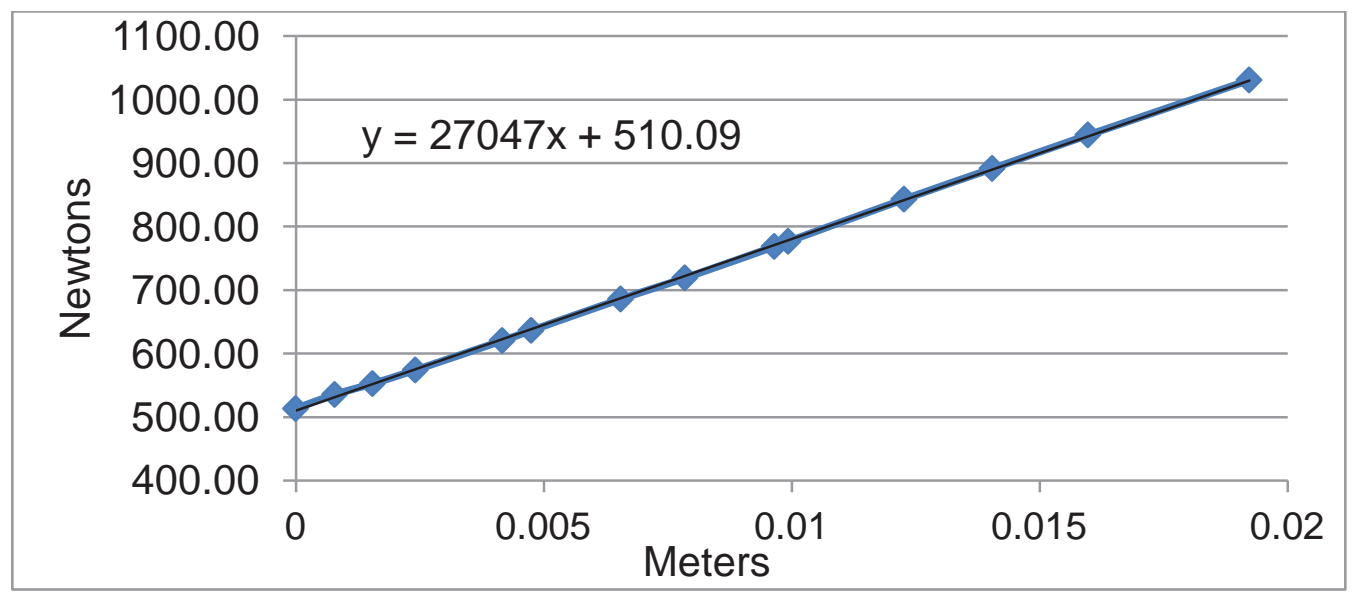

Figure 48: Stiffness measurement for spring in front shock absorber

\subsubsection{Contact Constraints}

To simulate the ground in the model a body was created named ground. This was fixed to the universal ground within the model to show the direction gravity 
should act upon the final suspension during the animation of a solution. A secondary ground was created called track ground that contained the fiberglass stiffener rod profile seen in earlier in Figure 42. By overlaying these two extruded bodies the abbreviated model becomes a possibility by allowing the skis to see one surface and the guide wheels to see another.

The method chosen to create a contact constraint between the ski, ground and the guide wheels was to model the point of contact as a sphere on the ski and a surface that sphere couldn't cross. This type of constraint is what tells the two bodies that they cannot intersect one another and how much force they will exhort against one another. The very large stiffness of 2 e+011 $\frac{\mathrm{N}}{\mathrm{m}^{2}}$ was applied normal to both the contact sphere and the extrusion to ensure the sphere would not cause a ski or guide wheel to dip below the ground.

Three spheres were placed under each ski and one sphere was placed on the lowest point on the bottom of each of the guide wheels as seen in Figure 49.

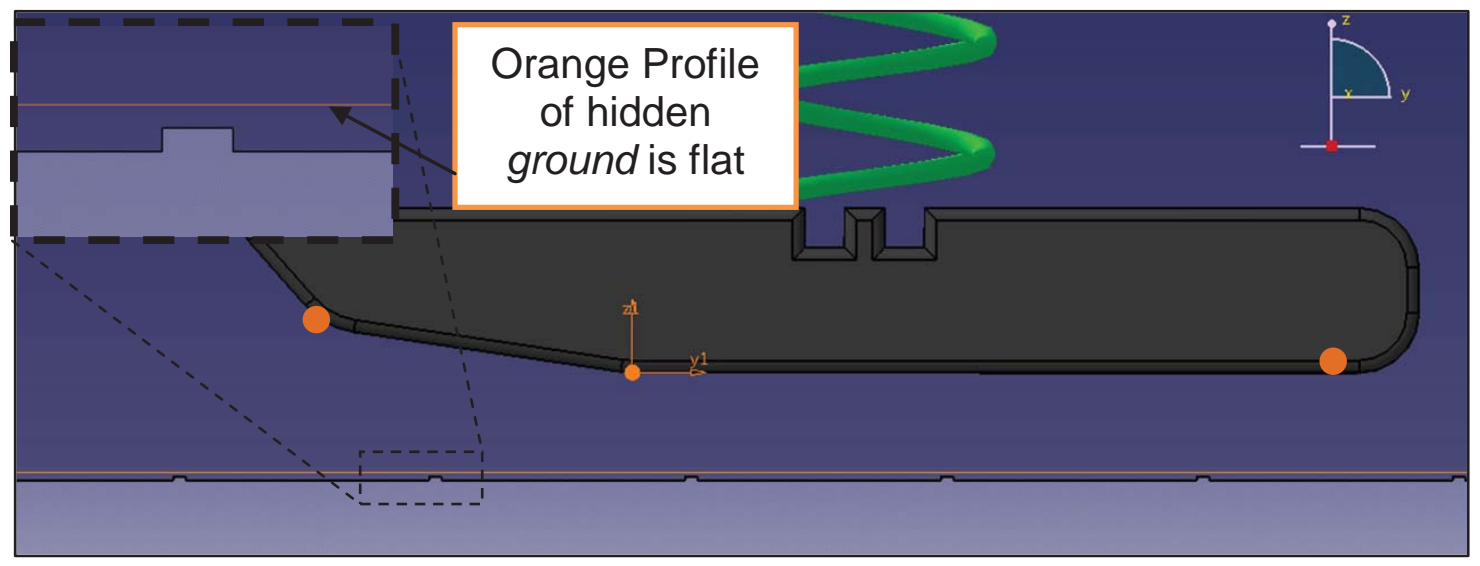

Figure 49: Sphere elements modeled between the ski and flat ground surface

The skis were modeled to contact the ground component to simulate a perfectly flat surface. In order to simulate the effects of the fiberglass stiffener rods passing each guide wheel the contact spheres of each guide wheel were set to contact the track ground profile as seen in Figure 50. The skis and guide wheels 
were modeled to contact different surfaces in order to better represent of operating conditions. The guide wheels see the inner surface of the track and the skis see the ground. For purposes of this project the ground was modeled as perfectly flat to allow dynamic properties to be more clearly identified without other sources such as ground imperfections impacting the data.

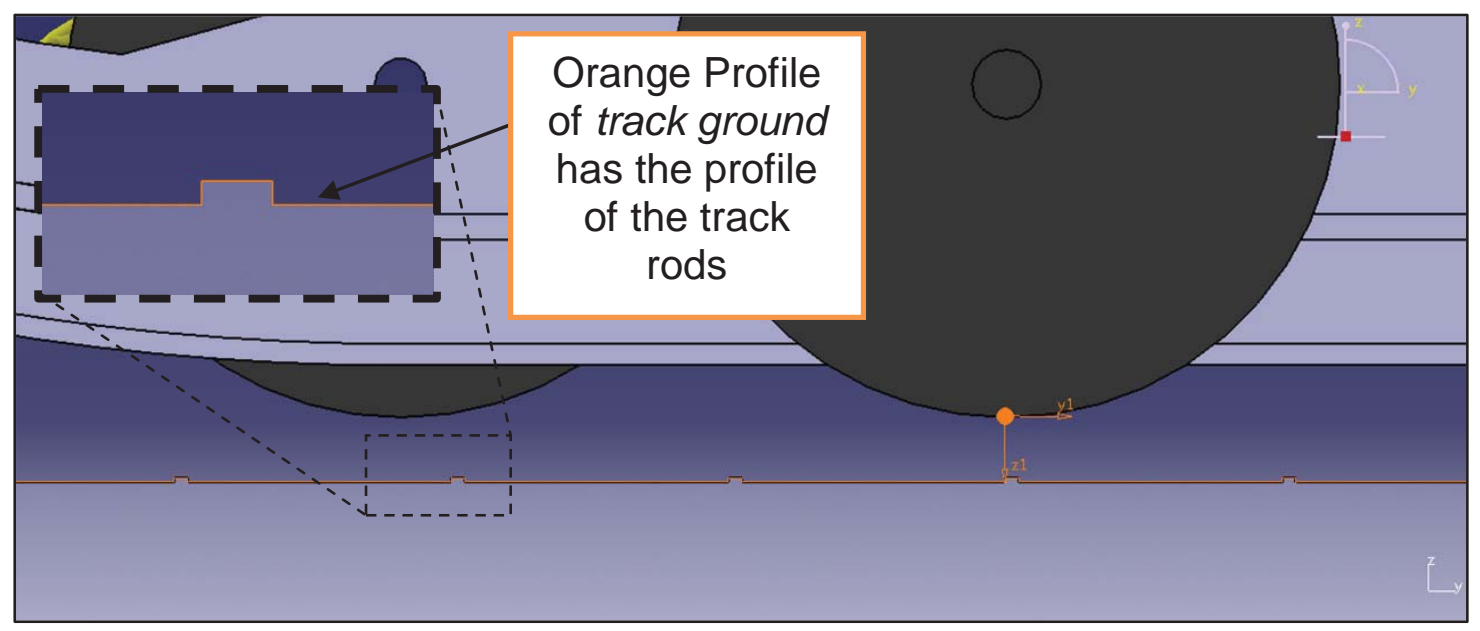

Figure 50: Spheres modeled between the guide wheels and the track ground surface

Each sphere was set up using a sphere radius and maximum penetration depth of two millimeters. In both cases the orange line demonstrates the visualization of the profile the sphere point will see during the solution. This ensures the skis follow a flat profile and the guide wheels follow the rod profile.

To simulate the weight of the chassis with a preload of a $150 \mathrm{lb}$ passenger three point masses were attached to the rear suspension. Six components named shaft mass left, shaft mass right, front mass left, front mass right, rear mess left and rear mass right were attached to simulate the weight of the chassis and driver. In a lab test, three scales were placed under the fully assembled snowmobile with a $150 \mathrm{lb}$ driver sitting on the seat. The front scale was placed under the center of the skis and read $347 \mathrm{lbs}$, the second scale was under the first front guide wheel and read $397.5 \mathrm{lbs}$ and the last scale was placed on the 
rear axle with a reading of 218.7 lbs. Each weight was equally distributed between each side and the six masses were applied as seen in Figure 51.

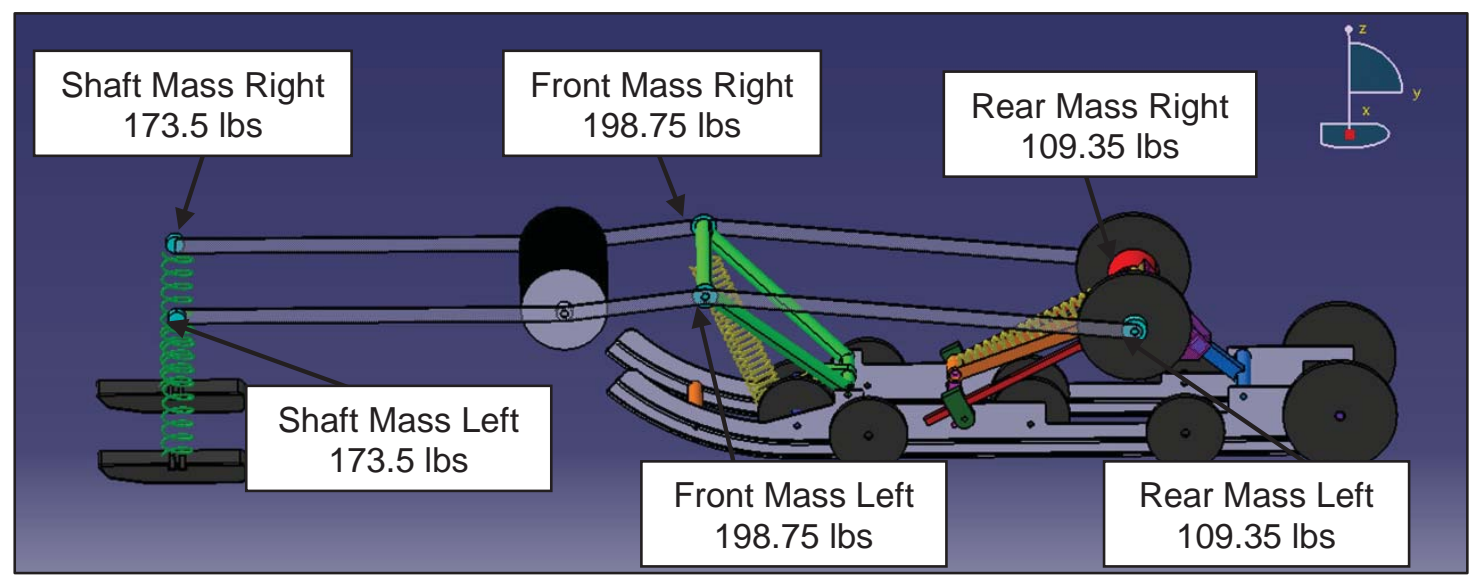

Figure 51: Locations of applied preloads to simulate chassis and driver

\subsection{Solving the Model}

To solve for the forced based response at the driver's ear, multiple preliminary solutions were found. Figure 52 shows the process to find the solutions in LMS Virtual Lab.

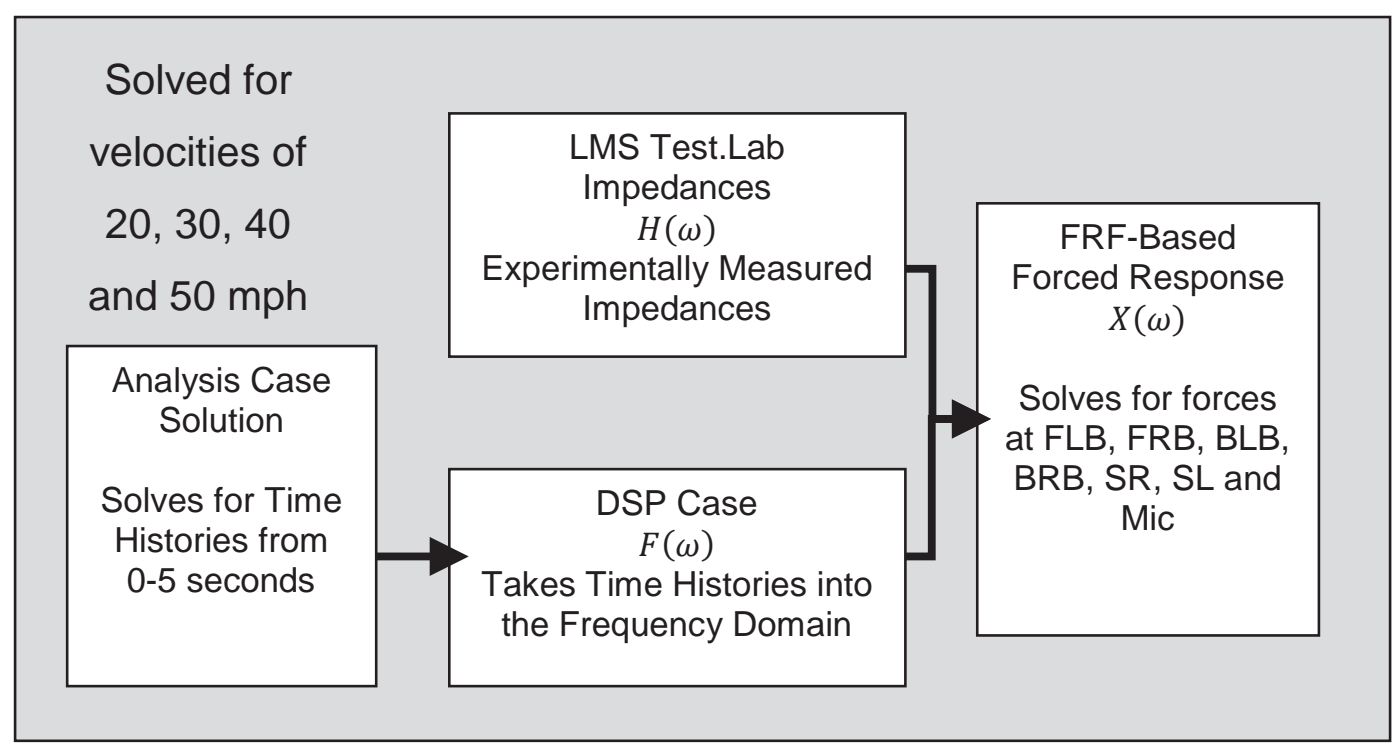

Figure 52: Flow chart of the process used to solve for the responses at the receiver locatiogns 
The first solution tool used was an Analysis Case Solution set which found the time histories of the rear suspension traveling forward at each given velocity. An example time history for SL from the Analysis Case Solution can be seen in Figure 54.

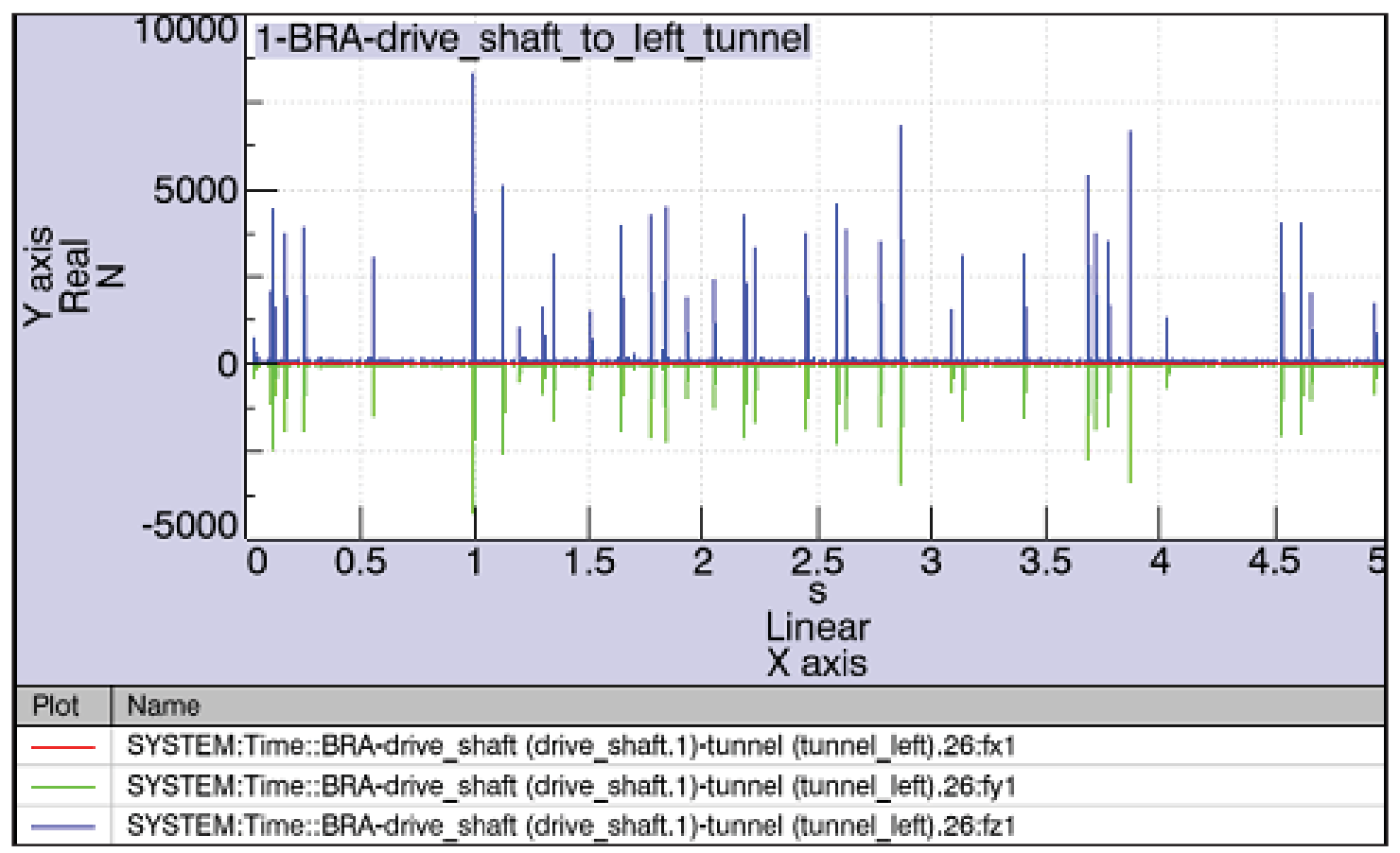

Figure 53: Time history for FRB at 20 mph from Analysis Case solution

To move the suspension forward at each velocity a One Body Position Driver was attached to the center of Shaft A as seen in Figure 54.

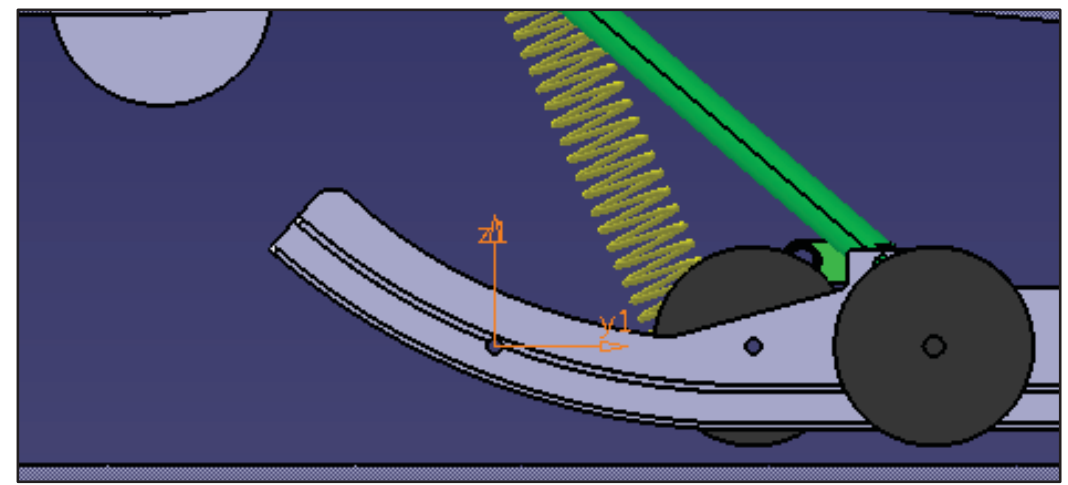

Figure 54: Position of the One Body Position Drivers on shaft A 
This driver was set at each of the velocities and allows choices such as acceleration time and deceleration time.

To find $F(\omega)$ from the time histories a Digital Signal Processing Case (DSP Case) was used to convert it to the frequency domain. Figures 55, 56 and 57 show the FRFs in the $+Z$ direction for each velocity.

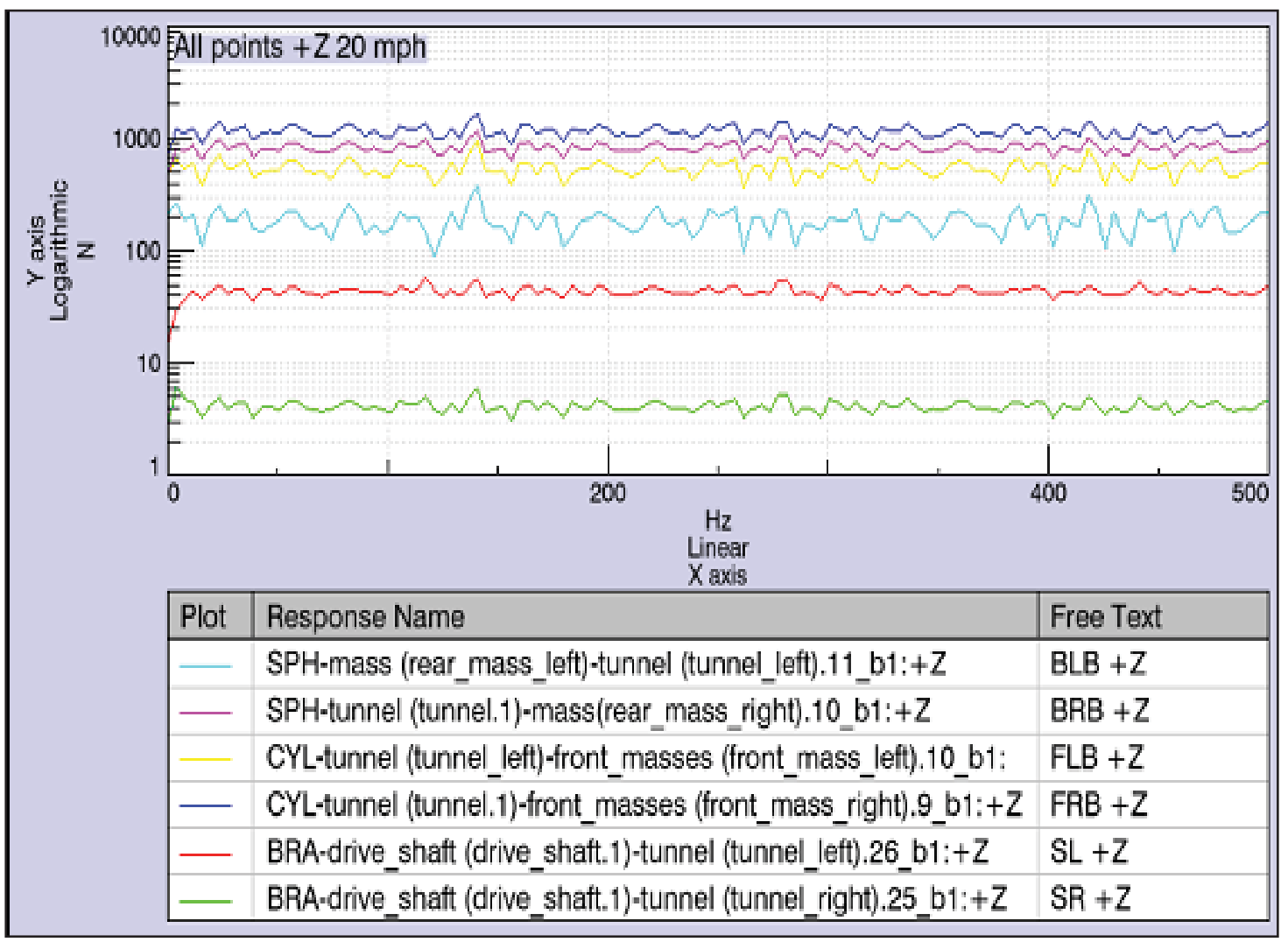

Figure 55: FRFs for BLB, BRB, FLB, FRB SL and SR at $20 \mathrm{mph}$ 


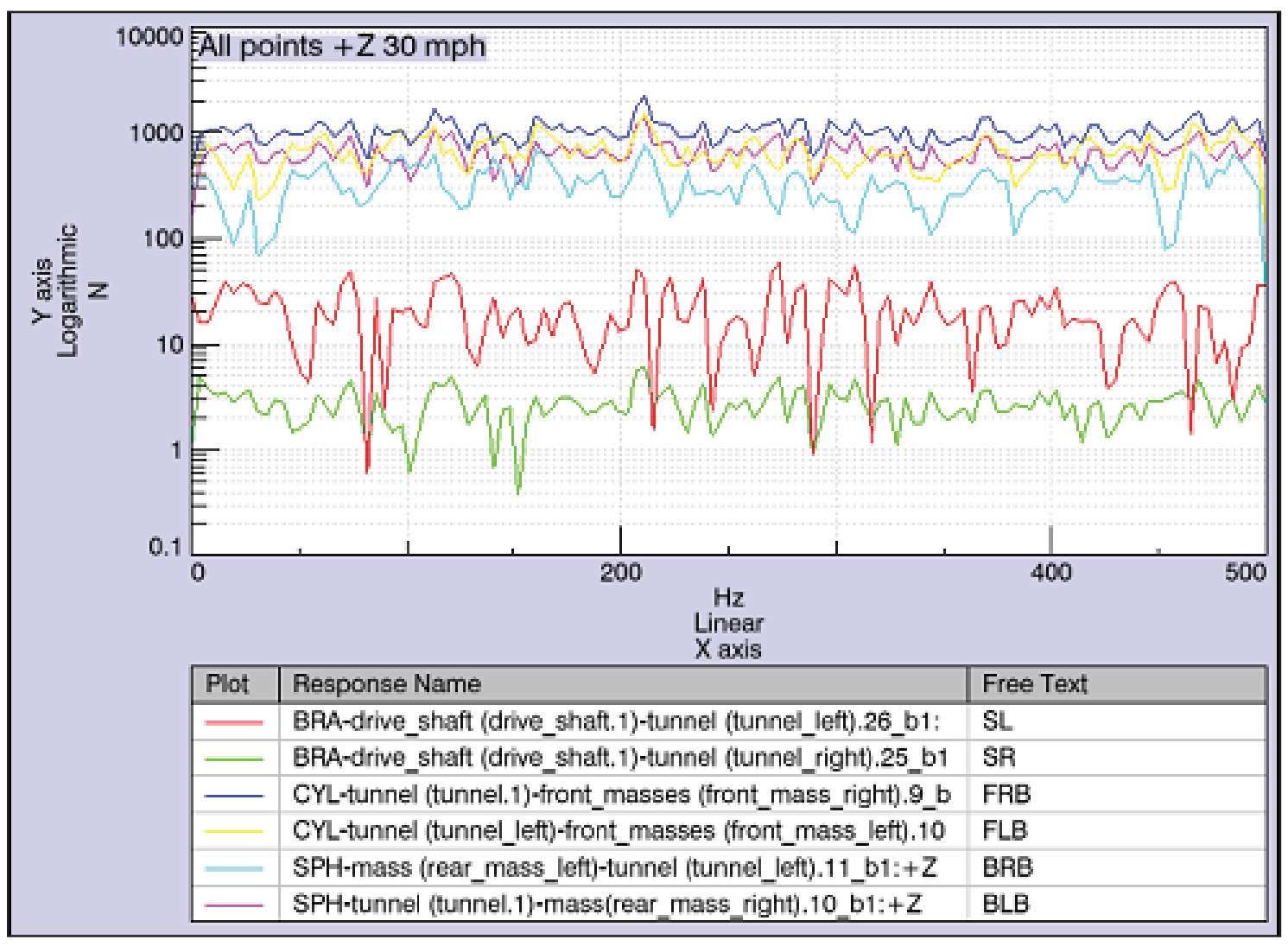

Figure 56: FRFs for BLB, BRB, FLB, FRB, SL and SR at $30 \mathrm{mph}$ 


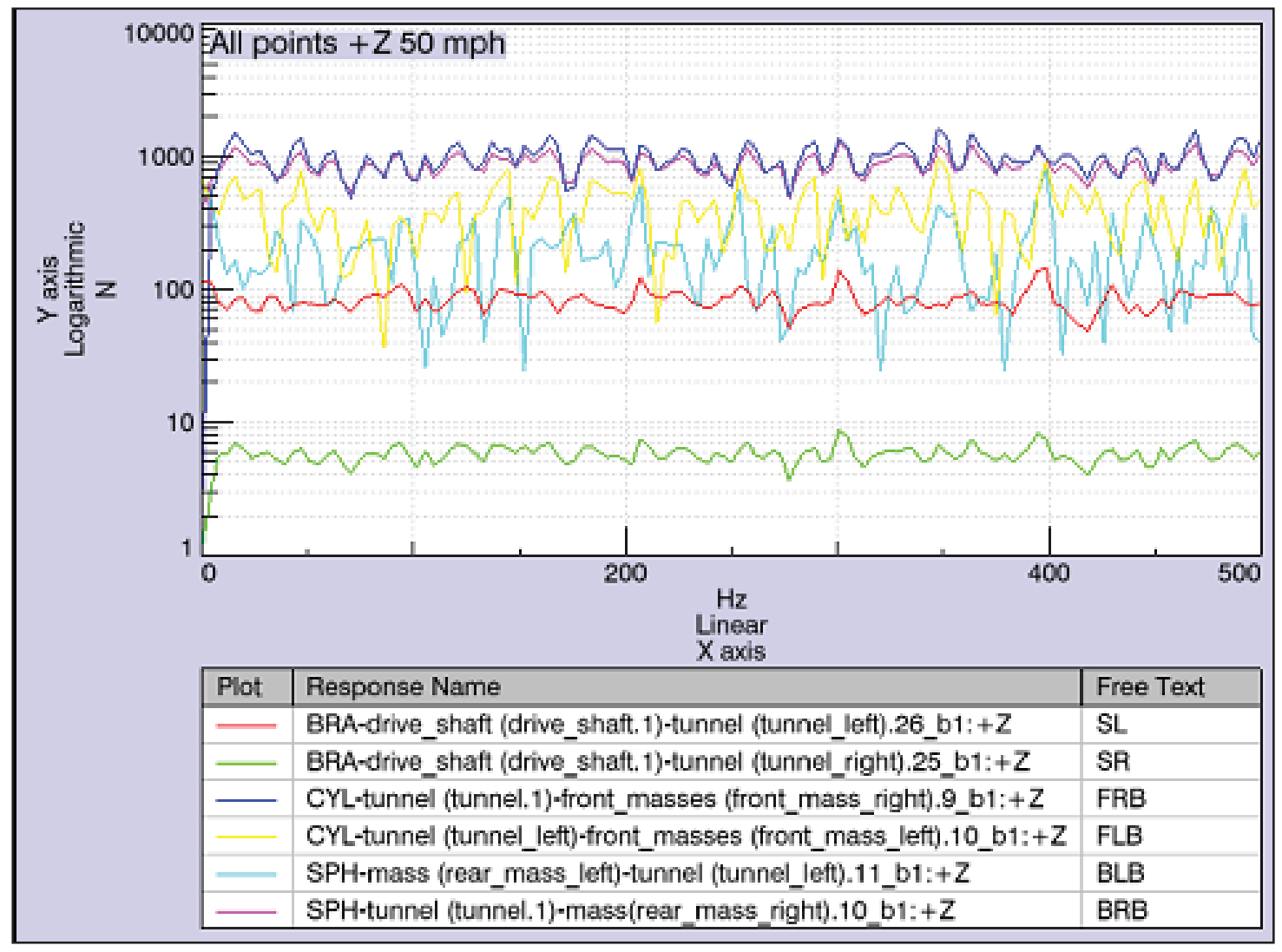

Figure 57: FRFs for BLB, BRB, FLB, FRB, SL and SR at $50 \mathrm{mph}$

To solve for $X(\omega)$ the impedance data was imported into the model. Using the direct LMS Test.Lab project file allowed the point IDs SL, SR, FRB, FLB, BRB, BLB and Mic to be imported. These impedances were then referred to as a Transfer Function Set by the software.

To solve for the forced response and sound pressure a FRF-Based Forced Response was used. This response was generated through the Noise and Vibration module in LMS Virtual.Lab. This feature performs TPA using the results of the DSP Case and the imported Transfer Function Set to solve for the response at the receiver.

The forced based response for the driver's ear at each velocity can be seen in Figures 58, 59 and 60. 


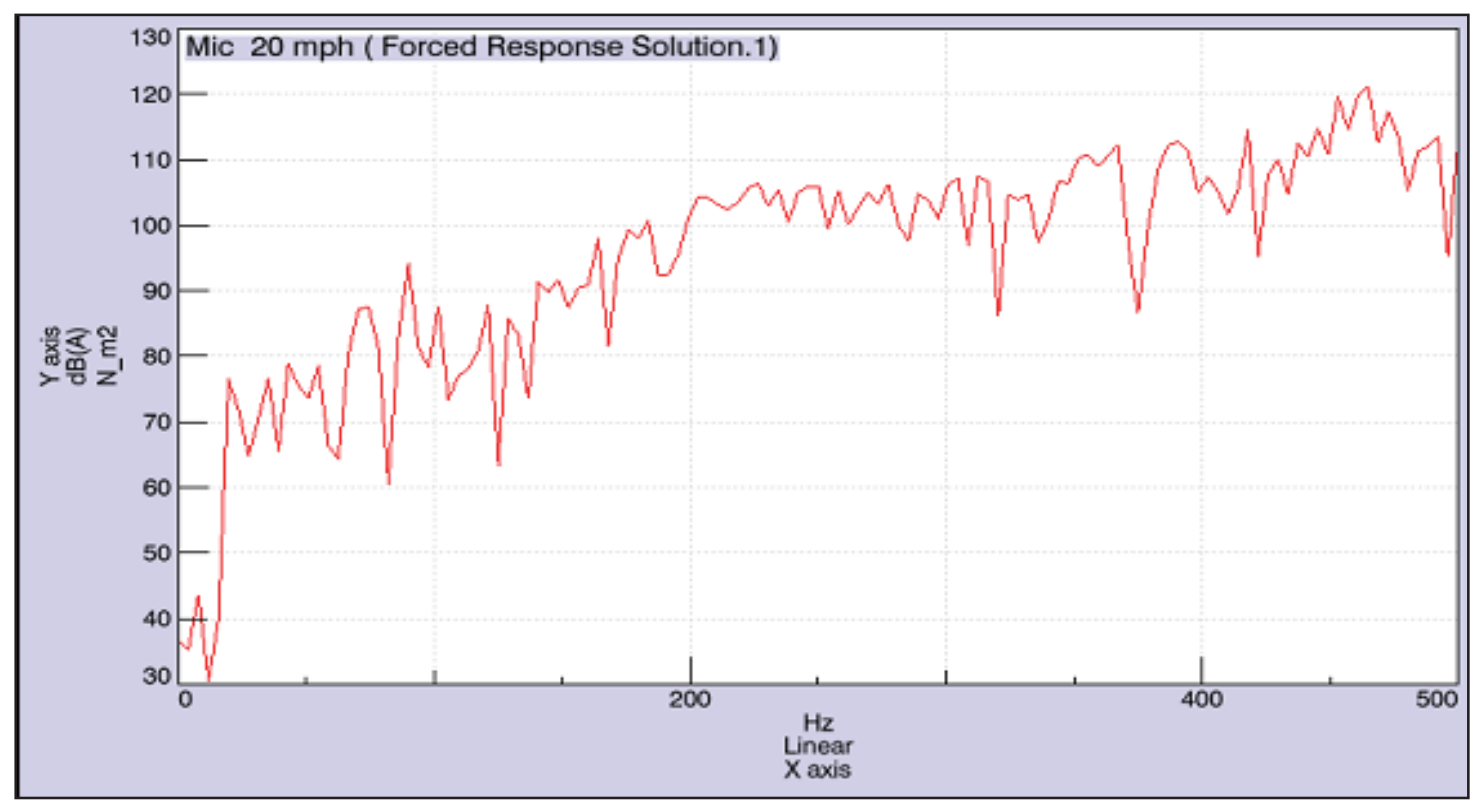

Figure 58: Response at the driver's ear at $20 \mathrm{mph}$

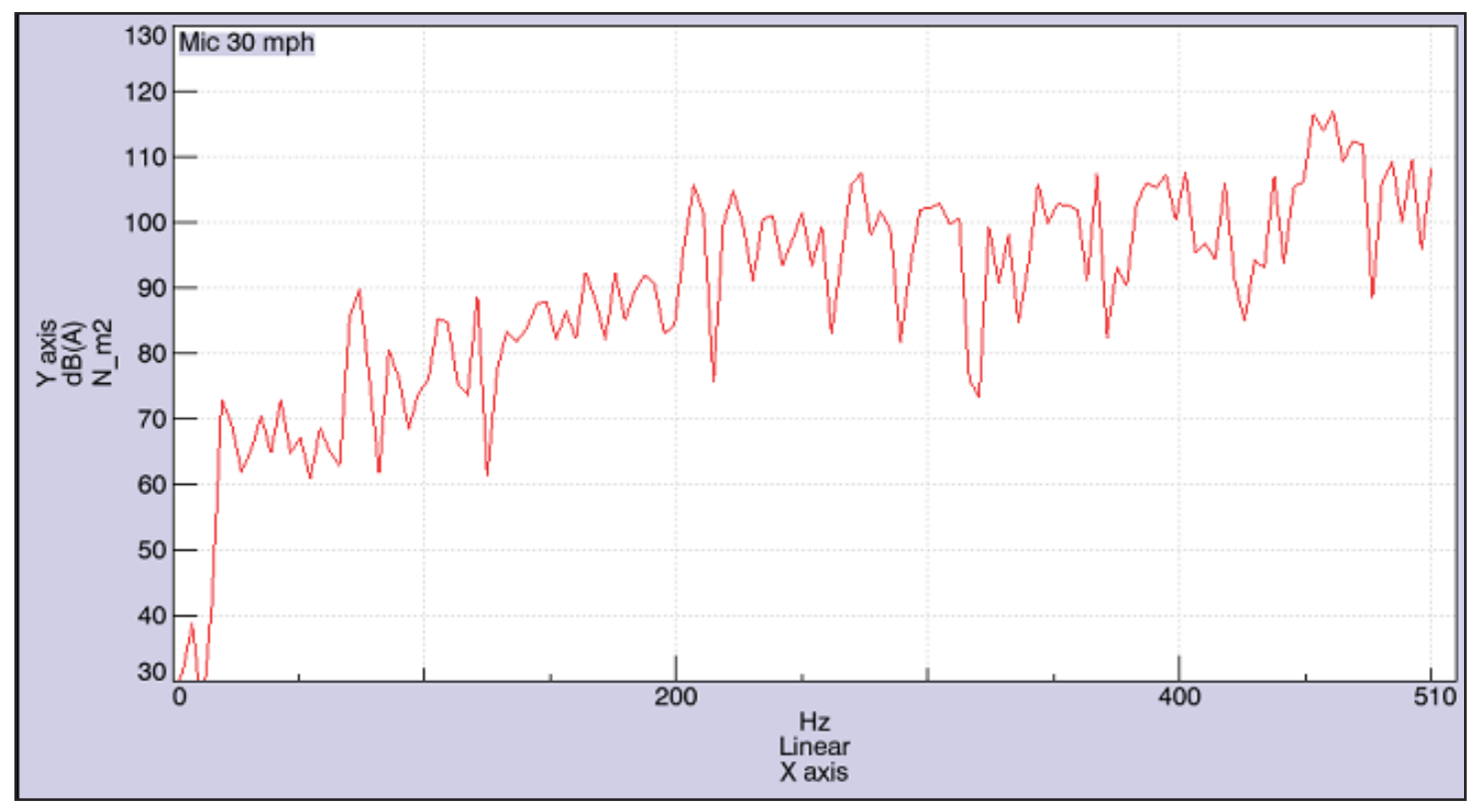

Figure 59: Response at the driver's ear at $30 \mathrm{mph}$ 


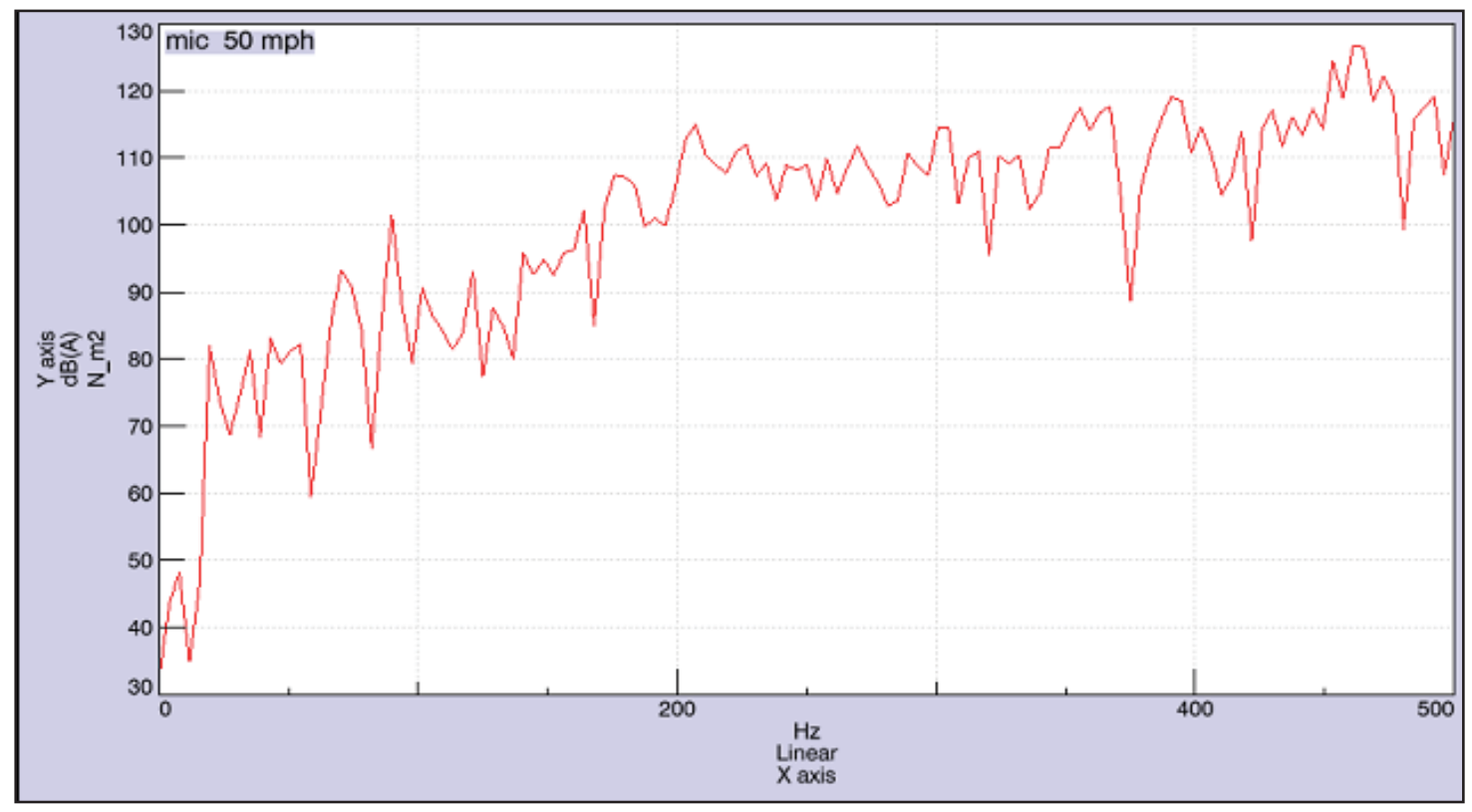

Figure 60: Response at the driver's ear at $50 \mathrm{mph}$

Parameters used to solve for each solution can be found in the Appendix.

Responses for point IDs SL, SR, FRB, FLB, BRB and BLB can be found in Figures 61 and 63. For comparison the operating data for the same points at the same velocities can be found in Figures 62 and 64. 


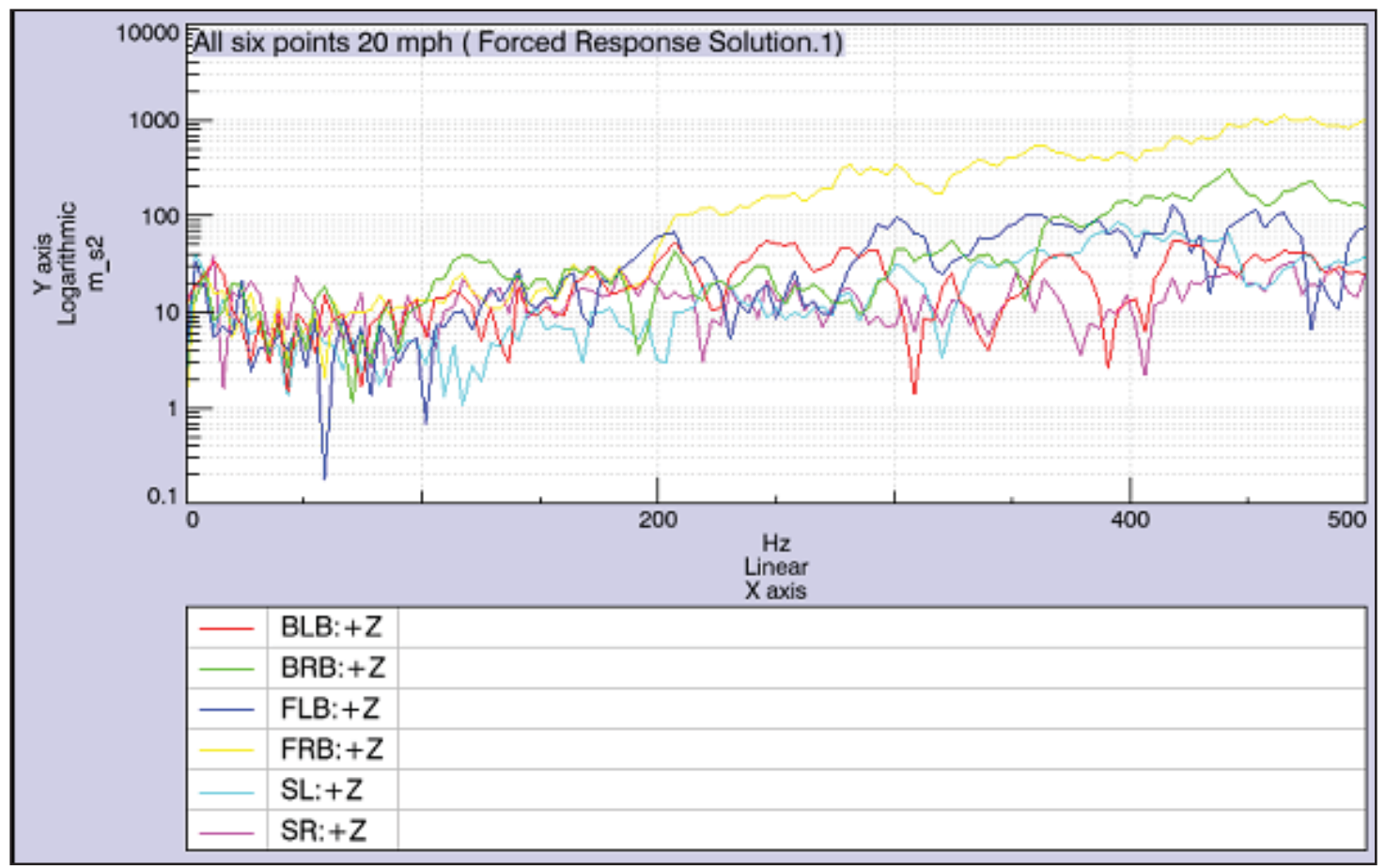

Figure 61: Forced response for SL, SR, FRB, FLB, BRB and BLB at $20 \mathrm{mph}$ in the $+Z$ direction 


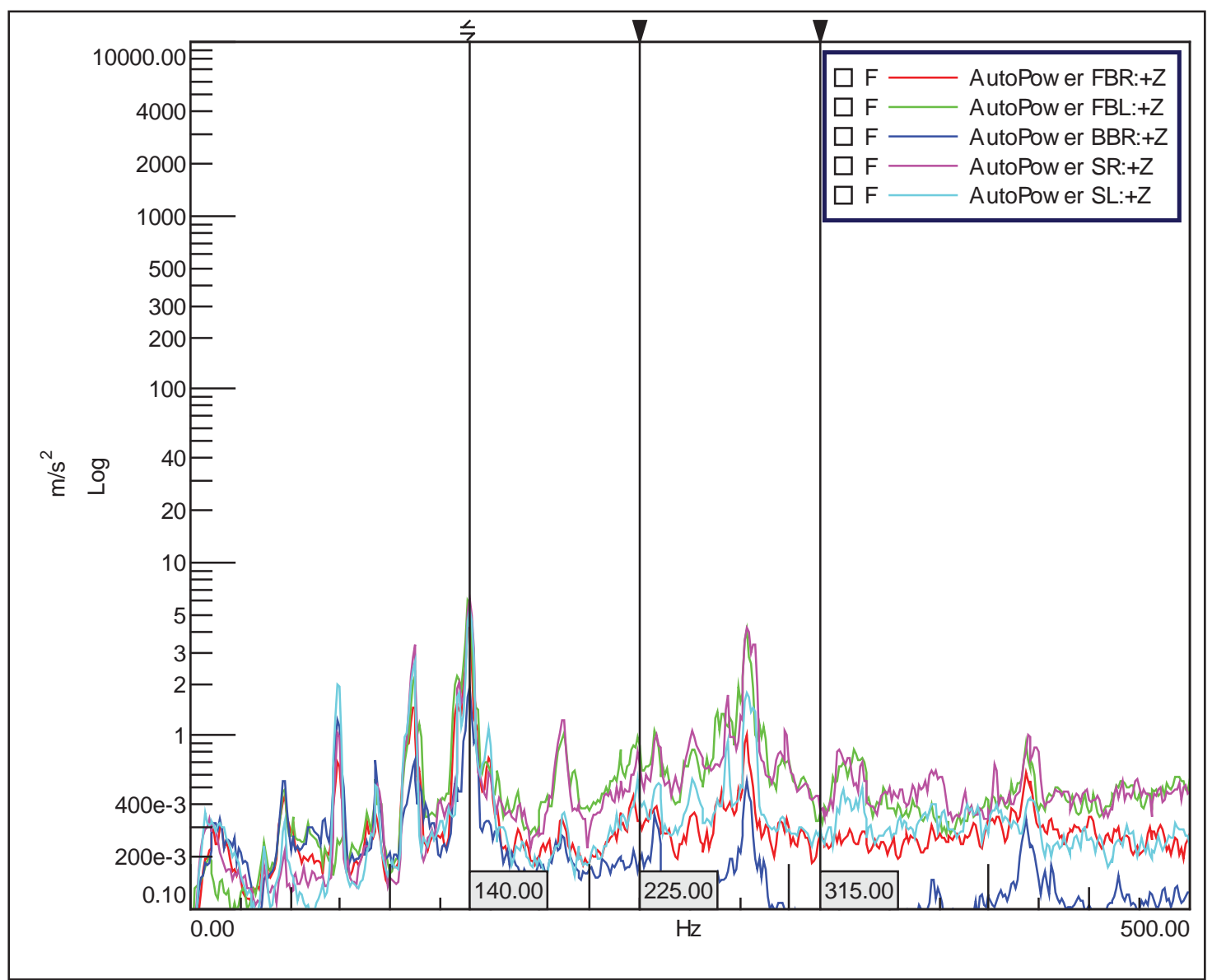

Figure 62: Operating data response for SL, SR, FRB, FLB, and BRB at $20 \mathrm{mph}$ in the $+Z$ direction 


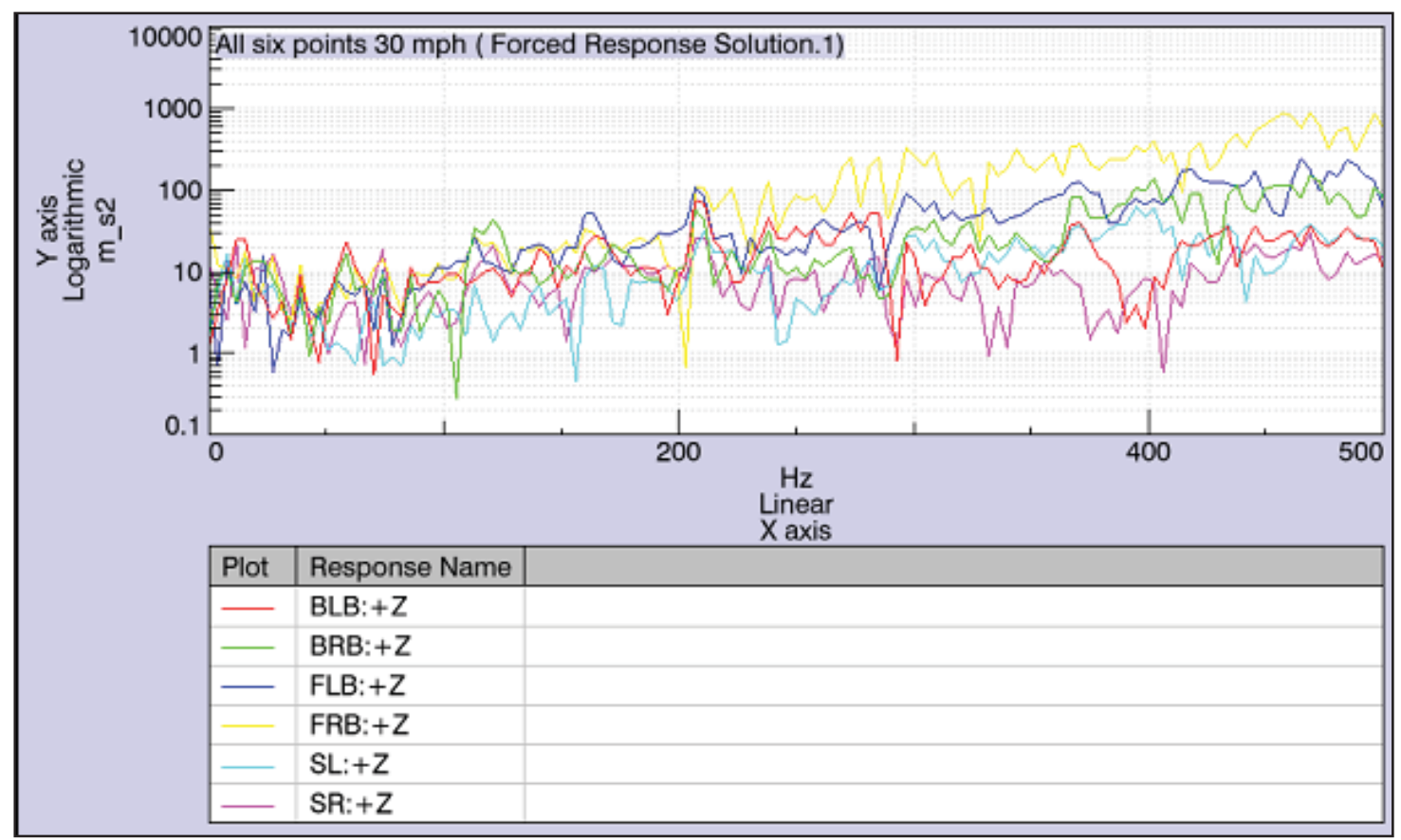

Figure 63: Forced response for SL, SR, FRB, FLB, BRB and BLB at $30 \mathrm{mph}$ in the $+Z$ direction 


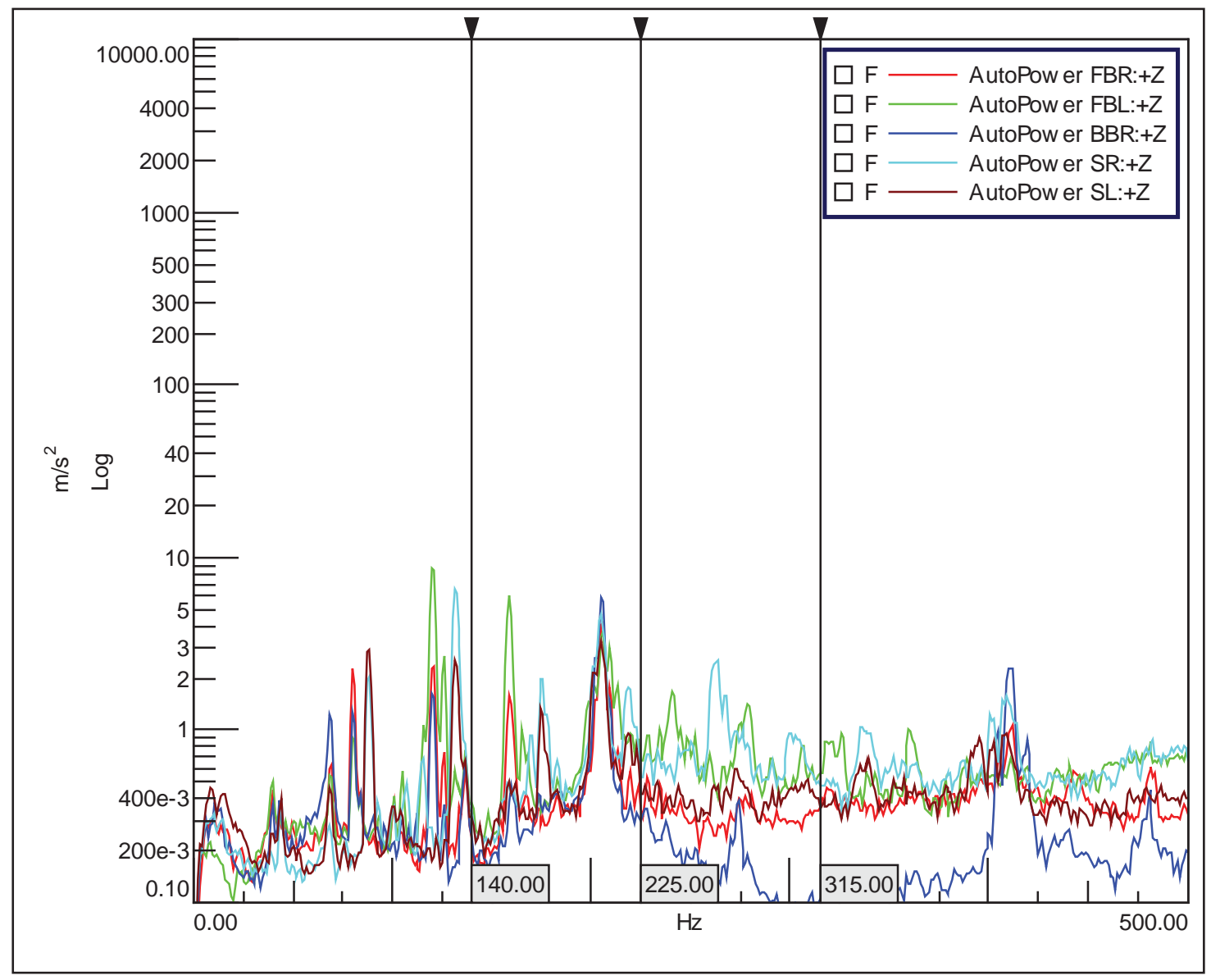

Figure 64: Operating data response for SL, SR, FRB, FLB, and BRB at $30 \mathrm{mph}$ in the $+Z$ direction

\subsubsection{Interpreting the Solutions and Key Findings from Phase Three}

Comparisons made in Figure's 61, 62, 63 and 64 demonstrate that there were some major differences between the measurements taken during operation and the responses from the FRF-Force Based Response case in LMS Virtual.Lab. The most noticeable difference is in the overall level of the responses. The operating data is lower by at least an order of magnitude over the simulated data. This comparison makes differences in peak frequencies more apparent. 
The operating data demonstrates the behavior that is expected at the three frequencies of interest. The forced response does not indicate any peaks at any key frequencies within the frequency range of 0 to $500 \mathrm{~Hz}$. This variance indicates that the model itself is not accurately simulating the mechanism.

There are a few variables to consider when trying to understand why the model did not accurately represent the suspension including surface contact, exclusion of the engine and clutches and material property assumptions. One area where there could be error in the modeling of the surface contact is between the track ground profile and the guide wheels. If the sphere to extruded contact points do not follow each bump on the profile by maintaining $100 \%$ contact the simulation will not represent what the guide wheels actually see on the inner face of the composite track during operation. By losing contact with the inner track surface the simulation might be missing stiffener rod inputs which would result in the key peaks being absent from the spectrum.

Another area of possible variance is in the modeling of the skis and the front suspension. The snowmobile contains an elaborate kinematic system in its front suspension and modeling this as simple springs appears to be causing a coupled rocking motion between the front and rear of the model during the animation. This rocking hasn't been shown to occur during operation and is believed to be caused by the methods used to simulate it. Additionally the model was built using impedances taken under static conditions. This test constraint leaves out any input from the power train. There are a variety of cyclic and unique events occurring within the engine and clutches throughout operation that are not accounted for in the model.

The approach taken for this project of modeling the ground as the track surface was pursued when full body solid models of the snowmobile were not successfully obtained. Modeling the road surface to simulate the track was hypothesized to be a faster, more efficient and simpler approach to testing changed variables within the rear suspension. 
Comparisons between the operating data and the simulated data demonstrate the need for future model changes including modeling the joint connections as bushings with damping and stiffness values, creating a flexible track model that fits properly around the rear suspension, modeling the complex mechanism of the front suspension and more accurate modeling of the ground surface under the skis. 


\section{Chapter 5: Conclusions and Future Work}

\subsection{Conclusions for the Experimental Approach}

Phase one identified four sensitive guide wheel paths to the four mounting bolt locations along with excessive ringing of the center coil. Wheels 1, 2, 3 and 6 were found to have the most sensitive paths to the front and rear mounting bolts. This makes these structural paths possible areas to target when making inexpensive changes in attempts to reduce the amount of energy successfully making to the receiver locations. It was also confirmed the tunnel portion of the chassis acts like a speaker during operation which has the potential to attenuate or amplify energy transferring through the FRB, BRB, FLB and BLB. This identifies each areas to modify structurally in order to redirect or attenuate energy within the system.

Phase two demonstrated the importance of identifying the energy paths through the rear suspension for prototype design and showed that the drive shaft design and track engagement contribute to the frequencies of interest. Driveshaft design and guide wheel spacing proved to be two key factors that affected two of the key frequencies of interest. Multiple rounds of operating data confirmed that staggering the guide wheel locations was related to a noticeable reduction in the response heard by the driver. This result was expected due to the fact that by staggering the wheels each input from a track stiffener rod is offset by a fraction of a second causing the energy to smear throughout the spectrum. The more wheels that are offset the greater the reduction of amplitude.

The first round of operating data demonstrated the need to track the RPMs while collecting operating data. The observation of harmonics in the spectrum led to the second set of operating data which captured the RPMs. By acquiring the data with respect to the RPM and using the Offline RPM Extraction tool it was 
confirmed that the $9^{\text {th }}$ order significantly contributed to the second frequency of interest at $225 \mathrm{~Hz}$.

The baseline driveshaft had nine teeth and was believed to be a portion of the problem at $225 \mathrm{~Hz}$. To better understand how much the individual shaft itself was contributing a modal analysis was done with boundary conditions that reflected operation in the snowmobile to mimic operating conditions. This modal confirmed suspicions and showed high modal density around $228 \mathrm{~Hz}$. The contribution of the driveshaft was tested using different prototypes to measure the effects. A new driveshaft and track, different sized upper guide wheels and new staggered guide wheel pattern were all tested. The only two that showed a noticeable impact in the data at $225 \mathrm{~Hz}$ were run four and run five. Run four consisted of suspension $B$ with the new prototype driveshaft and track and run five consisted of the alternate suspension $C$. The new driveshaft and track had a large effect on the amplification of energy heard in the driver's microphone while suspension $\mathrm{C}$ shifted the energy through the spectrum.

It's difficult to know if the changes in the spectrum observed in phase two were due to the drive shaft or if they are a property of the system. It's clear a rotating component is amplifying the response but if it's a property of the entire system, or natural frequency of the system, changes the number of sprocket teeth will only move the same amount of noise elsewhere in the spectrum.

\subsection{Future Work for the Experimental Approach}

In phase one the center coil was tightly taped and showed a desirable reduction in the amplitude and duration of ringing in the rear suspension. Although the design of the boot itself was already in production, more testing could be conducted to test more variables such as material composition, boot stiffness, fit and size. 
In addition to testing the boot variables the guide wheel placement, material composition and joint material properties should be tested along the sensitive paths found from wheel 1, 2, 3 and 6 to the suspension mounting bolt locations. These were found to be the most sensitive structural paths and could be testing with varying bushings and bearings to test the effects attenuating more energy before the mounting bolt locations. These changes could be made with the provided prototype snowmobile and would be fairly inexpensive.

Phase two tested multiple suspension variables including the drive shaft sprocket design. With respect to the drive shaft's effect on the frequency of $225 \mathrm{~Hz}$ more testing will be needed in order to decouple where the energy in the response is coming from. The conditions under which the prototype driver was tested maintained the shaft design of the original drive shaft. This means it was considered to be part of the rear suspension system and the only variable that changed was the sprocket itself. The eight tooth sprocket driver caused the energy to shift to a higher frequency within the spectrum. This observation confirms that the amplified response was a product of the sprocket design but does not conclude how the drive shaft design affects the system. A different shaft design, which differs from the original, needs to be tested to draw conclusions about the shaft designs role within the system.

\subsection{Conclusions for the Analytical Approach}

To gather data for the analytical model impedances were measured and impacted at the six points of interest. This data was then used in transfer path analysis of the energy at the six locations in conjunctions with FRFs found using the model.

The model was built using the road profile to represent the fiberglass stiffener rods in the molded track. This configuration would have allowed for easy changes of the track pitch and the height of the bumps. 
The forced based response calculations ended up showing no relevant information and were nothing that could lead to any conclusions. The way the model was approached had a variety of limitations including a large front to rear coupling that happened multiple times throughout the five second speed sweep. When the data was compared side by side from the model to comparable operating data the operating data was observed to be an order of magnitude below the simulated data. Another difference was that the simulated data didn't indicate large responses at any of the key frequencies. It was concluded that the simulation was not useful to understand properties of the system and further model changes would be required.

\subsection{Future Work for the Analytical Approach}

With a model that completely incorporates the track condition using flexible bodies it would be useful to the manufacturers. The way the model was developed would have been an easy approach, without a lot of detail, to see the effects of changing variables throughout the system. Because this approach did not yield the desired outputs, it is recommended that this model be converted to include the whole track.

LMS Virtual.Lab has multiple features that allow for complex flexible multi-body models. Material properties such as dynamic stiffness and environmental conditions like ambient air temperature can also be taken into considerations. Although an abbreviated model would be more simple and efficient for some varieties of testing having a more complex calibrated model could help deepen a manufacturers understanding of how suspension components behaved in a general sense.

The fully modeled multi body model would allow for effective modeling of bushing and hardware stiffness. It's possible the order of magnitude of difference in the response could have resulted from the deficit of these variables in the 
abbreviated model. This lack of damping in the system would likely cause much higher amplitudes even if the key frequencies didn't show up.

The investment of time and energy to create a fully functioning muti-body model would allow for a deeper understanding of the rear suspension of a snowmobile. Even though the model would be specific to one make and model is has the potential to gain insight into the system as a whole and could be utilized across many manufacturers. 


\section{Bibliography}

1. Blough J. Current and Future Snowmobile Noise Technology. American Snowmobiler2009.

2. Blough J. Snowmobile Design and Snowmobile Sound Basics. American Snowmobiler2009.

3. Dilworth BJ. Identification of ground and environmental effects to the passby noise testing of snowmobiles [Ph.D.]: Michigan Technological University; 2009. 239 leaves $p$.

4. James DeClerck PoP. MEEM 5702 Analytical Vibroacoustics Lecture 2. Michigan Technological University; 2009. p 21.

5. LMS. LMS Virtual.Lab Online Help, Joints Toolbar. Rev 11-SL2: Siemens; 2013.

6. $\quad$ LMS. Real World Ready Making Virtual Simulation Realistic. 2013. p 9.

7. Palm WJ. Mechanical vibration. Hoboken, NJ: John Wiley; 2007. xiv, 700 p. p.

8. SAE. Maximum Exterior Sound Level for Snowmobiles. J192 Revision A. Warrendale: Society of Automotive Engineers; 2013.

9. Waldron KJ, Kinzel GL. Kinematics, dynamics, and design of machinery. Hoboken, NJ: J. Wiley; 2004. xi, 668 p. p. 


\section{Appendix}

Figures 65 and 66 show the variables selected to solve the DSP Case for the FRFs of the rear suspension traveling at each velocity using the portion of the time history from 0.5 seconds to 5 seconds.

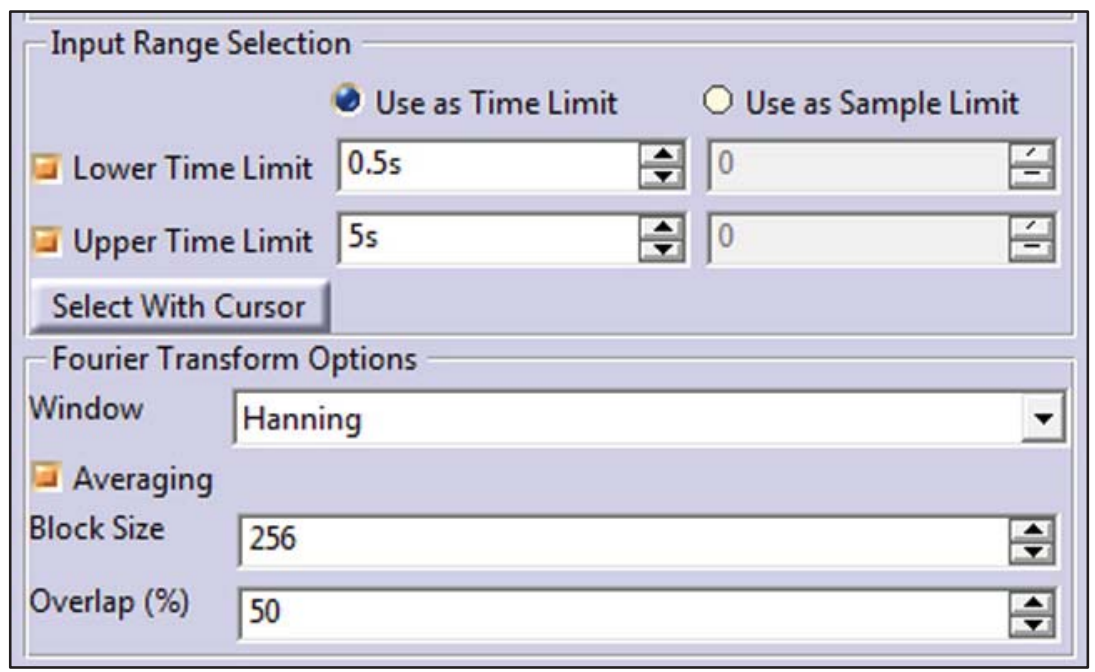

Figure 65: Processing variables used to calculate the FRFs in the DSP Case 


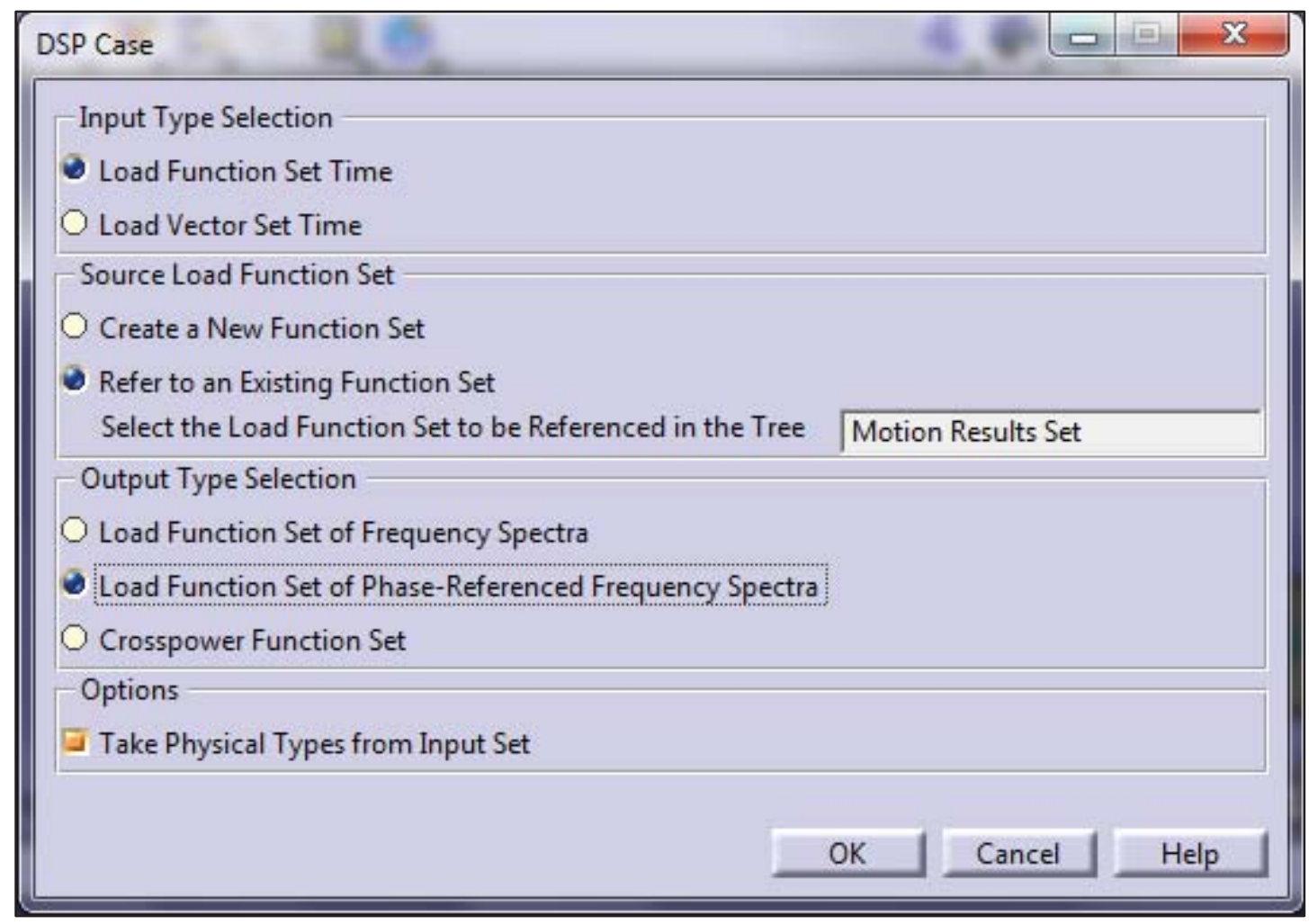

Figure 66: DSP Case settings to obtain FRFs from time histories in the Motion Results

Figures 67, and 68 show the variables used to create the FRF-Based Forced Response in LMS Virtual.Lab. 


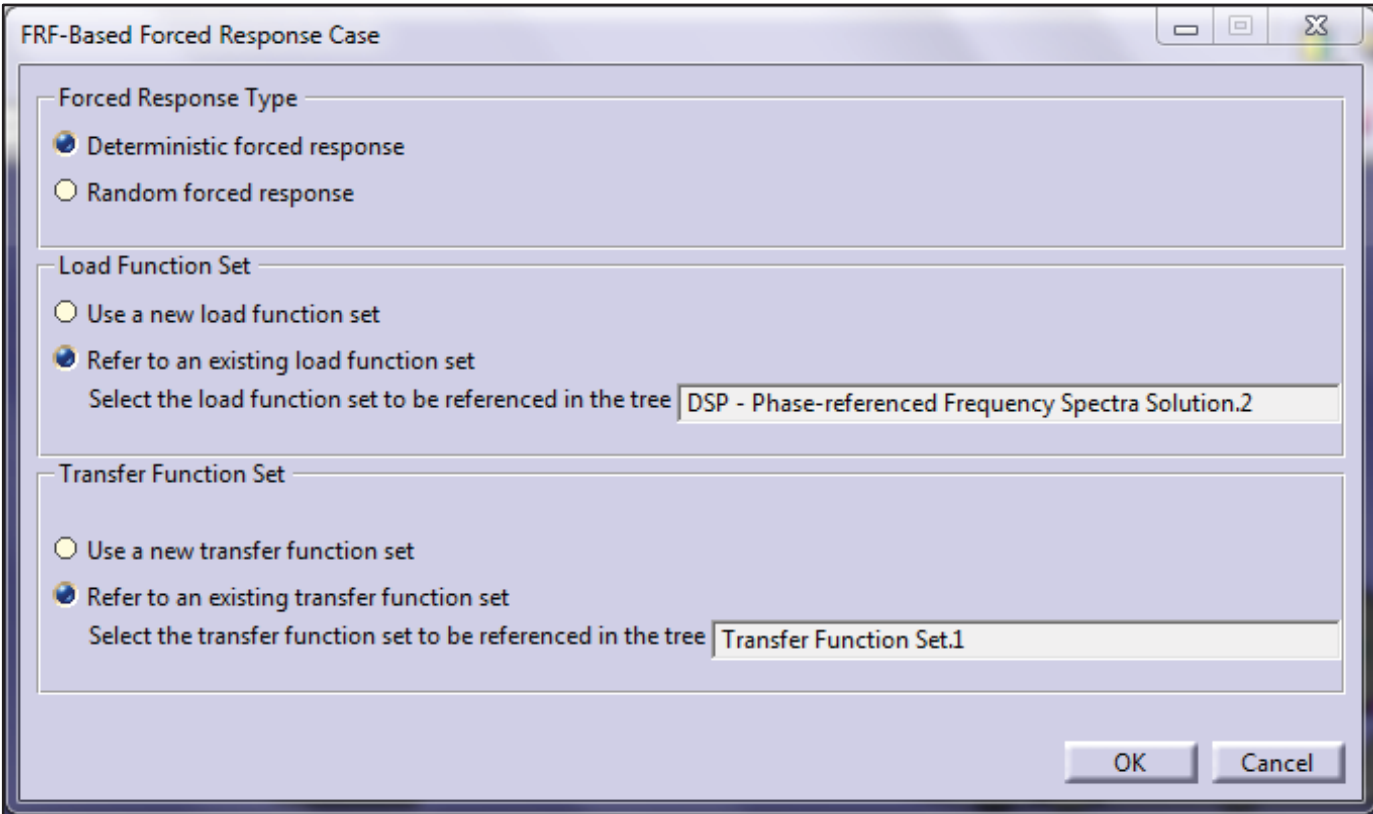

Figure 67: Selections to reproduce the FRF-Based Forced Response Case 


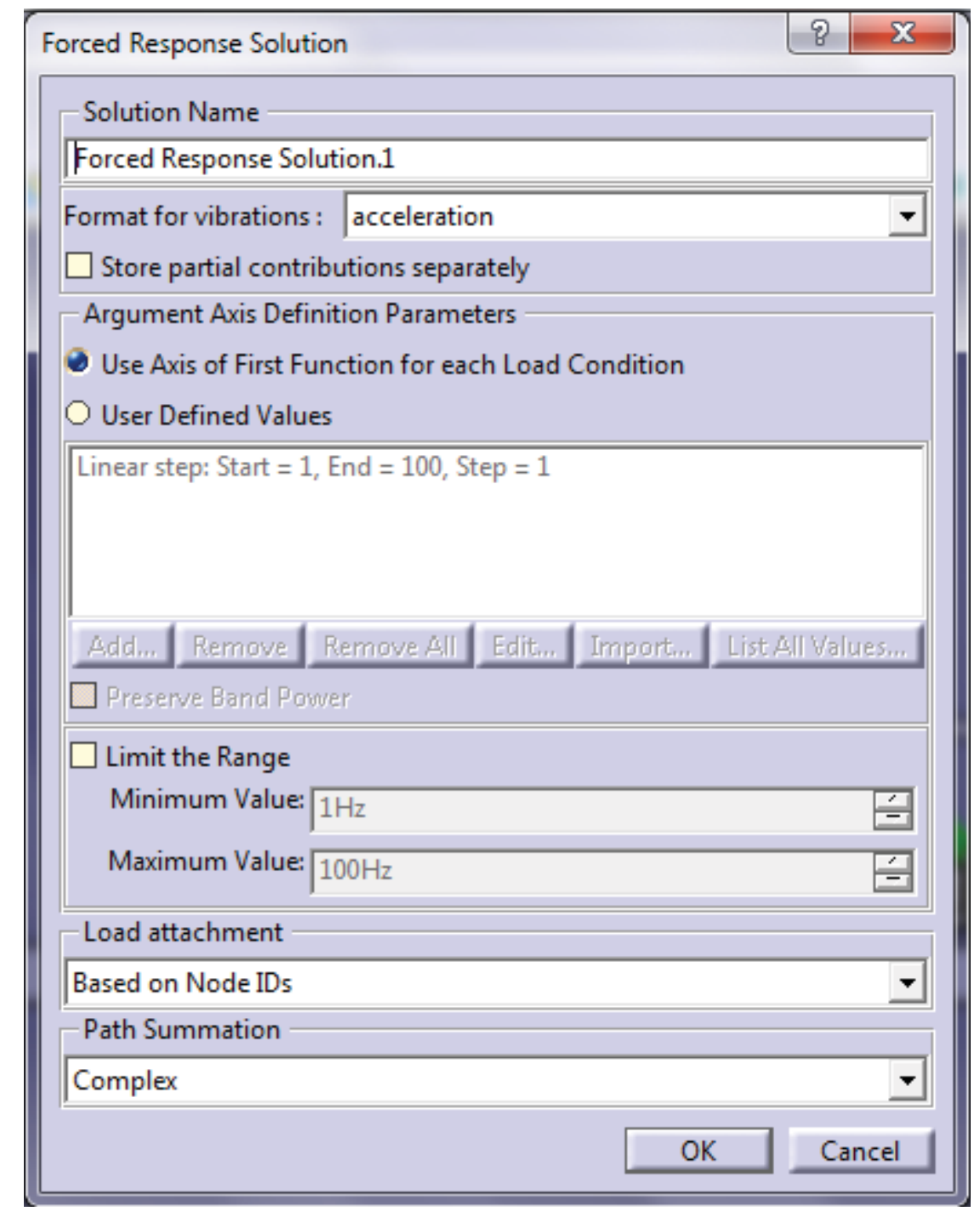

Figure 68: Selections to reproduce the FRF-Based Forced Response Solution

Table 8 shows the number used to calibrate the stiffness of the spring contained in the front shock absorber. 
Table 8: Values from strain box and dial indicator used to fins the stiffness of the spring in the front shock absorber

\begin{tabular}{|l|l|c|c|}
\hline Inches & Meters & $\begin{array}{l}\text { Strain Box } \\
\text { Number }(x)\end{array}$ & $\begin{array}{l}\text { Newtons } \\
\left(\text { Strain }^{*} 0.128236\right)\end{array}$ \\
\hline 0.000 & 0 & 4003 & 513.33 \\
\hline 0.031 & 0.000787 & 4176 & 535.51 \\
\hline 0.061 & 0.001549 & 4310 & 552.70 \\
\hline 0.095 & 0.002413 & 4477 & 574.11 \\
\hline 0.164 & 0.004166 & 4839 & 620.53 \\
\hline 0.187 & 0.00475 & 4964 & 636.56 \\
\hline 0.258 & 0.006553 & 5349 & 685.93 \\
\hline 0.309 & 0.007849 & 5609 & 719.28 \\
\hline 0.380 & 0.009652 & 5995 & 768.77 \\
\hline 0.391 & 0.009931 & 6058 & 776.85 \\
\hline 0.483 & 0.012268 & 6576 & 843.28 \\
\hline 0.553 & 0.014046 & 6953 & 891.62 \\
\hline 0.629 & 0.015977 & 7365 & 944.46 \\
\hline 0.757 & 0.019228 & 8040 & 1031.02 \\
\hline
\end{tabular}

